Göttinger Studien zur Kulturanthropologie / Europäischen Ethnologie Göttingen Studies in Cultural Anthropology / European Ethnology

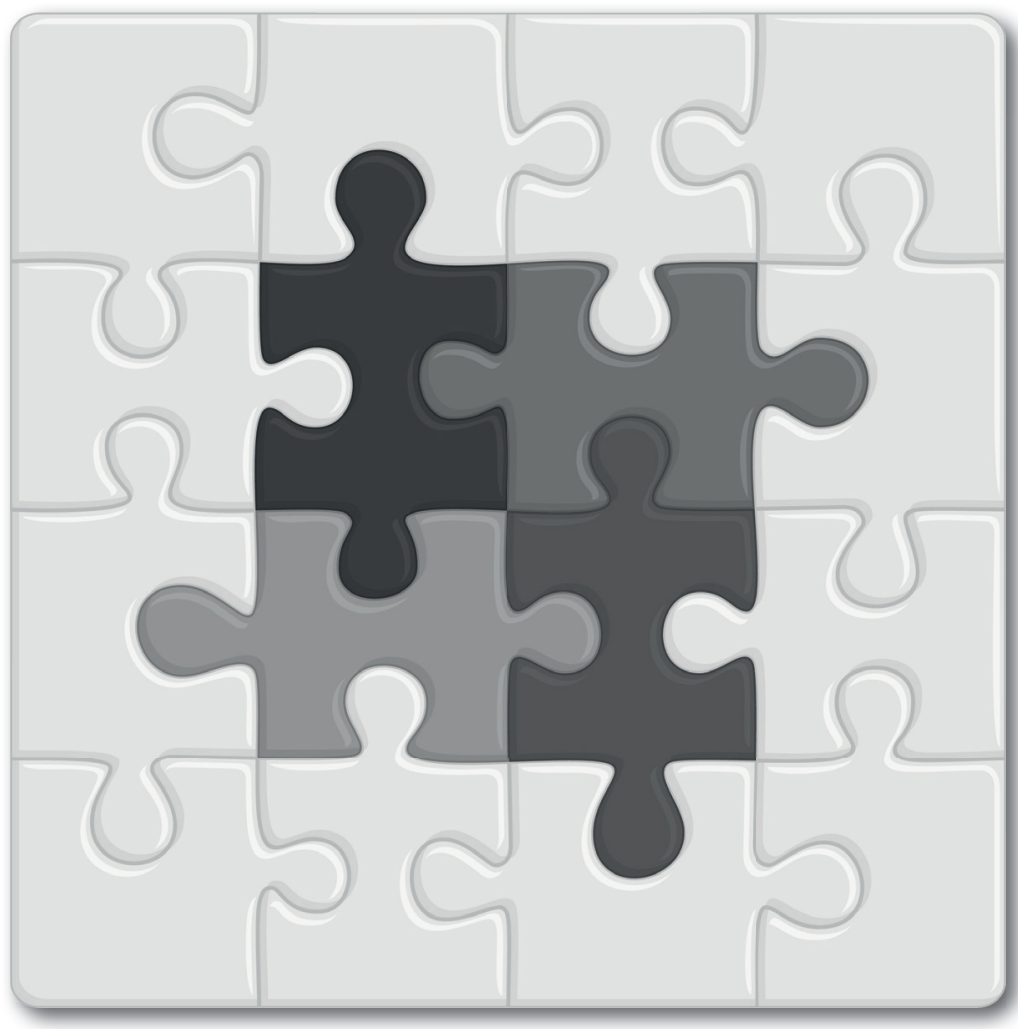

Karima Popal-Akhzarati

\title{
Inkludierte Exkludierte
}

Studentische Verhandlungsweisen von

Rassismus und Rassismuserfahrungen 

Karima Popal-Akhzarati

Inkludierte Exkludierte

Dieses Werk ist lizenziert unter einer

Creative Commons

Namensnennung - Weitergabe unter gleichen Bedingungen

4.0 International Lizenz.

(c) (1) ()

BY SA 
erschienen als Band 8 in der Reihe „Göttinger Studien zur Kulturanthropologie/Europäischen Ethnologie“ im Universitätsverlag Göttingen 2019 
Karima Popal-Akhzarati

Inkludierte Exkludierte

Studentische Verhandlungsweisen von Rassismus und Rassismuserfahrungen

Göttinger Studien zur

Kulturanthropologie/Europäischen

Ethnologie, Band 8

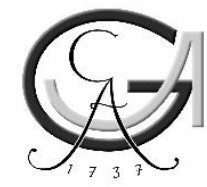

Universitätsverlag Göttingen 2019 


\section{Bibliographische Information der Deutschen Nationalbibliothek}

Die Deutsche Nationalbibliothek verzeichnet diese Publikation in der Deutschen Nationalbibliographie; detaillierte bibliographische Daten sind im Internet über $<$ http://dnb.dnb.de $>$ abrufbar.

„Göttinger Studien zur Kulturanthropologie/Europäischen Ethnologie“, herausgegeben von

Prof. Dr. Regina Bendix

E-Mail: rbendix@gwdg.de

Prof. Dr. Moritz Ege

E-Mail: mege@uni-goettingen.de

Prof. Dr. Sabine Hess

E-Mail: shess@uni-goettingen.de

Prof. Dr. Carola Lipp

E-Mail: Carola.Lipp@phil.uni-goettingen.de

Dr. Torsten Näser

E-Mail: tnaeser1@gwdg.de

Georg-August-Universität Göttingen

Institut für Kulturanthropologie/Europäische Ethnologie

Heinrich-Düker-Weg 14

37073 Göttingen

Anschrift der Autorin

Karima Popal-Akhzarati

E-Mail: k.popal-akhzarati@gmx.de

Der Druck dieses Buches wurde gefördert von der Gerda-Weiler-Stiftung für feministische Frauenforschung e. V., www.gerda-weiler-stiftung.de.

Dieses Buch ist auch als freie Onlineversion über die Homepage des Verlags sowie über den Göttinger Universitätskatalog (GUK) bei der Niedersächsischen Staats- und Universitätsbibliothek Göttingen (http://www.sub.uni-goettingen.de) erreichbar. Es gelten die Lizenzbestimmungen der Onlineversion.

Satz und Lektorat: Sascha Bühler Umschlaggestaltung: Jutta Pabst

Titelabbildung: Khvost/Shutterstock.com

(C) 2019 Universitätsverlag Göttingen

http://univerlag.uni-goettingen.de

ISBN: 978-3-86395-367-6

DOI: https://doi.org/10.17875/gup2019-1134

eISSN: 2512-7055 


\section{Inhalt}

Danksagung. . . . . . . . . . . . . . . . . . . . .

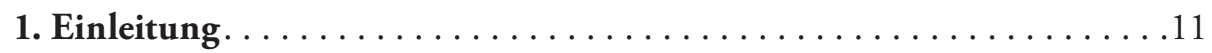

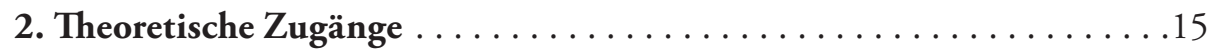

2.1 Das Rassismus-Verständnis der vorliegenden Arbeit ............ 15

2.1.1 Zur Notwendigkeit und Schwierigkeit einer

Rassismusdefinition ........................ 17

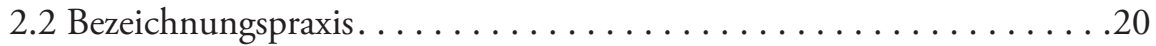

2.2.1 Begriffe und Bezeichnungen in der vorliegenden Arbeit. . . . . . .23

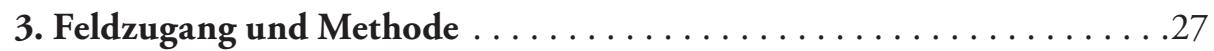

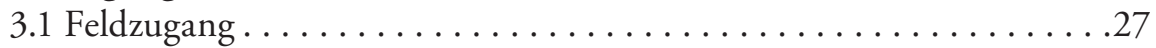

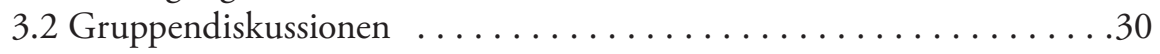

3.2 .1 Auswertung ...............................

3.2.2 Die Gruppendiskussionen: Verlauf und Reflexionen .........31

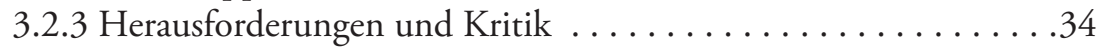

3.3 Position als Forscherin . . . . . . . . . . . . . . . . . 35

4. Verhandlungsweisen von Rassismus(erfahrungen) im

Hochschulkontext . . . . . . . . . . . . . . . . . . . . . 37

4.1 Institutioneller Rassismus an der Hochschule . . . . . . . . . . . 38

4.2 Umgang der Hochschule mit Rassismus(erfahrungen):

Akademische Verschiebung ......................46

4.3 Effekte des Umgangs auf rassifizierte Studierende ............48

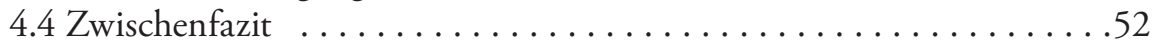

5. Studentische Verhandlungsweisen von Rassismus(erfahrungen) .....53

5.1 (De)Thematisierungsweisen . . . . . . . . . . . . . . 54

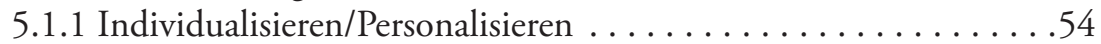

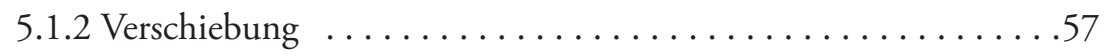

5.1 .3 Alternative Erklärungsmuster/-ansätze . . . . . . . . . . . . . 59

5.1.4 Verleugnung und (Nicht) Wissen . . . . . . . . . . . . . .62 
5.2 Die Position als Anderes........................64

5.2.1 Die (kritiklose) Akzeptanz der Position als Anderes . . . . . . . . .66

5.2.2 Die kritische Akzeptanz der Position als Anderes . . . . . . . . . . .69

5.2.3 Das Andere als (umkämpfte) Ressource . . . . . . . . . . . .71

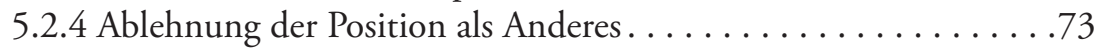

5.3 Verwendung zugänglicher Machtverhältnisse . . . . . . . . . . 76

5.3.1 Die Verwendung zugänglicher Machtverhältnisse: Klassismus . . .77

5.3.2 Die Verwendung zugänglicher Machtverhältnisse:

Klassismus + Sexismus . . . . . . . . . . . . . . . . . . . . . . .79

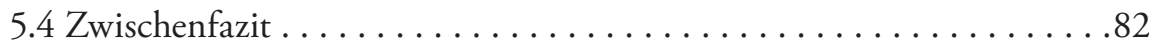

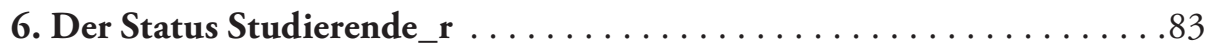

6.1 Der Status Studierende_r und Ermächtigung. . . . . . . . . . . 84

6.2 Bedingungen der Ermächtigung $\ldots \ldots \ldots \ldots \ldots \ldots \ldots \ldots \ldots$

6.3 Die Frage nach der politischen Repräsentation . . . . . . . . . . . 88

6.4 Zwischenfazit .............................

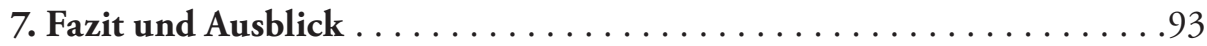

8. Literatur . . . . . . . . . . . . . . . . . . . . . .97 
Diese Arbeit widme ich meinen Eltern, die für mich und meine Geschwister alles gegeben haben und immer noch geben. Dank ihnen bin ich heute, wo ich bin.

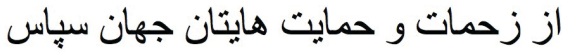

$$
\begin{aligned}
& \text { اين كتاب را به بهترين و الدين تقديم ميكنم } \\
& \text { شكر كه شمار را دارم }
\end{aligned}
$$





\section{Danksagung}

Von der Ideenentwicklung bis zum Druck der Arbeit haben mich viele Menschen mit Ideen, Inspiration und Liebe unterstützt. Ihnen allen gilt hiermit mein Dank.

Insbesondere danke ich den Gesprächsteilnehmenden für ihr Vertrauen, ihr Wissen und ihre Erfahrungen mit mir zu teilen und für meine Arbeit zur Verfügung zu stellen. Ihre Stimmen haben mich intensiv begleitet - nicht zuletzt aufgrund der tagelangen Transkriptionen - und mich zu vielen erkenntnisreichen Aha-Momenten geführt - auch über mich selbst.

Für die inhaltliche Betreuung und Unterstützung danke ich meinen Gutachter_innen Prof. Dr. Sabine Hess und Dr. Uta Schirmer. Diese Veröffentlichung wäre zudem ohne die aktive finanzielle und ideelle Förderung von Prof. Dr. Sabine Hess nicht zustande gekommen. Danke für Dein Vertrauen.

Isabel Dean danke ich herzlich für ihre inhaltlichen Anregungen sowie ihre detaillierte Durchsicht und Korrektur in der Endphase.

Der Hans-Böckler-Stiftung danke ich für die Finanzierung meines Studiums und die Privilegien als HBS-Stipendiatin, die mich jetzt auch in meiner Promotion begleiten.

Meinem Partner und ewigen Wegbegleiter Sadyk danke ich für seine intensive Teilnahme am gesamten Projekt der Abschlussarbeit und rundum Fürsorge. Danke, dass du da bist.

Last but not least, danke ich meiner Schwester, die in jedem Krisenmoment mit einem offenen Ohr und einem guten Rat da war. Im Herzen verbunden. 



\section{Einleitung}

Universitäten stellen auf unterschiedlichen Ebenen eine gesellschaftlich bedeutsame Institution dar. Als Ort der (anerkannten) Wissensproduktion entsteht an den Universitäten gesellschaftlich relevantes Wissen, das auf verschiedene Weise soziale Verhältnisse prägt. Neben ihrer Funktion als wissenschaftliche Arbeits- und Lernorte sind sie somit wichtige politische Räume, in denen Wissen hergestellt, verhandelt und anerkannt wird. Darüber hinaus regeln sie über die Vergabe öffentlich finanzierter Arbeits- und (Aus)Bildungsplätze den Zugang zu hochqualifizierten Arbeitsmärkten. Demnach tragen Universitäten eine große Verantwortung für die Gesellschaft, in der sie im Allgemeinen die Anerkennung genießen, aufgeklärte Orte der Objektivität und Rationalität zu sein und demokratisch-emanzipatorische Werte zu vertreten. Mit dem Versprechen von individueller Chancengleichheit erheben Hochschulen in der Regel den Anspruch, offen, barriere- und diskriminierungsfrei zu sein und im akademischen Alltag niemanden aufgrund von Geschlecht, (vermeintlicher) Herkunft, religiöser Zugehörigkeit, Behinderung, Alter, sexueller Orientierung oder sozialer Herkunft auszuschließen oder zu benachteiligen.

Allerdings sind Diskriminierungsverhältnisse an den Hochschulen selbst wie auch mögliche fördernde Maßnahmen bislang wenig erforscht. Dabei stellt sich die Herausforderung, Wissen an der und über die Universität zu erheben, ohne jene Kategorien zu (re)produzieren, die damit eigentlich kritisch erforscht und überwunden 
werden sollen. Dies kann gelingen, wenn u. a. von einer Mehrfachpositionierung der Akteur_innen ausgegangen wird.

Vor diesem Hintergrund setzte sich das zweisemestrige Lernforschungsprojekt „Mehrfachdiskriminierung an der Universität erforschen?!“ mit Beginn des Wintersemesters 2014/15 an der Georg-August-Universität Göttingen mit Theorien der Ungleichheit sowie mit Fragen der methodischen Erforschung von Diskriminierungsverhältnissen an der Universität auseinander.

Unterschiedlich angesetzte Forschungen von Studierenden sollten die universitäre $(\mathrm{Re})$ Produktion von Machtverhältnissen innerhalb der eigenen Strukturen untersuchen: Inwiefern wird die Universität ihren eigenen Ansprüchen auf Chancengerechtigkeit gerecht?

Im Rahmen meiner Tutor_innenbeschäftigung beim Lehrforschungsprojekt entwickelte sich die Idee zum Thema der vorliegenden Masterarbeit. Dabei setzte ich den Fokus meiner Untersuchung auf Rassismus an der Hochschule aus der Perspektive von Studierenden, die selbst Rassismus im Alltag erfahren.

Die thematische Konzentration auf Rassismus ergab sich zum einen aus meinem theoretischen Schwerpunkt im Verlauf des Studiums, ${ }^{1}$ zum anderen spielt mein erfahrungsweltlicher Zugang zu Rassismus an der Hochschule eine wesentliche Rolle. Während meines gesamten Studiums ist und war mir die Abwesenheit der Thematisierung von (Alltags) Rassismus trotz seiner Existenz im akademischen Raum bewusst.

Selbst wenn Diskriminierungsverhältnisse an der Universität insgesamt wenig Beachtung finden, bestehen zur Auseinandersetzung mit einzelnen von ihnen verschiedene Programme und Projekte. So gibt es an der Georg-August-Universität beispielsweise die Projekte Brückenschlag und MoveMento, die beide die Dimension der sozialen Herkunft abdecken. Die Dimension Geschlecht ist an der Hochschule mittlerweile gesetzlich über Maßnahmen, wie beispielsweise der Einführung von Gleichstellungsbüros, Professorinnen-Programmen sowie der Verankerung von Gleichstellungsnormen in der Exzellenzinitiative verankert. Das Diversity Büro der Georg-August-Universität befasst sich schwerpunktmäßig mit der Dimension Abelism/Behinderung und barrierefreiem Studieren. Die Auseinandersetzung mit Rassismus allerdings hat in diesem Rahmen bislang keinen Eingang an der GeorgAugust-Universität gefunden.

So beabsichtigte ich in meinen Vorüberlegungen zum Themenfeld Rassismus und Hochschule zunächst vor allem folgenden Fragen nachzugehen: In welcher Form und auf welche Weise zeigt sich Rassismus im universitären, akademischen Alltag der Georg-August-Universität? Welche (effektiven) Maßnahmen können hinsichtlich einer rassismuskritischen Praxis an der Georg-August-Universität sinn-

1 Dabei wird Rassismus im vorliegenden Rahmen dennoch in seinen Interdependenzen mit weiteren Machtverhältnissen, wie Sexismus und Klassismus reflektiert und analysiert. 
voll sein? Den Hauptteil meiner Arbeit sollte dabei die Entwicklung von Strategien für eine rassismuskritische Praxis an der Universität darstellen. ${ }^{2}$

Allerdings entwickelte sich nach der Erhebung der zwei Gruppengespräche, die ich nach dem Prinzip der Offenheit geführt hatte, eine andere Schwerpunksetzung. Das Material eröffnete neue Fragen, die sich möglicherweise in einem Schritt vor den Überlegungen einer Praxis stellen müssten: In welcher Form und auf welche Weise tritt Rassismus im akademischen Raum auf und wie wird er von Betroffenen wahrgenommen? Wie wird Rassismus an der Hochschule sowohl von der Institution selbst als auch von den Studierenden - in diesem Fall von rassismus_erfahrenen Studierenden - überhaupt verhandelt?

Die Tendenzen, die sich dabei zeigten, führten mich zum Titel der Arbeit: Inkludierte Exkludierte. Einerseits eröffnet der akademische Rahmen rassifizierten Studierenden die Möglichkeit einer (limitierten) Inklusion, indem sich die Studierenden weitgehend mit der Institution Hochschule identifizieren und darüber Privilegien erlangen können. Andererseits bleiben sie aufgrund ihrer rassifizierten Position trotzdem in einem Außerhalb, also Exkludierte. So ergibt sich das Paradox der (beschränkten) Zugehörigkeit bei gleichzeitigem Ausschluss.

Dieser Umstand wirkt sich wesentlich auf die studentischen Verhandlungsweisen von Rassismus aus, die den Hauptteil der vorliegenden Arbeit darstellen.

Einführend stelle ich im Rahmen des 2. Kapitels Theoretische Zugänge zunächst das Rassismus-Verständnis der vorliegenden Arbeit vor. Dies erscheint mir aus unterschiedlichen Gründen notwendig, u. a., weil jedes empirische Material - je nach Definition von Rassismus - zu sehr unterschiedlichen Befunden führen kann. Entgegen der bestehenden Notwendigkeit einer (theoretischen wie auch alltagstauglichen) Rassismusdefinition existieren in der deutschen Öffentlichkeit große Herausforderungen, Rassismus überhaupt sprechbar zu machen bzw. zu thematisieren. Diese Aspekte beleuchte ich unter Kapitel 2.1.1 Zur Herausforderung und Notwendigkeit einer Rassismusdefinition.

Daran anschließend geht es unter Punkt 2.2 Bezeichnungspraxis um die (unzureichende) Bezeichnungspraxis im deutschsprachigen Raum für Menschen, die Rassismus erfahren. Dabei gehe ich insbesondere folgenden Fragen nach: Mit welchen Begriffen werden rassismus_betroffene Personen in Deutschland bezeichnet? Wer setzt diese Bezeichnungen? Wie benennen sich die Gesprächsteilnehmenden selbst? Welche Herausforderungen, aber auch alternative Handlungsmöglichkeiten ergeben sich daraus? Wieso ist die Bezeichnung „mit Migrationshintergrund“ unzureichend, obwohl sie öffentlich-politisch als „korrekt“ gilt?

2 Dazu orientierte ich mich an Universitäten, die (zumindest auf studentischer Ebene) versuchten, eine rassismuskritische Praxis an ihrer Institution zu etablieren, indem sie beispielsweise wie die HU-Berlin, Beratung für Rassismus_Betroffene anbietet (vgl. https://www.refrat.de/adb. html?1405602686, 12.02.2016). Außerdem sollte das Strategiepapier von Natascha A. Kelly für den Umgang mit institutionellem Rassismus als Grundlage für eine Umsetzung in die Praxis dienen (vgl. http://www.natashaakelly.com/institutioneller-rassismus-was-tun/, 12.02.2016). 
Nach dem theoretischen Einstieg stelle ich im 3. Kapitel den Feldzugang sowie die gewählte Methode der vorliegenden Untersuchung vor, die aus zwei Gruppengesprächen mit rassismus_betroffenen Studierenden besteht. Darüber hinaus führe ich in diesem Zusammenhang einige Aspekte bezüglich meiner Position als Forscherin aus, da ich mich im vorliegenden Kontext der Hochschule nicht nur als Wissenschaftlerin im Feld befand, sondern als Studentin selbst ein Teil des Feldes bin. Ebenso ergibt sich aus der gleichen gesellschaftlichen Situierung als rassismus_ betroffene und erfahrene Person eine weitere Parallele zu den Gesprächsteilnehmenden. Hier gehe ich der Frage nach, welche Rolle diese Faktoren für die vorliegende Untersuchung spielen und welchen Einfluss sie sowohl auf die Erhebung des Materials als auch die Ergebnisse haben.

Der Hauptteil der Untersuchung beginnt im 4. Kapitel Verhandlungsweisen von Rassismus(erfahrungen) im Hochschulkontext, in dem ich zum einen die institutionelle Verstrickung der Hochschule in rassistische Verhältnisse und zum anderen ihre Umgangsweisen damit analysiere. Ebenso wird hier die Rolle der Hochschule im Zusammenhang mit den Verhandlungsweisen der Studierenden von Rassismus sowie Rassismuserfahrungen beleuchtet.

Im 5. Kapitel Studentische Verhandlungsweisen von Rassismus(erfahrungen) arbeite ich drei unterschiedliche Verhandlungsweisen heraus. Erstens stellen verschiedene (De)Thematisierungsweisen (Kapitel 5.1) eine zentrale studentische Verhandlung von Rassismus dar, d. h. wie rassifizierte Studierende über Rassismus(erfahrungen) sprechen bzw. wie sie Rassismus als Begriff (de)thematisieren? Hier arbeite ich wiederum vier verschiedene (De)Thematisierungsweisen heraus. Zweitens wird Rassismus primär in der Auseinandersetzung mit der gesellschaftlich zugeschrieben Position der rassifizierten Studierenden als Andere verhandelt (Kapitel 5.2). Auch hierbei weisen die Gesprächsteilnehmenden sehr unterschiedliche Umgangsweisen auf. Drittens schließlich eröffnet den Studierenden die Verwendung ihnen zugänglicher Machtverhältnisse, hier Klassismus und Sexismus, eine weitere Verhandlungsmöglichkeit von Rassismus (Kapitel 5.3).

In allen Verhandlungsweisen stellt der Status als Studierende einen zentralen Faktor dar, der wichtigen Einfluss auf sie nimmt. Dieser Aspekt wird im 6. Kapitel Der Status Studierende_r analysiert. 


\section{Theoretische Zugänge}

\subsection{Das Rassismus-Verständnis der vorliegenden Arbeit}

Rassismus ist als Gesellschaftsstruktur historisch gewachsen und gehört als Normalität zum gesellschaftlichen Funktionieren dazu (vgl. Terkessidis 2004: 92). Die Gesellschaft ist durch verschiedene Machtverhältnisse, u. a. auch durch Rassismus, strukturiert, nach denen sozial-politische Teilhabe, Zugang zu Ressourcen und Zugehörigkeiten organisiert sind. Rassismus ist ein Machtverhältnis, das „der Rechtfertigung der hegemonialen Struktur und den daraus hervorgehenden Praxen des Ausschlusses und der Ungleichbehandlung" dient (Mecheril/Melter 2011: 16). Dabei stellt Rassismus keine zentralisierte Herrschaftsform dar, sondern ist „eine Art allgemeine strukturelle Logik des gesellschaftlichen Zusammenhangs, die auf allen Ebenen gesellschaftlicher Wirklichkeit bedeutsam sein kann" (Scharathow/Melter u. a. 2011: 11).

Grada Kilomba macht in ihrer Definition drei Eigenschaften des Rassismus aus, die auf verschiedenen Ebenen (Gesetze, Institutionen, alltagsweltliche Interaktionen, individuelle Selbstverständnisse) einer Gesellschaft wirken:

Die erste Eigenschaft umfasst die Konstruktion einer Differenz, die Personengruppen nach rassistischen Merkmalen wie (vermeintlicher) Herkunft, religiöse Zugehörigkeit, Hautfarbe, Migrationsgeschichte, Name und Sprache einteilt. Dieser Prozess der Differenzierung wird mit dem Akt der rassistischen Diskriminierung erst wirksam. Deshalb sind bestimmte Gruppen nicht einfach anders, sondern sie werden durch institutionelle, strukturelle Praxen der Diskriminierung zu Anderen gemacht (vgl. Kilomba 2013: 40).

Die zweite Eigenschaft des Rassismus liegt in der Bewertung der o. g. Differenz entlang eines hierarchischen Wertesystems, innerhalb dessen weiß-Sein den Maß- 
stab darstellt. „And in this sense, racism is white supremacy.“ (ebd.: 41; Hervorh. im Original).

Und schließlich ist Rassismus an Macht geknüpft, die er benötigt, um die ersten beiden Eigenschaften überhaupt wirksam durchsetzen zu können. Er ist damit ein historisch gewachsenes, politisches, soziales und wirtschaftliches Machtverhältnis (vgl. ebd.).

Seine Wirkmacht ist vor allem in einem Prozess der Wissensformation eingebettet: Rassistische Erklärungssysteme plausibilisieren und legitimieren seine (gewaltvolle) Macht (vgl. Scharathow/Melter, u. a. 2011: 11). Dabei sind diese Erklärungssysteme und damit auch die Erscheinungsformen des Rassismus flexibel und wandlungsfähig. Der biologistische Rassismus des neunzehnten und frühen zwanzigsten Jahrhunderts erweitert und verfeinert sich beispielsweise durch neoliberale Tendenzen:

„Rassismus präsentiert sich in den postkolonialen und postmigrantischen Einwanderungsgesellschaften Europas als ein Gefüge verschiedener, einander zum Teil überlagernder Formationen von offen rassistischer Gewalt bis hin zu subtilen Varianten eines institutionalisierten Rassismus [...]. Es handelt sich hierbei um Diskurse, Politiken und Praktiken von staatlichen und zivilgesellschaftlichen Institutionen, die systematische Ausgrenzung und Diskriminierung produzieren, ohne sich explizit und vorsätzlich rassistischer Begründungs- und Deutungsmuster zu bedienen" (Tsianos/Pieper 2011: 121).

Folglich ist Rassismus nicht nur eine Frage der Intentionen, sondern vielmehr eine Frage der Praxis und muss dementsprechend in Bezug auf seine Konsequenzen und Wirkungen hin analysiert werden (vgl. Lentin/Titley 2011: 92). Zudem ist es zentral zu erkennen, dass neuere Entwicklungen und Ebenen des Rassismus nicht ausschließlich intentional über direkten Ausschluss oder gar körperliche Gewalt funktionieren, sondern eben auch, wie Terkessidis herausarbeitet, kleine „banale“ Erlebnisse sein können, die nicht unbedingt „böse“ (2004: 78) gemeint sein müssen. Die scheinbar „unbedeutenden“ rassistischen Ereignisse sind jedoch die, die eine strukturelle Spaltung der Gesellschaft in ein Wir und die Anderen bewirken und aufrechterhalten.

Aktuelle Entwicklungen von Rassismus weisen u. a. eine hohe Komplexität auf, die aus einem Zusammenwirken von „Wissensproduktion und Machttechnologien, juridischen Regelungen, institutionellen Strukturierungen, situativen Gelegenheiten, Affekten und einer Vielheit der menschlichen und nicht menschlichen Akteur_innen und deren sich wandelnde mikrosoziale Praxen“" (Tsianos/Pieper 2011: 126) besteht. Obwohl er gegenwärtig zunehmend offener ist, wirkt Rassismus als moderne Machttechnik subtil über Prozesse der Subjektivierung und Normalisierung, wobei hier in der Regel (zunächst) auf offensichtliche Gewalt und Kontrolle verzichtet werden kann bzw. könnte. Das rassifizierte Subjekt entsteht somit aus einem komplexen Zusammenspiel von Herrschafts- und Selbsttechnologien (vgl. Velho 2010: 119). Unter Berücksichtigung dieser Entwicklungen kann das Begreifen 
von Rassismus - im Sinne eines ganzheitlichen Prozesses, der neben des rationalen Verstehens auch emotionales Wahrnehmen und Erkennen umfasst - schwierig sein. Auch für diejenigen, deren Lebensrealität und Alltag von Rassismus geprägt ist.

\subsubsection{Zur Notwendigkeit und Schwierigkeit einer Rassismusdefinition}

In Deutschland besteht vor dem historischen Hintergrund des Nationalsozialismus eine große Hürde, den (emotional beladenen) Begriff des Rassismus im Alltag über die Zeit und den Kontext des Nationalsozialismus hinausgehend zu verwenden. Der Begriff des Rassismus ist generell tabuisiert und seine Benennung kann bei der Mehrheit der Gesellschaft heftige Abwehrreaktionen auslösen (vgl. Rommelspacher 2011: 32f.; Scherschel 2011). Paul Mecheril und Claus Melter stellen in diesem Zusammenhang fest, dass „,[d]ie Tendenz der Verharmlosung und Leugnung rassistischer Realität [...] in Deutschland nach wie vor relevant [ist] - dies macht das Sprechen über Rassismus gerade im deutschsprachigen Raum so schwierig" (2011: 14). Die fehlende öffentliche Auseinandersetzung mit Rassismus führt folglich zu einem weitgehenden Nicht-Wissen über Rassismus im Alltag. Eine Konsequenz daraus zeigt sich beispielsweise in den

„Versuche[n] der [ehemaligen] Familienministerin Kristina Schröder in Diskussionsrunden und Interviews mit Hilfe der ,Deutschenfeindlichkeit' das Argument des ,umgekehrten Rassismus' zu etablieren. [...] Im Gegensatz zu früheren Interventionen Schröders gelang es diesmal, das Thema breit im hegemonialen Diskurs zu verankern" (Friedrich 2011: 21).

Eine solche öffentliche Relativierung von Rassismus - basierend auf dem mangelnden Alltags- und Grundverständnis von Rassismus - stellt letztendlich eine (Re) Produktion von rassistischen Strukturen dar, da sie die Lebensrealitäten derjenigen relativiert und leugnet, die tatsächlich von (strukturellem) Rassismus betroffen sind. Insbesondere vor dem Hintergrund der aktuellen rassistischen Entwicklungen in Deutschland ${ }^{3}$ ist es notwendig, sowohl öffentlich-politisch als auch wissenschaftlich ein klares Verständnis bzw. einen Grundkonsens von Rassismus zu erarbeiten und zu vermitteln.

In einer detaillierten Auseinandersetzung mit der (deutschsprachigen) Rassismusforschung wird jedoch auch hier die Bandbreite an unterschiedlichen Verständnissen, Auslegungen und Schwerpunkten des Phänomens deutlich. Eine kritische Zusammenfassung der vielfältigen Theoretisierungen von Rassismus stellt Mark Terkessidis in seiner Dissertation bereit (vgl. Terkessidis 2004). Er zeigt auf, dass selbst in Wissenschaft und Forschung „überhaupt keine Kohärenz und Kontinuität“ hinsichtlich der Definition von Rassismus besteht (ebd.: 214). Dies ist u. a. auch auf

An dieser Stelle sei auf Pegida und Co., die aktuelle Erstarkung der AfD, die brennenden Unterkünfte von Geflüchteten, die Vorfälle u.a. in Freital (2016), Chemnitz (2018) und die insgesamt zunehmende Akzeptanz rechter Parolen und Einstellungen verwiesen. 
die hohe Komplexität von Rassismus, seiner Interdependenz mit weiteren Machtverhältnissen sowie seinen vielfältigen Auswirkungen abhängig von Raum und Zeit zurückzuführen. Aus diesem Grund ist es auch nicht verwunderlich, dass einige Rassismusforscher_innen dazu übergegangen sind, von Rassismen zu sprechen (vgl. Tsianos/Pieper 2011: 120). Der Versuch einer (notwendigen) analytischen Differenzierung ist nachvollziehbar, jedoch „muss es irgendeinen strukturellen Rahmen geben, der diese Phänomene miteinander verbindet" (Terkessidis 2004: 83). Denn ohne ein einheitliches Grundverständnis über das, was Rassismus kennzeichnet, besteht m.E. die Gefahr, dass einerseits der Zugang zu einem alltagstauglichen Rassismus-Verständnis zu komplex wird und andererseits Rassismuskritik ohne ein gemeinsames Fundament an Analysekraft verlieren kann.

Der Umstand eines fehlenden alltagstauglichen Rassismus-Verständnisses wirkt sich folglich auch auf das Verständnis derer aus, die selbst Rassismus erfahren. Mark Terkessidis arbeitet in seiner Untersuchung zum Wissensbestand von sogenannten „Migrant_innen“'heraus, dass

„[d]ie meisten Befragten sich ihr epistemisches Wissen über Rassismus quasi im Alleingang angeeignet [haben] - es gibt unter Migranten hierzulande kaum explizite, geteilte Wissensbestände. Oft ist die Wahrnehmung von Rassismus kaum mehr als ein Gefühl“ (Terkessidis 2004: 118).

Ähnliche Muster zum Wissensstand über Rassismus zeigen die Ergebnisse der vorliegenden Untersuchung: Die Gesprächsteilnehmenden berichteten von rassistischen Vorfällen, ohne diese unter Rassismus zu fassen, oder sie verneinten explizit Rassismus als Erklärung für ihre Erfahrungen. Dieses Paradox stellte mich in der Auswertung des Materials vor eine große Herausforderung und schließlich vor die Frage, wer mit welchen Voraussetzungen darüber entscheiden kann, was rassistisch ist.

In Ablehnung einer objektivistischen Auffassung von Wissenschaft habe ich als Forscherin den Anspruch, den Interviewteilnehmenden auf Augenhöhe zu begegnen und möglichst nicht der Hierarchielogik von Forscherin und Beforschten zu folgen. Dies erfordert für mich in erster Linie die Berücksichtigung der Lebenswirklichkeiten und Denkrealitäten der Gesprächsteilnehmenden in der Analyse und Auswertung. Jedoch stellte ich in der Auswertung des Materials fest, dass sich meine (wissenschaftliche) Auffassung von Rassismus nicht mit der der Gesprächsteilnehmenden deckte. In der Auseinandersetzung damit habe ich zwar keine eindeutige Lösung formulieren können, allerdings haben die Erkenntnisse anderer Forschungen, die vor ähnlichen Schwierigkeiten standen, mir einen Umgang ermöglicht:

Der Erziehungswissenschaftler Mark Schrödter befasst sich beispielsweise in seinem Artikel Die Objektivität des Rassismus. Anerkennungsverhältnisse und prekäre Identitätszumutungen u. a. mit der Schwierigkeit, „Rassismus an das Urteil der Betroffenen“ zu binden, denn „[d]amit würden [...] nur jene Rassismen und Diskriminierungen als Rassismus und Diskriminierung kritisierbar werden, insofern sie bereits von sozialen Bewegungen als solche artikuliert werden" (2007: 72). 
In diesem Zusammenhang bezieht er sich auf Sandra Hardings Standpunkttheorie, die Erfahrungen als gesellschaftliches Verhältnis herausarbeitet. Sie geht davon aus, dass es

„nicht sein [kann], daß die Erfahrungen von Frauen oder die Auffassungen, die sie vertreten, für sich genommen schon zuverlässige Grundlagen für Erkenntnisansprüche über Natur und gesellschaftliche Verhältnisse liefern. Schließlich wird die Erfahrung durch gesellschaftliche Verhältnisse geprägt: Z. B. mußten Frauen erst lernen, auch bestimmte sexuelle Übergriffe in der Ehe als Vergewaltigung zu begreifen. Vorher haben Frauen diese Übergriffe nicht als Vergewaltigung erlebt, sondern als Teil der Bandbreite heterosexueller Sexualität, die Ehefrauen erwarten sollten" (Harding 1991: 139).

Ähnlich verhält es sich auch mit Rassismuserfahrungen. Berücksichtigt man die oben angeführten strukturellen Schwierigkeiten, vor denen das Wissen über Rassismus sowie sein Thematisieren und Benennen stehen, wäre es eine Zumutung, die Betroffenen Rassismus definieren zu lassen bzw. von ihnen zu erwarten, „dass ausgerechnet sie nun explizite Vorstellungen vom Gegenstand haben" (Terkessidis 2004: 115). Dabei soll den Rassismus_Betroffenen nicht ihre Expertise über ihre Lebensrealität und bedingungen abgesprochen werden. Jedoch muss diese Expertise nicht zwangsläufig einen exklusiven Zugang zum Wissen über Rassismus bedeuten. Wie auch die vorliegenden Ergebnisse zeigen, ist es vielmehr

„das ,Lageschema‘ der Migranten, welches ein spezifisches Wissen ermöglicht. [...] Im Wissen der Migranten von ihrer Praxis steckt daher implizit ein Wissen über Rassismus. Es spielt keine Rolle, ob die Befragten ihre Lebenspraxis insgesamt als vom Rassismus mitbestimmt betrachten" (ebd.).

Zudem muss beachtet werden, dass „[d]ie Schwierigkeit, Rassismus zu identifizieren, nicht nur funktional für Rassismus, sondern ein Teil des Rassismus selbst “ ist (Ferreira 2003: 156, zit. in Velho 2010: 118). Folglich bedeutet es also, dass Rassismus und Diskriminierung auch unabhängig von den Empfindungen und Bewertungen der Betroffenen festgelegt und gestellt werden können bzw. müssen.

Heißt das nun jedoch, dass der wissenschaftliche Objektivismus doch bestimmen muss, was als rassistisch gilt oder nicht? Da die Wissenschaft selbst zu einem großen Teil an der rassistischen Wissensproduktion beteiligt war und ist (vgl. Golly 2006: 392; Terkessidis 2004: 110), kann und sollte sie nicht als Maßstab von Objektivität betrachtet werden. Doch

„[w] as bedeutet es nun für die Erkenntnis des Rassismus, wenn die Epistemologie der ,Objektivität‘ sich nicht mehr anwenden lässt? Die Beschäftigung mit dem Rassismus kann weder wertfrei noch unparteiisch sein. Um Rassismus als Gegenstand hervortreten zu lassen, ist es notwendig, die Perspektive zu ändern" (Terkessidis 2004: 110). 
Demnach kann eine kritische Haltung und Reflexion gegenüber der eigenen Forschung und Forschungsfrage, dem methodischen Verfahren sowie der Auswertung und Analyse einen Umgang ermöglichen. Darüber hinaus stellt Rassismus eine soziale Struktur und Realität dar, die „unabhängig von meinen Einstellungen oder Gefühlen ,in der Welt dort draußen' existiert" (Schrödter 2007: 77), sodass Rassismusforschung sowie Erkenntnisse über rassistische Verhältnisse einer Gesellschaft durchaus „mit Anspruch auf objektive Geltung“ (ebd.: 78) stattfinden können.

\subsection{Bezeichnungspraxis}

„Wie heißt es jetzt richtig politisch korrekt, bin ich jetzt Türkin mit deutschem- keine Ahnung, oder bin ich Deutsche mit türkischem ((holt Luft)). Ich bin einfach nur Lale ${ }^{4}$ und das ist okay. ${ }^{\text {"5 (Lale) }}$

„Mit Migrationshintergrund, wie auch immer das heißt, wie man das auch nennt, blablabla“ (Suzan)

„Leute, die als Ausländer, Migranten, wie auch immer bezeichnet werden“

(Metin)

Während beider Gruppendiskussionen fiel eines besonders auf: Den Teilnehmenden fehlten oft die passenden Worte, um sich selbst oder die Gruppe, zu der sie sich zugehörig sehen bzw. zu der sie zugehörig gemacht werden, zu bezeichnen. Ähnliches stellte auch Mark Schrödter während seiner Interviewführung mit Rassismus_ Betroffenen fest: „Der Interviewte ringt förmlich innerlich um die Bezeichnung seiner ethnischen Identität - für die ihm die ,prekären Verhältnisse‘ (Mecheril 2003) der deutschen Sprachgemeinschaft keine Begriffe zur Verfügung stellen“ (Schrödter 2007: 87).

Eine fehlende bzw. unzureichende Bezeichnungspraxis für bestimmte Personen(gruppen) ist ein Anzeichen dafür, dass diese in Deutschland zum einen nicht zur Norm zählen und zum anderen deren angemessene Benennung von keiner politischen Relevanz zu sein scheint. Dies verweist auf strukturelle gesellschaftliche Machtverhältnisse, in der die Definitionsmacht, sich selbst (und andere) bezeichnen zu können, nur bestimmten Gruppen zukommt.

So lässt es sich erklären, dass die Teilnehmenden der Gruppendiskussionen eine große Variation an (Selbst)Bezeichnungen in den Gesprächen nannten. Teilweise geht dieser Umstand, wie im Eingangszitat von Lale zu erkennen ist, mit Resignation oder gar Frustration, aber mindestens mit Momenten der eigenen Irritation einher. Das gesamte von mir erhobene Material bezeugt die Problematik der fehlenden Bezeichnungspraxis von Personen(gruppen), denen trotz ihres Lebensmittelpunkts

4 Alle Namen der Gesprächsteilnehmenden sind anonymisiert.

5 Transkription nach Rosenthal 2005: 95. 
in Deutschland ihr „deutsch_Sein“ nicht fraglos anerkannt wird. Sie werden unabhängig ihrer Selbstdefinition „zu Anderen gemacht und erfahren sich als solche“ (Goel 2007: 206).

Folglich greifen die Teilnehmenden selbst auf - wie weiter unten ausgeführt unzureichende Begriffe wie „Ausländer_in“, „Kanake“ oder „Schwarzkopf“ zurück, um sich in Deutschland bezeichnen zu können. In der folgenden Abbildung sind alle (Selbst)Bezeichnungen aus beiden Gruppengesprächen aufgeführt, dabei kann durch die Darstellungsweise als Cloud die fehlende Stringenz und Sicherheit im Umgang mit diesen Begriffen visualisiert werden.

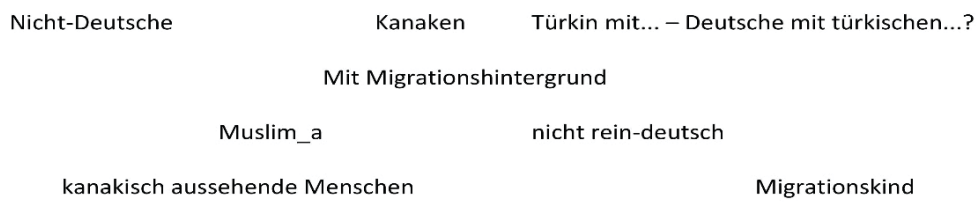

\section{Selbstbezeichnungen}

Menschen, die mehrere Sprachen sprechen
Migrationshintergrund habende Person
Ausländer-innen $\quad$ Schwarzkopf unsere Generation

\section{Abb. 1: Cloud der Selbstbezeichnungen}

Die Bezeichnung „mit Migrationshintergrund“ wird von den Teilnehmenden insbesondere am Anfang der Gespräche verwendet, um sich scheinbar formell und „politisch korrekt" auszudrücken, da dieser Begriff in der deutschen Öffentlichkeit als die einzige vermeintlich wertneutrale Möglichkeit der Benennung zur Verfügung steht. In den Gesprächen wurde dieser Begriff jedoch in keinem Fall unkommentiert als Selbstbezeichnung benutzt. Eine der Teilnehmenden distanzierte sich sogar ausdrücklich von dieser Bezeichnung. Suzan: „Mein Migrationshintergrund ist sowieso einer, der mir von außen eher angedichtet wird. Ich identifizier' mich mit diesem Hintergrund gar nicht."

Diese Reaktionen sind in Anbetracht des Entstehungskontextes des Begriffes nicht verwunderlich: Wie ist diese öffentlich-politisch anerkannte Bezeichnung, der etwa 17 Millionen Menschen in Deutschland bezeichnen soll, zustande gekommen? Wer war bzw. wer war nicht in die politische Entstehung und Festlegung der 
Bezeichnung miteinbezogen? Wie sieht die Meinung der Personen aus, die „mit Migrationshintergrund“ fremdbezeichnet werden? Sehen sie sich mit diesem Begriff repräsentiert? Neben der problematischen Fremdbestimmung in der Entstehung des Begriffs wirft auch die inhaltliche Bedeutung die Sinnfrage auf:

„Warum werden Menschen, die selbst nicht migriert sind, ,MigrantInnen“ genannt? Warum werden auch Kinder aus binationalen Partnerschaften so bezeichnet? Auch hier ist der Begriff unpassend - und mehr als das: Er bleibt in diesen Kontexten einer besonders zweifelhaften Variante des Abstammungsdenkens verhaftet" (Battaglia 2007: 198).

Hinzu kommt, dass viele der Bezeichnungen im Kontext der rassistischen „Integrationsdebatte" negativ konnotiert sind:

„So neutral der Begriff auch im Entstehungsmoment definiert wurde, verbindet sich mit ihm durch den öffentlichen Diskurs eine Bezeichnungspraxis, der eine soziale Praxis folgt, die vorwiegend Differenz-Momente hervorhebt und die in der öffentlichen Wahrnehmung vor allem mit Defiziten und Problemen verbunden wird“" (Foroutan 2010).

So gesehen gibt es viele Hürden für Personen, die unter der Bezeichnung „mit Migrationshintergrund" gefasst werden, positive Bezüge zu oder eine Identifikation mit bestehenden (gesellschaftspolitisch anerkannten) Bezeichnungen herzustellen. Ähnlich verhält es sich auch mit Begriffen wie „Migrant_in“ und „Ein-“ oder „Zugewanderte_r“, die in den Medien und im Alltag oft als Synonym zu „Mensch mit Migrationshintergrund" verwendet werden. Positiv belegte Alternativen bestehen in der breiten Öffentlichkeit nicht.

Interessanterweise wurde die Bezeichnung „Ausländer_in“von den Teilnehmenden unbefangen am häufigsten für ihr Selbstverständnis bzw. als Selbstbezeichnung verwendet, selbst wenn der Begriff juristisch nicht auf die Teilnehmenden zutrifft, da sie alle die deutsche Staatsangehörigkeit besitzen. Sich dennoch als Ausländer_innen wahrzunehmen verweist möglicherweise auf die (eigene) Positionierung in der Gesellschaft: Sie sehen sich in einem Außerhalb des Landes bzw. der Gesellschaft (positioniert).

Der widerständige Charakter in der Entscheidung für einzelne Begriffe scheint für einige der Teilnehmenden zentral zu sein. Der ursprünglich als Schimpfwort geltende Begriff „Kanake“ wurde beispielsweise bereits Ende der 1990er-Jahre vom Zusammenschluss Kanak Attak ${ }^{6}$ als Widerstandsstrategie in seiner Bedeutung umgekehrt und als Selbstbezeichnung verwendet.

Im Weiteren geht mit gewählten Begriffen der Teilnehmenden auch eine Selbstethnisierung einher, die ich angesichts der o. g. Problematiken der Bezeichnungspraxis in Deutschland wie folgt einordnen würde:

Zur Selbstbeschreibung von Kanak Attak, siehe: http://www.kanak-attak.de/ka/about/manif_ deu.html (02.05.2016). 
„Sie [die Selbstethnisierung] ist die Umkehrung und Einverleibung von Zuschreibungen sowie die Konstruktion einer Kollektivität, die es für viele erst möglich macht, hier in Deutschland zu leben. Als ,Strategie der bloßen Umkehrung' (Hall 1994, 20) erlangt Selbstethnizität ihre Wesenhaftigkeit, in dem sie sich an Nationen (Heimat), Kulturen oder Religionen bindet. [...] Selbstethnisierung ist somit Selbstbehauptung. Sie behauptet im wahrsten Sinne des Wortes eine eigene Identität und ein intaktes Selbstbild und schützt diese so vor den Demütigungen der Mehrheitsgesellschaft, um sich in dieser zu behaupten" (Akka 2009: 197f.).

Wie Akka herausarbeitet, erfolgt das Selbstverständnis vor allem auch im Verhältnis zur herrschenden Norm. Die Gesprächsteilnehmenden definierten sich beispielsweise selbst als „Ausländer_in“ in klarer Abgrenzung von der Norm des „deutsch_ Seins“. Dabei werden „Deutsche“ und „Ausländer_innen“ als starre Identitätskategorien verhandelt, die sich gegenüberstehen.

Sprachliche Kategorien und die (Selbst)Benennung von Gruppen sind grundsätzlich wichtig, um gesellschaftliche sowie politische Prozesse und Kämpfe aufzeigen, benennen und langfristig verändern zu können. Doch hierbei kommt es auf den Prozess der Begriffsfindung und die Intention der festgesetzten Bezeichnung an. Die Notwendigkeit einer intensiven wissenschaftlichen und politischen Auseinandersetzung mit der aktuellen Bezeichnungspraxis wird aus den o. g. Aspekten ersichtlich. Die derzeitig zur Verfügung stehenden Begriffe genügen weder der Erfassung all derjenigen Gruppen, die in der öffentlichen Wahrnehmung auch gemeint sind, noch reichen sie aus, um den heterogenen Lebensrealitäten und hybriden Persönlichkeiten gerecht werden zu können. Die Schriftstellerin und Journalistin Jagoda Marinic konkretisiert, was hierzu gebraucht wird: „Mehr Worte für mehr Wirklichkeiten und mehr Lebenswelten, die benannt werden können, ohne dass es ihnen zum Nachteil gereicht" (Marinic 2013).

Für einen kritischen Umgang mit Begriffen müssen diese flexibel behandelt und gedacht werden. Es kann und wird nicht den einen Begriff geben, der für immer Geltung beanspruchen kann. Begriffe müssen mit gesellschaftlichen Prozessen entwickelt werden und benötigen die Freiheit, auch wieder verändert, neu reflektiert, diskutiert und an Lebensrealitäten angepasst zu werden. Denn: „Ich spreche von so vielen, Wirs', wie ich Identitäten habe. Diese sind genauso vielfältig und veränderbar wie die Begriffe, die ich für Selbstdefinitionen heranziehe und wieder fallenlasse" (Konuk 1996: 234).

\subsubsection{Begriffe und Bezeichnungen in der vorliegenden Arbeit}

Es kann insgesamt festgehalten werden, dass in Deutschland große Problematiken hinsichtlich einer geeigneten (Selbst)Bezeichnungspolitik im Kontext von Rassismus bestehen. Daraus ergeben sich vielfältige Fragen für eine Forschung, die eine 
Rassismusanalyse zum Ziel hat: Welche Bezeichnungen verwende ich als Forscherin? Bleibe ich im Wortlaut der Teilnehmenden und bezeichne sie folglich auch als „Kanaken“ und „Ausländer_innen“? Oder distanziere ich mich von den Begriffen und orientiere mich an gesellschaftlich, gängigen“ Bezeichnungen wie „Migrant_in“ oder „mit Migrationshintergrund“?

Da der Fokus der vorliegenden Untersuchung auf Rassismus(erfahrungen) liegt, eignet sich weder die eine Variante noch die andere. Stattdessen werde ich im Weiteren Begriffe verwenden, die auf Rassismus(erfahrungen) verweisen.

Rassismus existiert in einem Prozess der Konstruktion, deshalb sollen die Bezeichnungen rassifiziert, migrantisiert und geanderte bzw. Andere in der vorliegenden Arbeit als kritische Ansätze für die Analyse von Othering-Prozessen (vgl. Kilomba 2013: 40ff.) weitgehend synonym verwendet werden und diese hervorheben. Aufgrund der gesellschaftlich vorherrschenden Nichtbenennung von Rassismus sollen zudem die Begriffe Rassismus_Betroffene ${ }^{7}$ bzw. Rassismus_Erfahrene verwendet werden, um dieser Tendenz entgegenzuwirken. Dabei soll die Schreibweise mit Unterstrich - analog zum Gender_Gap - auf die Vielfältigkeit von Erfahrungen und Konzepten hinweisen, die sehr unterschiedlich ausgelegt werden (können). Am Beispiel Rassismus_Erfahrene soll der Unterstrich darauf aufmerksam machen, dass sowohl Rassismus als Konzept wie auch die Erfahrungen damit komplex, mehrdimensional und dynamisch sind. ${ }^{8}$ Diese Schreibweise und seine Bedeutung gelten ebenso für weitere Begriffe wie deutsch_Sein oder inkludiert_Sein.

Als Selbstbezeichnung eignen sich diese Begriffe weniger, da sie eine (negative) Erfahrung fokussieren und damit keine Identifikationsmöglichkeit anbieten. Allerdings erscheinen mir diese Begriffe aufgrund der o. g. Gründe für den Rahmen der vorliegenden Rassismusanalyse als geeignet.

Zudem verwende ich wie einige Wissenschaftler_innen die Bezeichnung muslimisch Markierte in Bezug auf Personen, die von antimuslimischem Rassismus betroffen sind: „Yasemin Shooman (2011: 64ff.) bezeichnet damit die Menschen, denen aufgrund ihrer Markierung qua Namen, Phänotyp und/oder religiöser Symbole eine islamische Religionszugehörigkeit zugeschrieben wird" (Friedrich/Schultes 2013: 2).

Schwarz beschreibt hier eine gesellschafts-politische Kategorie und ist eine Selbstbezeichnung ,Schwarzer Deutscher'. Um diesen Aspekt zu markieren wird Schwarz großgeschrieben (vgl. Lauré al.Samarai 2011: 611).

Zur Benennung der dominanten und hegemonialen Position ziehe ich im Weiteren die Bezeichnung weiß bzw. weiß-deutsch heran. Hierbei ist weiß nicht als

7 Hierbei möchte ich darauf hinweisen, dass in einer rassistisch strukturieren Gesellschaft alle von Rassismus betroffen sind, jedoch die einen positiv und die anderen negativ. Allerdings werde ich diese Unterscheidung sprachlich nicht durchgehend benennen. Mit dieser Bezeichnung sind hier nur negativ Betroffene gemeint.

8 Die Verwendung des Unterstrich ist mir außerhalb der Gender-Thematik das erste Mal im folgenden Werk begegnet: Kuria, Emily Ngubia (2015): eingeschrieben. Zeichen setzen gegen Rassismus an deutschen Hochschulen, Berlin. 
„Hautfarbe“ zu verstehen, sondern als politische Kategorie, mit der Privilegien und eine Machtposition einhergehen:

„Weißsein wird in diesem Sinne als Analysekategorie verstanden, bei der aus einer weißen Position heraus Weißsein zur unhinterfragten und dethematisierten gesellschaftlichen Norm wird. Damit einher gehen die Nicht-Wahrnehmung von Privilegien und Verstrickungen in rassistische Strukturen" (Friedrich 2011: 13).

Ebenso versprachlichen die Begriffe Mehrheits- oder Dominanzgesellschaft diese Position, dabei sollen die Begriffe jedoch „keine quantitative Mehrheit kennzeichnen, sondern beschreib[en] im Kontext der Einwanderungsgesellschaft und vor dem Hintergrund unseres Analysefokus zunächst die ,Gruppe, die über die Mittel der politischen, kulturellen und auch wissenschaftlichen Re-Präsentation verfügt' (Broden/Mecheril 2007: 10)“ (Friedrich/Schultes 2011: 78). 



\section{Feldzugang und Methode}

\subsection{Feldzugang}

Im Rahmen des Lehrforschungsprojekts wurden unterschiedliche methodische Herangehensweisen an das Thema Mehrfachdiskriminierung an der Universität reflektiert und diskutiert. Bei meinem Fokus auf Rassismus an der Hochschule aus der Perspektive von rassismus_erfahrenen Studierenden eignen sich Gruppendiskussionen, da sie einen vielversprechenden Zugang zu einer breiten Auseinandersetzung mit dem Thema ermöglichen. ${ }^{9}$

Allerdings ergab sich die Herausforderung, dass sich im Rahmen des Lehrforschungsprojekts zur selben Zeit und im selben Feld mehrere Forscher_innen zur ähnlich ausgerichteten Forschungsfrage der (Mehrfach)Diskriminierung an der Hochschule aufhielten. Auch wenn jede_r von uns einen eigenen Schwerpunkt gesetzt hatte, so ließen sich Überschneidungen bezüglich der Zielgruppen und damit potenziellen Interviewpartner_innen nicht gänzlich vermeiden: Über Aushänge, Emailverteiler, Facebook und Kontakte aus dem eigenen universitären Umfeld hatte das Thema zu dieser Zeit eine breite Präsenz an der Universität in Göttingen. Folglich bestand das Risiko, dass potenziell Interessierte verwirrt waren, wer welche Forschung realisierte und bei welcher $/ \mathrm{m}$ der Interviewenden sie sich bei grundsätzlichem Interesse melden sollten.

Es zeigte sich jedoch, dass sich der Zugang zum Feld auch aus weiteren Gründen als insgesamt schwierig gestaltete.

Zunächst arbeitete ich an einem Aushang, der um die Teilnahme an einem Gruppengespräch zum Thema Rassismuserfahrungen an der Universität bat und

9 Näheres dazu wird im nächsten Kapitel zur Gruppendiskussionen (3.2) erläutert. 


\section{Kennst du das?}

- Dein Name wird von Dozierenden oder Kommiliton_innen meistens falsch ausgesprochen oder falsch geschrieben und du musst ihn i.d.R. buchstabieren.

* „Woher kommst du? Also so richtig?", „Du sprichst aber gut deutsch!“... Solche Fragen/Aussagen sind auch an der Uni nichts Neues für dich.

* Es gab schon Situationen, in denen du dich an der Uni fehl am Platz gefühlt hast oder dir wurde das Gefühl gegeben, du gehörst nicht hierhin. Und du denkst es könnte etwas mit deiner Hautfarbe, deiner (zugeschriebenen) Religionszugehörigkeit oder deiner (vermeintlichen) Herkunft zu tun haben?

\footnotetext{
In meiner Masterarbeit beschäftige ich mich mit Ungleichheit und Diskriminierung an der Hochschule und den Perspektiven von Studierenden, die aufgrund von (vermeintlicher) Herkunft, ihrer Religionszugehörigkeit, ihrer Hautfarbe und/oder anderer äußerlichen Merkmalen damit konfrontiert sind. Dazu möchte ich auf anonymer Basis entweder Gruppeninterviews führen, bei Bedarf auch Einzelinterviews. Diese Erfahrungen und den Umgang damit sollen im Mittelpunkt der Untersuchung stehen. Wenn du mitmachen möchtest, weil du das das Thema wichtig findest oder deine Meinung einbringen möchtest, dann schreib mir eine Email an folgende Adresse.

Einen Termin für das Interview werden wir gemeinsam festlegen.
}

Abb. 2: Aushang "Kennst du das?"

potenziell Interessierten die Möglichkeit geben sollte, eigenständig zu entscheiden, ob sie sich von Rassismus betroffen sehen und ggf. darüber sprechen möchten. Aufgrund der geringen Resonanz der anderen Forscher_innen, die ebenfalls u. a. mit Aushängen arbeiteten, beschloss ich, diese Idee zu verwerfen und wich stattdessen nach dem Schneeballsystem auf private Kontakte aus.

Dies hatte zwar den Vorteil, dass ich in relativ kurzer Zeit genügend Personen für zwei Gruppeninterviews finden konnte, allerdings hatte dieses Vorgehen auch einige Nachteile. Zum einen erfolgte damit die Teilnahme am Gruppengespräch nicht primär aus eigenem Antrieb und Interesse am Thema, sondern (zunächst) vorrangig aus der sozialen Absicht heraus, mich in meinem Vorhaben zu unterstützen. Schwerwiegender war zum anderen der Umstand, dass ich bei der Suche nach 
Interviewteilnehmenden die zu diesen ,passenden' Kategorien selbst festlegen und benennen musste, von denen ich annahm, sie damit anzusprechen. Der Aushang hingegen hätte möglicherweise einen Prozess der Identifikation mit der Ansprache und damit ein Bewusstsein für die eigenen Rassismuserfahrungen vorausgesetzt. Da jedoch das Thema Diskriminierung (an der Hochschule) anscheinend als ein sensibles Thema wahrgenommen bzw. verhandelt wird und zudem das Sprechen darüber generell und institutionell tabuisiert ist, lässt sich die geringe Resonanz der anderen Forscher_innen aus dem Lehrforschungsprojekt u. a. auch damit erklären.

Aufgrund der bereits beschriebenen Schwierigkeit des mangelnden Wissens über Rassismus sowie die insgesamt eingeschränkten Möglichkeiten, Rassismus in Deutschland zu thematisieren, entschied ich mich bei der Suche nach Teilnehmenden gegen die konkrete Benennung des Begriffs. Einerseits können in der Regel nur wenige Personen, selbst Rassismus_Betroffene, etwas mit Rassismus anfangen. Andererseits befürchtete ich, mit der konkreten Nennung gar keine oder nur sehr wenige Interviewteilnehmende zu finden.

Schlussendlich formulierte ich für die Suche nach potenziellen Interviewpartner_innen folgende Nachricht, die von einem Bekannten über o. g. Kanäle verteilt wurde:

„Eine Freundin sitzt derzeit an ihrer Masterarbeit und dabei soll es um Exklusion und Benachteiligung an der Uni gehen. Insbesondere soll es um die Erfahrungen von Studis mit einem sogenannten ,Migrationshintergrund gehen. Und da wollte sie Gruppendiskussionen oder auch Einzelinterviews führen. Hätte jemand Lust, daran teilzunehmen? Oder kennt ihr Leute, die Interesse hätten da so für ein zwei Stunden darüber zu diskutieren?"

Trotz meiner oben angebrachten Kritik an der Dethematisierung von Rassismus sowie an der unzureichenden Bezeichnung „Migrationshintergrund“ habe ich mich in der Forschung selbst aufgrund der rassistischen strukturellen Gegebenheiten, die eine Benennung von Rassismus nicht erlauben, sowie einer fehlenden alternativen Bezeichnungspraxis paradoxerweise gezwungen gesehen, mich innerhalb dieser Struktur zu bewegen und diese zu reproduzieren, um zu Rassismus forschen zu können. Dieser Prozess verdeutlicht bereits die Wirkmacht und Existenz von Rassismus - auch im universitären/akademischen Raum.

Die Einschränkung von potenziellen Interviewpartner_innen auf mein soziales Umfeld führte dazu, dass mein Zugang auf bestimmte Rassismuserfahrungen beschränkt war, sodass ich letztendlich ausschließlich muslimisch_markierte Studierende als Interviewteilnehmende gewinnen konnte. Idealerweise hätte ich möglichst unterschiedliche Rassismuserfahrungen zur Sprache gebracht, z. B. auch die von afro-deutschen oder asiatisch-deutschen Studierenden. 


\subsection{Gruppendiskussionen}

Der Erkenntnisanspruch der vorliegenden Untersuchungen besteht darin, Rassismus an der Hochschule aus studentischer Perspektive nachzuvollziehen. Dazu scheinen Gruppengespräche mit rassismus_betroffenen Studierenden ein geeigneter Zugang zu sein. Für die Untersuchung von Rassismus(erfahrungen) sowie die (subjektivierenden) Auswirkungen von rassistischen Verhältnissen weist ein qualitativer Zugang gegenüber quantitativen Methoden viele Vorteile auf, denn

„quantifizierende Daten erfassen, modellieren und geben eine Realität wieder, der die feineren Verästelungen rassistischer Praxen in Interaktionen, Selbstverständnissen und Deutungen entkommen. Da diese Verästelungen, das Subtile häufig im offiziell dem Rassismus abgeschworen habenden deutschsprachigen Raum aber eine sehr zentrale Wirkungsweise darstellen, strebt Rassismusforschung vor allem anhand qualitativer Studien an, die ideologisch vielgestaltigen, in den Zielgruppen wechselnden Vielgesichtigkeit und Indirektheit von Rassismen empirisch nachzuweisen und zu rekonstruieren" (Mecheril/Melter 2011: 19).

Das spezifische Erkenntnispotenzial rekonstruktiver Sozialforschung liegt nach Meuser darin, soziales Handeln von Individuen in sozial strukturelle Verhältnisse einzubetten. Individuelle Entscheidungen sind dabei als „Ausdruck überindividueller sozialer Zugehörigkeiten (Geschlecht, soziales Milieu, Generation u. a.) und kollektiver Orientierungen“ (Meuser 2011: 142) zu verstehen. Nach Bohnsack können kollektive Phänomene adäquater in einer Gruppe erfasst werden, da Sinn- und Bedeutungszuschreibungen sowie Lebensorientierungen primär aus sozial konstituierten, gemeinsamen Erfahrungsräumen entstehen und sich im Miteinander von Menschen mit gleichen oder ähnlichen Erfahrungen zeigen (vgl. Bohnsack 2000: 378). Hinter individuell-prozesshaften Sinnzuschreibungen sollen somit kollektivstrukturelle Sinnmuster erkennbar werden. Somit kann es in diesem Rahmen jene kollektiven Orientierungen sowie überindividuelle Zugehörigkeiten zusammenzubringen. Folglich stehen im Fokus der vorliegenden Arbeit keine individuellen Biografien von Studierenden, sondern vielmehr die geteilten Erfahrungen, die sie aufgrund ihrer rassifizierten Position innerhalb der deutschen Gesellschaft machen. Dazu ermöglicht das hier gewählte Gruppenverfahren einen relativ unkomplizierten Zugang zu einer breiten Datenerhebung.

Im Sinne der geteilten Erfahrungen waren die Gruppen geschlechterhomogen eingeteilt, da die Wirkung von Geschlecht als Machtverhältnis in der Analyse mitberücksichtigen werden sollte. Dieser Einteilung liegt die Idee zugrunde, dass in Räumen, in denen eher von einer gemeinsamen Erfahrungswelt ausgegangen werden kann, die Hürde geringer ist, von dieser zu erzählen. Die Gruppe war somit auch als empowernder Raum für die Teilnehmenden gedacht.

Ein wichtiger Aspekt bei der Durchführung eines Gruppendiskussionsverfahrens besteht in der Herstellung von Selbstläufigkeit, d. h. dass die milieutypische Art 
des Aufeinander-Bezugnehmens gegeben sein muss (vgl. Hirth/Ziegler 2006). Hier liegt die Annahme zugrunde, dass sich der Sinngehalt einer Äußerung auch in der Rekonstruktion nachfolgender Reaktionen anderer Redner_innen auf die betreffende Äußerung erschließen lässt (vgl. Bohnsack 2007: 350).

\subsubsection{Auswertung}

Für die Auswertung wurde das Material zunächst vollständig transkribiert, um eine nachstehende thematische Feingliederung sowie -analyse zu vereinfachen. Dabei wurden Themenschwerpunkte und Passagen mit erhöhter Diskursdichte herausgearbeitet und mit Überschriften in thematischen Kategorien zusammengefasst. Die Vorgehensweise bei der Materialanalyse orientierte sich an der offenen Forschungslogik der qualitativen Sozialforschung.

In der inhaltlichen Interpretation wurde nach Bohnsack zwischen der Interpretation des Expliziten (was wird gesprochen) und des Impliziten (wie wird gesprochen) unterschieden (vgl. Bohnsack 2000: 384). Der Gesprächsverlauf wurde mit Fokus auf die formale und sprachlich-rhetorische Struktur und die interpretativ-analytische Rekonstruktion der Aussageinhalte interpretativ analysiert. Hierbei stand im Zentrum der Aufmerksamkeit, wie sich die Gesprächsteilnehmenden aufeinander beziehen, welche Themen sich durch die Diskussion verfolgen lassen und wie sich im Zusammenspiel von inhaltlichen Bezügen und formaler Diskursorganisation ein kollektiver Orientierungsrahmen entwickelt bzw. rekonstruieren lässt (vgl. ebd.). Jede Aussage verweist nämlich stets auf kollektive Wissensbestände sowie einen Bedeutungskontext, in dem sie Sinn macht.

Die Ergebnisse der verschiedenen Schritte wurden schließlich aufeinander bezogen, einzelne Diskussionssequenzen miteinander verglichen und abschließend mit theoretischen Grundlagen in Beziehung gesetzt.

An dieser Stelle sei darauf hingewiesen, dass der methodische Anspruch einer Gruppendiskussion in ihrem Umfang von der Entwicklung der Fragstellung über die Zusammenstellung des Datenkorpus bis hin zu seinen spezifischen Auswertungsschritten gerecht zu werden, den vorliegenden Rahmen einer Masterarbeit weitaus überschreiten würde. Um den umfangreichen inhaltlichen Analyseergebnissen gerecht zu werden, musste an der Verschriftlichung der Methode stark gekürzt werden, sodass nicht alle relevanten inhaltlichen Ebenen sowie einzelnen methodischen Auswertungsschritte in die Verschriftlichung aufgenommen werden konnten.

\subsubsection{Die Gruppendiskussionen: Verlauf und Reflexionen}

Das erste Gruppengespräch führte ich im Mai 2015 mit Aslan, Hafez, Metin und Samet. Aslan kannte ich bereits aus gemeinsam besuchten Seminaren. Er unterstützte mich aktiv dabei, weitere Kontakte für die Gruppengespräche zu finden. Samet gehörte ebenfalls zu meinen Bekanntschaften aus der Universität. Den Kontakt zu Metin und Hafez stellten Freund_innen her, wir kannten uns nicht bzw. 
nur flüchtig. Das zweite Gruppengespräch ${ }^{10}$ fand etwa drei Wochen später mit Lale, Suzan und Rabia statt. Eine weitere Teilnehmende war kurzfristig verhindert.

Bezüglich des Raumes war es mir wichtig, dass das Gespräch mit Studierenden über ihre Diskriminierungserfahrungen an der Hochschule in einer räumlichen Distanz bzw. Trennung von der Hochschule stattfinden kann. Deshalb wurden beide Gespräche im Jugendraum der DGB-Jugend geführt, den ich vorher mit Süßigkeiten und Tee vorbereitet hatte.

$\mathrm{Zu}$ Beginn erklärte ich den Rahmen meines Anliegens - die Masterarbeit -, wobei ich auch hier nicht explizit von Rassismus sprach, sondern mit folgender Eingangsfrage einleitete:

„Also ihr müsst ja eine Idee gehabt haben, wie ihr hierhergekommen seid. Wenn euch Freunde gefragt haben, was macht ihr heute um $18 \mathrm{Uhr}$, was habt ihr da gesagt? Also welche Idee hattet ihr, was wir heute hier machen? Und welchen Bezug seht ihr zu dem Thema, zu euch selbst?"

Die Eingangsfrage zielte zum einen auf ein Zusammentragen der Informationen und Vorstellungen, worum es bei dem Gespräch gehen sollte. Zum anderen bot die Frage meines Erachtens einen guten Einstieg in das Thema. In der Gruppe A erklärte Metin:

„Es soll eine Diskussion für dich [Karima] stattfinden, für deine Masterarbeit und dass du dafür Jugendliche suchst, die in Deutschland geboren und aufgewachsen sind und die studieren. Und es soll über das Thema Diskriminierung an der Uni gehen. Und ich bin auch halt mit dem Gedanken dann hergekommen."

In dieser Gruppe war somit transparent, dass es um Diskriminierungserfahrungen von Studierenden ging. In der Gruppe B war dies hingegen nicht in derselben Form deutlich. Lale eröffnete und erläuterte, mit welcher Idee und welchem Wissen sie zum Gespräch gekommen war:

Lale: „[Ich habe] von Aslan Bescheid bekommen, [...] dass diese Person eine Masterarbeit schreibt und dafür Studenten und Studentinnen benötigt, die einen Migrationshintergrund haben. Und deswegen dachte ich, helfe ich ihr mal und komme ((lacht)) hierher. Aber inhaltlich habe ich keine Ahnung. Aber ich weiß, dass es halt um die Universität und das Studieren mit Migrationshintergrund geht, und mehr weiß ich nicht."

Sowohl Lale als auch die beiden anderen Teilnehmerinnen Rabia und Suzan gingen nicht auf den Aspekt der Diskriminierung ein, deshalb beschloss ich kurzfristig, dies in dieser Gruppe offenzuhalten, um das Gespräch durch den thematischen Fokus nicht einzuschränken. Demnach wusste die eine Gruppe, dass es konkret auch um Diskriminierung geht, wohingegen die andere annahm, es ginge (nur) um ihre

10 Im Weiteren wird die erste Gruppe als Gruppe A bezeichnet und die zweite als Gruppe B. 
allgemeinen Erfahrungen an der Universität als Studierende „mit Migrationshintergrund“. Dieser Umstand wirkte sich in unterschiedlicher Weise auf den Gesprächsverlauf aus, was im Hauptteil der Analyse ausführlich beleuchtet wird.

Um einem Aufkommen möglicher Hierarchien innerhalb der Gruppe aufgrund von Semesteranzahl oder Studienfachrichtung entgegenzuwirken, bat ich die Teilnehmenden am Anfang, ihr Studienfach, ihre Semesteranzahl, ihre Tätigkeiten (Ehrenamt, Hochschule, Hiwi-Stellen, Nebenjobs etc.) auf einen Zettel zu schreiben, sodass ich die Daten zwar hatte, sie aber nicht zwingend im Gespräch aufkommen mussten. In Gruppe A ging diese Idee auf. Lediglich als die Studienfächer inhaltlich relevant wurden, erwähnten die Teilnehmenden diese (kurz). In Gruppe B spielten die Fächer, vor allem Jura und Medizin, eine zentralere Rolle. Insgesamt erwies sich die Idee als eine gute Lösung, da die Teilnehmenden in beiden Gruppen keinen Druck empfanden, sich eingangs mit Studiengang etc. vorzustellen, sondern sich direkt auf das Thema einlassen konnten.

$\mathrm{Zu}$ meiner Rolle während des Gruppengesprächs legte ich zu Beginn offen, dass ich zwar präsent sein und mir einige Notizen machen, aber auf diese ggf. erst am Ende eingehen und mich ansonsten nicht aktiv am Gespräch beteiligen werde. Nach dem Prinzip der Offenheit vermied ich eine hypothesengeleitete Datenerhebung, um der Darstellung der Themenschwerpunkte sowie der Erfahrungswelt der Gesprächsteilnehmenden so viel Raum wie möglich zu gewähren (vgl. Bohnsack 2007: 361). Aus diesem Grund nahm ich mich trotz immer wieder vorhandener Impulse, etwas zum Geschehen beizutragen, zurück, um das Gespräch thematisch nicht (zu sehr) zu lenken. Für den Fall von langen Redepausen hatte ich einige Fragen als Impulse vorbereitet.

Das erste Gruppengespräch dauerte ohne längere Redepausen oder Unterbrechungen etwa zwei Stunden, und die Gruppe A benötigte keine inhaltlichen Impulse meinerseits, da alles wie von alleine verlief. Es herrschte überwiegend eine positive Gruppendynamik, sodass beispielsweise bereits nach etwa zehn Minuten das erste Mal in der "Wir-Form“ von der Gruppe gesprochen wurde. Außerdem zeigte sich ein harmonisches Miteinander darin, dass der Sprecherwechsel in der Regel mit (bestätigendem) Rückbezug auf den Vorredner stattfand. Dabei war trotzdem der Raum gegeben, sich unterschiedlich zu positionieren, was die Teilnehmenden beispielsweise in Bezug auf die Religionszugehörigkeit oder ihre Erfahrungen auch taten. So schaffte diese Atmosphäre die Möglichkeit, über sensible Themen zu sprechen, bspw. erzählte ein Teilnehmender im späteren Verlauf des Gesprächs, dass seine Eltern Analphabet_innen seien.

Im Anschluss an meinen Nachfrageteil wurde das Gespräch mit der Frage nach ihren Vorstellungen und Wünschen nach dem Studium beendet. Nachdem das Tonband abgestellt war, fragten mich die Teilnehmenden interessiert nach meiner Arbeit und ob ich beispielsweise auch einen Dritten Raum für Trans*-Personen mit 
Rassismuserfahrungen an der Universität anbieten würde. ${ }^{11}$ Einige erklärten sich bereit, auch für eventuelle Einzelinterviews zur Verfügung zu stehen.

Auch das zweite Gruppengespräch dauerte etwa zwei Stunden, wobei die Teilnehmenden besonders am Anfang auf einen Impuls meinerseits warteten und sich nicht ohne Weiteres auf ein Gespräch einlassen konnten. Erst nachdem die Gruppe $\mathrm{B}$ eine konkrete Richtung gefunden hatte, verlief es relativ selbstständig. Dabei fiel in dieser Gruppe auf, dass anstelle eines Gruppenverständnisses (zunächst) starke Abgrenzungstendenzen gegeneinander vorherrschten. Doch im Verlauf der Diskussionen waren auch teilweise Versuche zu erkennen, gemeinsamen Erfahrungen und Verständnissen Raum zu geben. Zum Abschluss des Gesprächs meldeten die Teilnehmenden zurück, dass die unterschiedlichen Perspektiven und die Auseinandersetzung damit spannend gewesen seien und sie neue Kontakte auf dem Campus mitnehmen würden.

In beiden Gruppengesprächen gab es Teilnehmende, die mehr Raum zum Sprechen beanspruchten, und andere, die weniger sprachen. Dabei habe ich auf die Eigenverantwortung der Gruppe gesetzt und keinen Einfluss auf diese Tendenzen genommen.

\subsubsection{Herausforderungen und Kritik}

Die Gruppendiskussion ermöglicht als Methode einen umfangreichen Zugang zur Empirie. Dementsprechend erfordert die Auswertung und Analyse des auf Gruppengesprächen basierenden Materials die Berücksichtigung verschiedener inhaltlicher sowie formeller Ebenen. Das Ausmaß und der Umfang der dahinterstehenden Arbeit sind mir im Prozess der Auswertung deutlich geworden. Im Versuch, den Ansprüchen dieser Methode sowie ihrer Auswertung gerecht zu werden, habe ich ein Datenvolumen erzeugt, das den Rahmen einer Masterarbeit um ein Vielfaches übersteigt. Mit Fokus auf die Methode und die Auswertung hätte ich so eine eigenständige Arbeit verfassen können.

Somit fand ich mich im Verlauf der Auswertung des erhobenen Datenmaterials oft in der unbefriedigenden Situation wieder, meinem Material und vor allem der Auswertungsmethodik nicht in vollem Maße gerecht werden zu können. Hier stellte die Setzung deutlicher Schwerpunkte einen sinnvollen Ausweg dar. Ich musste entscheiden, welche inhaltlichen, aber auch methodischen Aspekte keinen oder nur punktuell Eingang in die vorliegende Verschriftlichung erhalten können: Inhaltlich mussten deshalb verschiedene Aspekte außer Acht gelassen werden, die mir im Grunde sehr wichtig sind. So konnte ich beispielsweise u. a. keinen inhaltlichen Schwerpunkt auf den Gender-Aspekt legen, obwohl dieser methodisch eingebaut war.

Hinsichtlich der Methode konnten beispielsweise gruppenbezogene Dynamiken und die Bedeutung gegenseitiger Bezugnahmen wenig Eingang in die Verschrift-

11 Aufgrund von zeitlichen Rahmenbedingungen konnte dies leider nicht realisiert werden. 
lichung erhalten. Letztendlich wurde die verschriftlichte Analyse auf einzelne Sequenzen des inhaltlich dichten Materials beschränkt. Dabei boten sich insbesondere lange Redebeiträge einzelner Teilnehmender zur ausführlichen Analyse dieser Sequenzen an, wie im Hauptteil ersichtlich wird.

\subsection{Position als Forscherin}

Mit den Gesprächsteilnehmenden teile ich als Forscherin verschiedene Erfahrungsebenen sowie räume: Mein Status als Studentin der Georg-August-Universität mit eigenen Diskriminierungs- und Rassismuserfahrungen ermöglichte mir mit den Gesprächsteilnehmenden eine Begegnung auf Augenhöhe. Damit einher geht eine soziale Nähe, die in der feministischen Methodologie als forschungsförderlich positiv gesucht wird. Grada Kilomba schreibt dazu:

„Doing research among equals has been strongly encouraged by feminists, as it represents the ideal conditions for nonhierarchical relationships between the researchers and the informants: shared experiences, social equality and involvement with the problematic" (2013: 45).

Die ähnliche Situierung in der Gesellschaft (rassismus_erfahrene Studierende) eröffnet einen Zugang zu den Teilnehmenden, den ich ohne diese gemeinsame Grundlage wahrscheinlich nicht hätte. Ich wage zu behaupten, dass die Teilnehmenden vorsichtiger oder zumindest gehemmter über bestimmte Erfahrungen gesprochen hätten, würde ich als Forscherin der dominanten Gesellschaftsgruppe angehören. Die Thematisierung von Rassismus wird von Mehrheitsangehörigen oft als Vorwurf gelesen, sodass Rassismus_Betroffene sich folglich erklären müssen bzw. sie nicht verstanden und somit viele Themen unsichtbar (gemacht) werden.

Darüber hinaus erlaubt mir dies nicht nur einen theoretischen, sondern auch einen auf Erfahrung basierten Zugang zum Material. In diesem Sinne sind Reflexionen aus eigener Erfahrung zu Rassismus(erfahrungen) im Hochschulkontext und dessen Sprechbarmachung in die Auswertung und Analyse des Materials implizit und explizit eingeflossen.

Meine gesellschaftliche Situierung sowie die (Erfahrungs)Nähe zu den Teilnehmenden erschweren gleichzeitig die gegebene Trennung zwischen Forscherin und Beforschten, da diese ebenso in ein Machtverhältnis eingebettet ist. Letztendlich entscheide ich als Forscherin über das Wissen der Gesprächsteilnehmenden, das sie mir im Vertrauen zur Verfügung stellen. Ich setze Schwerpunkte und interpretiere deren Aussagen, die eigentlich für sich stehen müssten, könnten und sollten. Die existente Hierarchie darf trotz des Anspruchs der Begegnung auf Augenhöhe nicht unsichtbar gemacht werden, sodass ich mir auch die Frage stellen musste: „Wie ist es möglich, ethisch die Erzählungen Anderer zu bewohnen, ohne sie zu vereinnahmen, ohne ihnen Gewalt anzutun?“ (Castro Varela/Dhawan 2007: 41). 
In anderen Worten: Wie gelingt mir als Forscherin der Balanceakt zwischen einer realen und gewünschten Nähe zu den Teilnehmenden und deren Lebensrealitäten sowie einer notwendigen Distanz, um deren Aussagen (auch kritisch) zu analysieren, ohne dabei zu vernachlässigen, dass ich in meiner Position als Wissenschaftlerin selbst innerhalb der hegemonialen Institution (der Wissenschaft) situiert bin?

Einen Umgang mit dieser Schwierigkeit ermöglichte mir die Haltung einer „persistenten Kritik“ (vgl. ebd.) gegenüber meiner eigenen Forschung sowie der Wissenschaft und ihrer vermeintlichen Neutralität insgesamt. 


\section{Verhandlungsweisen von Rassismus(erfahrungen) im Hochschulkontext}

Um die Verhandlungsweisen von Rassismus(erfahrungen) von Studierenden einordnen zu können, ist es notwendig, deren Kontext sowie Erfahrungsräume näher zu betrachten. Mit Terkessidis gesprochen bedeutet dies, dass „eine Eruierung und Rekonstruktion der Rassismuserfahrungen also auch die Möglichkeit [birgt], den Kontext in den Blick zu nehmen, welcher diese Erfahrungen bedingt und (mit) verursacht" (Terkessidis 2004: 89). Im vorliegenden Fall stellt u. a. der Kontext der Hochschule den Rahmen der Erfahrungen dar. Dabei sollen Zusammenhänge und Wechselwirkungen der studentischen Verhandlungsweisen verdeutlicht werden. Deshalb wird in diesem Kapitel zunächst die Hochschule und ihr institutioneller Umgang mit Rassismus(erfahrungen) beleuchtet. Daraufhin wird auf die Effekte des universitären Umgangs mit Rassismus auf rassifizierte Studierende eingegangen.

Mechtild Gomolla weist in ihrem Artikel Institutionalisierte Diskriminierung im Bildungs- und Erziehungssystem darauf hin, dass es unabdingbar sei, einzelne Organisationen in ihrem Diskriminierungsverhalten im Gesamtkontext einer Gesellschaft, d. h. in Wechselwirkung mit politischen Ansätzen, öffentlichen Diskursen und weiteren Institutionen zu reflektieren (vgl. Gomolla 2005: 100). Im Folgenden spielen die Werte, Normen und Diskurse der Gesamtgesellschaft eine zentrale Rolle in der Analyse der universitären Strukturen. Dabei darf jedoch die 
4. Verhandlungsweisen von Rassismus(erfahrungen) im Hochschulkontext

gesellschaftspolitisch zentrale Rolle der Hochschule für strukturelle Veränderungen nicht vernachlässigt werden.

\subsection{Institutioneller Rassismus an der Hochschule}

Rassismus ist im Hochschulkontext ebenso präsent, alltäglich und strukturgebend wie in allen anderen Bereichen der deutschen Gesellschaft. In seiner Komplexität und Flexibilität findet er nicht nur auf einer individuellen Ebene von Person zu Person statt, sondern ist auch institutionell verankert, d. h. Rassismus ist implizit und explizit mit den Normalitäten, den Alltäglichkeiten und Routinen einer Institution verflochten (vgl. Hall 2001: 165).

In der Gesprächsgruppe B wurden Diskriminierungserfahrungen als Themenschwerpunkte nicht explizit genannt, dennoch führte der Fokus auf den „Migrationshintergrund" unmittelbar zu den Themenbereichen von Diskriminierung, Grenzüberschreitung und Erklärungs- bzw. Rechtfertigungsdruck:

Suzan: „Also mein Migrationshintergrund ist sowieso einer, der mir von Außen eher angedichtet wird. Ich identifiziere mich mit diesem Hintergrund gar nicht. Also nicht hier aktiv in meinem Leben, das ich in Deutschland führe. Ich habe Familie in einem anderen Land, auch nur von einer Seite. Von der anderen Seite habe ich keine Familie im Ausland. (2) Und das ist etwas, das natürlich auch meine Identität ausmacht, aber ich definiere meine Persönlichkeit nicht so, dass ich jemand mit Migrationshintergrund bin, weil ich einfach nicht von irgendwo hierher migriert bin ((lachen))“

|_Lale: „Mit den Koffern oder ...“

Suzan: „... mit den Koffern. [...] Und auch meine beiden Eltern- nicht beide. Also das ist sowieso alles irgendwie - ich find, das ist sehr privat. Und es geht auch eigentlich nicht viele Menschen etwas an und ich finde, dass sich da viele Menschen sehr viel erlauben, wenn sie damit an einen herantreten, zu sagen, du bist ja jemand mit Migrationshintergrund. Und ich finde, das ist eine Grenzüberschreitung. [...] Das ist privat und genauso ist auch mein Hintergrund privat. Und so, wie ich mich definiere, so ist es dann. Und dann hat das akzeptiert zu werden. Und das ist dann etwas, wo ich dann wieder zu dem Uni-Dings komme, was dann auch in der Uni nicht akzeptiert wird. Auch unter Akademikern, auch unter Studenten, die vermeintlich so unglaublich weite Horizonte haben. [...] Diese Toleranz, Toleranz, so ExtremToleranz, ich bin so wahnsinnig tolerant, dass ich sofort erkenne, dass du ja Migrationshintergrund hast ((lachen)) und das ist ja so interessant, wo kommst du denn her und ich sag dann Hannover ((holt Luft))“

Lale: „Das reicht ja dann nicht ...“ 
Suzan: „Ja und dann, aber ursprünglich. Ja, dann halt immer noch Hannover."

Suzan verdeutlicht, dass Alltagserfahrungen der Nichtachtung und des Nichtrespektierens ihrer Selbstdefinition bzw. ihres Selbstverständnisses ihr auch durchaus im akademischen Raum begegnen. Suzan stellt klar, dass die Frage nach ihrer „ursprünglichen" Herkunft bzw. ihrem Migrationshintergrund eine private Angelegenheit ist. Diese Privatsphäre wird jedoch nicht respektiert, auch nicht von Akademiker_innen, die sich in der Regel als vermeintlich „tolerant“ und mit „weitem Horizont“ darstellten. In einem Interview zur Untersuchung der Perspektiven von Schwarzen Studierenden behandelt Ngubia Kuria auch die Frage nach der „ursprünglichen“ Herkunft. Ihre Interviewpartnerin Safira analysiert:

„Sie sortieren dich., Wer bist du? Woher kommst du?' Sie müssen wissen, wer du bist. Aber all dies ist gefiltert, durch einen Filter von Vorurteilen, Erfahrungen, die sie gemacht haben, und durch rassistische Fremddarstellungen. Ich glaube, es macht die Person, die gefragt wird, sehr verwundbar. Du weißt nicht, welche Voreinstellung die Person, die diese Frage stellt, dir gegenüber hat und du weißt nichts über den Gehalt der für dich vorformulierten Kategorie, in die sie dich einordnen möchte“ (Kuria 2015: 53).

Neben der (Fremd)Kategorisierung, die damit einhergeht, geht es darüber hinaus auch um Aspekte des Nicht-zugehörig-Machens. Für Grada Kilomba stellt die Frage nach der Herkunft eine Verortung des rassifizierten Subjekts außerhalb der (national) einheitlich imaginierten Gesellschaft dar (vgl. Kilomba 2013: 63f.). Die Frage drückt ein Machtverhältnis aus, in dem es eindeutige Fragende und Befragte gibt und bei der damit feststeht, wer selbstverständlich „dazugehört“ und wessen Zugehörigkeit infrage gestellt ist. Entlang dieser Analyse arbeitet die Psychologin Santina Battaglia den sogenannten „Herkunftsdialog“ als ein „Element des Diskurses über Rassismus" heraus (Battaglia 2007: 188f.).

Die Auseinandersetzung mit der Frage nach der „eigentlichen“ Herkunft wird in der Regel zusätzlich dadurch erschwert, dass sie von Fragenden als vermeintliches Interesse an der Person oder, wie es sich im Zitat von Suzan spiegelt, als Zeichen für „Weltoffenheit“ deklariert wird. So kann jeglicher Widerstand oder jede Zurückweisung dieser rassistischen Markierung als Kränkung der fragenden Person (um) gedeutet werden.

Insbesondere im universitären Kontext kann dies mit Konsequenzen verbunden sein, wenn sich die fragende Person in einer hierarchisch höheren Position befindet:

Suzan: „Wenn man selbst sagt, man kommt aus Hannover oder man kommt aus Deutschland oder so, und dass dann immer wieder nachgehakt wirddas ist ja die eine Sache. Das kommt immer wieder vor. Aber ich hatte halt auch diese Geschichte mit einem Professor hier an der Uni, der dann, als ich das geantwortet habe, dass ich eben aus Deutschland komme, aus Hanno- 
ver komme, dann dazwischengegrätscht ist und mich korrigieren wollte mit meiner Nationalität. Wo ich dann auch gedacht habe, was hast du hier für einen Auftrag, ja?! Also, was soll das? Du musst mich nicht korrigieren, wenn ich sage ich bin Deutsche, dann brauchst du nicht zu mir sagen, nein bist du nicht."

Rabia: „Hat er das gesagt?“

Suzan: "Ja ne, er hat nicht gesagt, nein bist du nicht, sondern als ich gesagt habe: ,Deutsche', hat er dann gesagt ((flüsternd)): ,Iranerin' (2) zu dem der gefragt hat. (2) ((unterdrücktes Lachen))“

Rabia: „Okay, das ist schon heftig.“

So erweitert sich die Hierarchiestruktur an der Universität für migrantische oder Schwarze Studierende zudem auf die Ebene weiß und nicht-weiß, da die große Mehrzahl der beschäftigten Professor_innen und Doktorand_innen (auch in Göttingen) weiß sind. ${ }^{12}$ Ngubia Kuria hält in diesem Kontext in Bezug auf die Situation in Berlin fest: „Die Werte der Institution zeigen sich in der Wahl ihrer Angestellten. Ich kenne beispielsweise keine Schwarze Professorin_ an der Humboldt-Universität in einer ordentlichen Position“ (Kuria 2015: 21). Die Belegschaft einer Hochschule spiegelt die rassistischen gesellschaftlichen Verhältnisse in den eigenen Strukturen wider: In der Cafeteria, der Mensa und anderen Bereichen der Dienstleitung sind migrantisierte und/oder Schwarze Personen durchaus beschäftigt. Verfolgt man die institutionelle Hierarchie jedoch nach oben, finden sich kaum noch Rassismus_Erfahrene als Dozierende oder Professor_innen. Selbst (vermeintlich) herrschaftskritische Stellen wie das Gleichstellungsbüro sind durchgehend weiß besetzt. In eigener Recherche habe ich zum Beispiel festgestellt, dass in allen Gleichstellungsbüros ${ }^{13}$ der (bekannten) Universitäten in Deutschland ausschließlich weiße Personen angestellt sind, ausgenommen sind einige studentische Hilfskräfte. ${ }^{14}$ So sind alle zentralen Gleichstellungsbeauftragten weiße Frauen. Dies hat auch Auswirkungen auf den Kanon der universitären Lehre:

12 Dieser Aspekt ist aus unterschiedlichen Gründen schwer nachzuweisen. Zum einen existieren keine offiziellen Zahlen, zum anderen wäre hier die Frage, wer unter welchen Kategorien statistisch geführt wird?

In einem Versuch des Nachweises bin ich in eigener Recherche auf folgende Internetseite gestoßen: https://www.meinprof.de/unis/niedersachsen/uni-goettingen (21.09.2015). Die Auflistung kann als eine Tendenz gewertet werden, die zeigt, dass eine große Mehrheit von Professor_innen in Deutschland als weiße Personen der Dominanzgesellschaft zugehörig sind.

13 Die Bezeichnungen für diesen Bereich variieren an den unterschiedlichen Universitäten, je nach Standort heißt es auch Diversity-Büro oder Büro für Chancengleichheit und Diversity.

14 Die Recherche erfolgte über die jeweiligen Homepages der Gleichstellungsbüros in den folgenden Städten: Hamburg, Berlin, Bremen, Hannover, Göttingen, Kassel, Frankfurt, Düsseldorf, Dortmund, Köln, Bochum-Essen, Münster, Heidelberg, Stuttgart, München, Konstanz. Stand vom 02.09.2015. 
„Durch die fehlende Präsenz von Schwarzen Dozentinnen und Dozenten werden auch die Inhalte von Lehre und Forschung geprägt. Seminare und Vorlesungen zu Schwarzen Themen in Deutschland finden nur vereinzelt an deutschen Universitäten statt und sind nirgends institutionalisiert oder als Schwerpunkt vorgesehen" (Golly 2006: 396).

Was Nadine Golly hier im Kontext Schwarzer Perspektiven anbringt, kann durchaus auf muslimisch_markierte Sicht erweitert werden. Teilnehmende beider Interviewgruppen verstanden sich entweder als Muslim_a oder werden von außen als Muslim_a markiert. Deshalb ist das Thema Islam bzw. antimuslimischer Rassismus in beiden Gesprächen zentral. Mit Iman Attia definiere ich diesen als eine Form von Rassismus, die nicht nur gegen Muslime gerichtet ist, sondern auch, wie oben beschrieben, gegen diejenigen, die als Muslime markiert und fremddefiniert werden:

„Zudem wird die Differenz nicht ausschließlich oder überwiegend religiös begründet, vielmehr werden religiöse mit sozialen, kulturellen, gesellschaftlichen, politischen und anderen Differenz(ierung)en und Position(ierung)en vermengt, so dass ein breites Spektrum an Bezügen hergestellt wird. Im antimuslimischen Diskurs überschneiden sich verschiedene Diskurse und Diskursstränge. Erst in der Wechselwirkung mit Geschlecht, Sexualität, Klasse, Rasse, Kultur, Körper, Religion entfaltet der antimuslimische Rassismus als ein Strukturmerkmal dieser Gesellschaft seine Effekte" (Attia 2013: 4, Hervorh. im Original).

In der Konsequenz werden soziale Missstände mit dem Islam begründet und damit kulturalisiert. Die vielfältig negativen Effekte des kulturalisierenden Rassismus wirken sich auf das Leben von Einzelnen aus, die zwangsläufig als Individuum für die homogene Gruppe „der Muslime“ einstehen und sich verteidigen müssen. So auch in Seminarkontexten der Hochschule, wie am Beispiel von Samets Aussage deutlich wird:

Samet: "Ja du hast einen sehr guten Punkt genannt und wo wir auch halt dann wieder auf die Diskriminierung bzw. Vorurteile in der Uni kommen. Es ist wichtig, dass die Menschen aufgeklärt werden. Und das Problem habe ich selber erlebt bzw. wir haben ein Seminar gehabt, Religion und Gender mit dem Schwerpunkt Islam. Da hatten wir auch einen Dozenten, wo ich [...] sage, die hat nicht aufgeklärt. Sie hat meiner Meinung nach genau das Gegenteil gemacht. Sie hat vieles in den Raum geworfen, ohne vernünftig eine Erklärung dahinter folgen zu lassen und das hat dann [...] wieder zu Vorurteilen geführt [...]. Das muss in diesem Moment erläutert werden, und dann gab es noch x verschiedene Beispiele, wo es dann nicht erläutert wurde. Oder zum Beispiel hat eine Freundin erzählt, die studiert Islamwissenschaften, da war ein Dozent, der hat dann auch immer - naja, nicht wirklich den Islam erläutert, sondern nach seiner Meinung nach interpretiert. Und da waren halt fünf Muslime, aber jedes Mal, wenn sie sich dagegen gewehrt haben oder 
bzw. sich überhaupt dagegen wehren wollten, wurden sie einfach entweder ignoriert oder einfach nur, nein das ist falsch, als falsch dargelegt [...]. Ich kann das in dem Moment, wo ich in diesem Seminar bin, ja argumentieren, aber falls mal nicht so viele Muslime in diesem Raum sitzen, hat sie freien Raum, wo sie, sag ich mal - vielleicht macht sie es ja auch nicht mit Absicht, aber Vorurteile oder Sachen nennt, die dazu führen, dass dadurch Vorurteile entstehen."

Auch in weiteren Interviewpassagen beider Gesprächsgruppen fand sich eine ähnliche defensive Haltung, in der die Studierenden sich gezwungen sahen, den Islam gegen vorherrschende Negativdiskurse zu „verteidigen“. Wie in Samets Zitat deutlich wird, machen muslimische Studierende dabei die Erfahrung, dass weder sie selbst noch der Islam ausreichend vertreten werden. Folglich fühlen sie sich in der zwingenden Verantwortung, Fehlinformationen richtigzustellen. Samet sah sich beispielsweise gezwungen, die Rolle des „Experten“ einzunehmen und sich trotz der hierarchischen Beziehung inhaltlich gegen die lehrende Person zu positionieren. Die Alternative wäre gewesen, das aus der eigenen Perspektive falsche Wissen unkommentiert stehen und seine Wirkmacht zuzulassen. Nadine Golly schreibt in diesem Zusammenhang analog über kolonialistische Wissensproduktion in Seminaren, in denen Schwarze Studierende anwesend sind:

„Dies bedeutet, immer aufmerksam zu sein, schnell zu entscheiden, ob man reagiert oder nicht, keinen großen Schock zulassen zu können, und das heißt, Energie und Kraft haben für jedes einzelne Seminar, welches besucht wird. Man wird in den seltensten Fällen nur ZuhörerIn sein können, darauf hoffend, dass die TeilnehmerInnen und der/die DozentIn sich um überlegte Inhalte und eine überlegte Sprache bemühen" (Golly 2006: 396).

Diese Anspannung, möglicherweise stets reagieren und gegen rassistische Äußerungen angehen zu müssen, lässt sich nicht nur in universitären Seminaren vorfinden, sondern ist Teil des Alltags für rassismus_erfahrene Personen. Somit stellt der universitäre Raum für rassifizierte Studierende eine nahezu nahtlose Erweiterung der rassistischen Erfahrungsräume des Alltags dar.

Auch während meiner Studienzeit fand der Islam als thematischer Schwerpunkt interdisziplinär Eingang in Seminare, wobei ausschließlich Nicht-Muslime die Referent_innen waren. Meines Wissens nach sind weder an der philosophischen (wo z. B. die Islamwissenschaft angesiedelt ist), der theologischen noch an der sozialwissenschaftlichen Fakultät der Georg-August-Universität muslimische Professor_ innen angestellt. Somit findet die (rege) Wissensproduktion über den Islam ausschließlich aus einer weißen, also vermeintlich neutralen Perspektive statt. Kilomba erläutert hierzu:

"[T] his place of ,Otherness" does not, as commonly believed, indicate a lack of resistance or interest, but rather a lack of access to representation [...]. It is not that we have not been speaking, but rather our voices - through a 
system of racism - have been either systematically disqualified as invalid knowledge; or else represented by whites who, ironically, become the ,experts' on ourselves. [...] In this sense, academia is neither a neutral space nor simply a space of knowledge and wisdom, of science and scholarship, but also a space of v-i-o-l-e-n-c-e“ (Kilomba 2012: 26).

Der existierenden rassistischen Normalität an der Hochschule zum Trotz gibt es an der Georg-August-Universität selbst nach Einführung des Allgemeinen Gleichstellungsgesetztes im Jahr 2006, das u. a. auch die Verhinderung bzw. Beseitigung von Diskriminierung aufgrund „der ethnischen Herkunft" sicherstellt, keine Beschwerde- oder Anlaufstelle für rassismus_betroffene Studierende.

Eine weitere Fortführung rassistischer Normalität im akademischen Raum findet auch über Bilder und Darstellungen statt, wie beispielsweise auf (Info)Broschüren und Flyern der Universität. bell hooks vertritt die umkämpfte Position, „daß die Welt

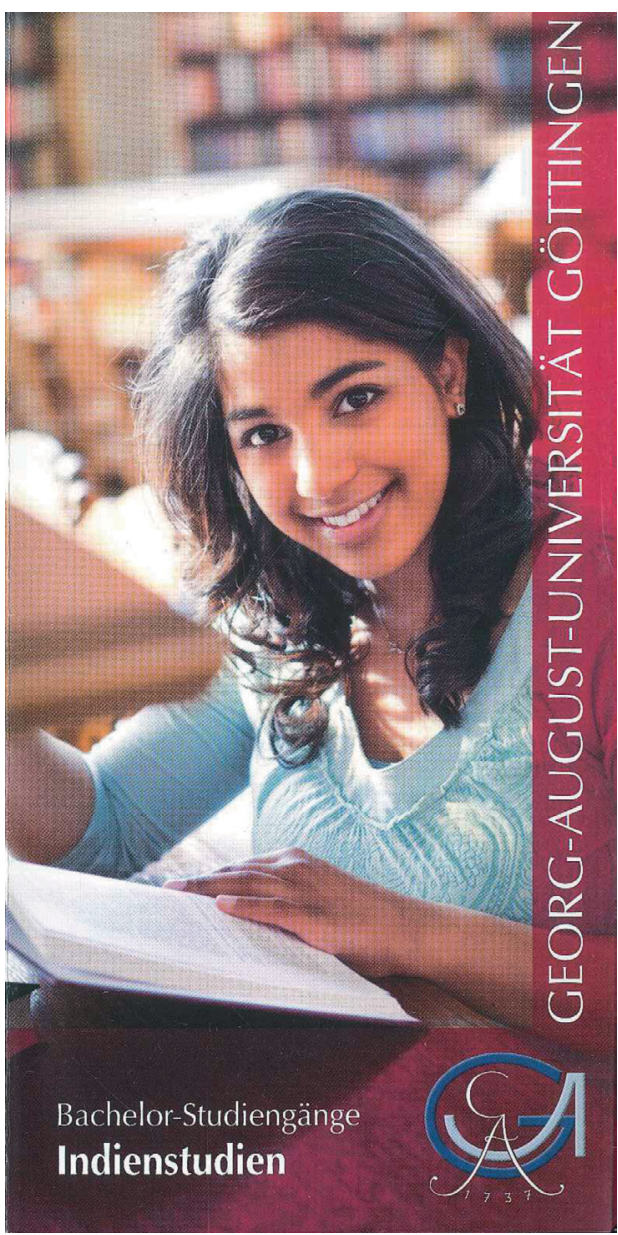

Abb. 3: Flyer Indienstudien des Bilder-Produzierens eigentlich politisch ist - daß Herrschaftspolitik die meisten Bilder, die wir konsumieren prägt: die Art, wie sie geschaffen und vermarktet werden" (hooks 1994: 15). Gleichzeitig betonen die Politolog_innen María Do Mar Castro Varela und Nikita Dhawan die wissenschaftlich-akademische Verharmlosung „der Macht und Gewalttätigkeit von [rassistischen; Anm. K. P.] Bildern“ (vgl. Castro Varela/Dhawan 2007: 29). Die relativierende Haltung der Universität gegenüber der Wirkmacht von (rassistischen) Bildern auf die Realitätsproduktion führt zu Lücken in der Entstehung sowie Analyse von Bildern, mit denen die Universität selbst wirbt.

So wird beispielsweise auf dem Infoflyer zum Bachelor-Studiengang Indienstudien eine Studentin abgebildet, die mit dem Raum Indien assoziiert werden kann bzw. die damit aus meiner Sicht auch assoziiert werden soll (vgl. Abb. 3). Mit dem Bild wird einerseits die Präsenz einer ,diversen' Studierendenschaft vermittelt. An- 
dererseits wird diese Präsenz sowohl studienbedingt als auch räumlich und regional auf einen bestimmten Raum reduziert und festgeschrieben. Der Studentin wird eine vermeintliche Expertise aufgrund rassistischer Merkmale zugeschrieben, die ihre Anwesenheit an der Universität erklärt und legitimiert.

Dahingegen werden „neutrale“ bzw. nicht rassifizierte Studiengänge wie der Masterstudiengang Unternehmensführung auch vermeintlich "neutralen“ also weißen - Personen zugewiesen (vgl. Abb. 4). Interessant ist jedoch, dass der weiß-männlich konnotierte Masterstudiengang Unternehmensführung von zwei weißen jungen Frauen repräsentiert wird. Dies stellt jedoch keinen $\mathrm{Zu}$ fall dar, betrachtet man den Rahmenplan der Georg-August-Universität zur Gleichstellung von Männern und Frauen. Demnach sollen u. a. „die strukturelle Benachteiligung von Frauen $\mathrm{ab}$ [gebaut] [werden] und [...] Männer und Frauen in allen Bereichen zu gleichen Teilen vertreten" (Rahmenplan Gleichstellung 2008: 444) sein. Trotz bestehender Kritik und Mängeln in der Umsetzung der Gleichstellung können institutionelle Bemühungen und Veränderungen konstatiert werden. Dabei profitieren allerdings überwiegend wei-

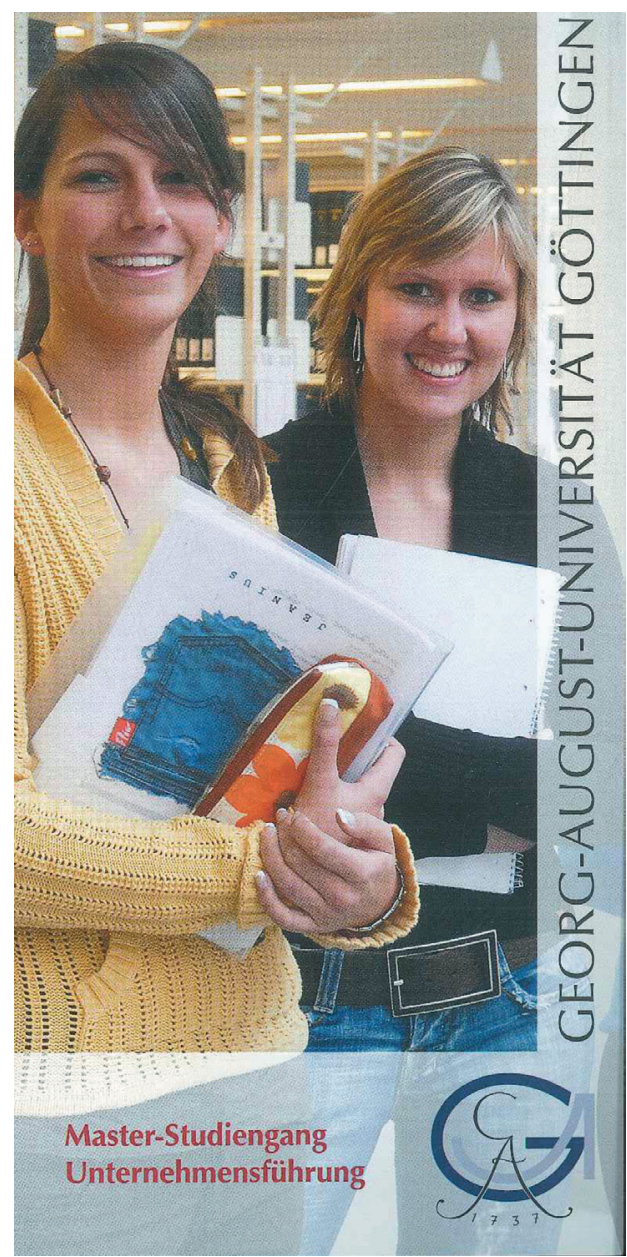

Abb. 4: Flyer des Masterstudiengangs Unternehmensführung

ße akademische Frauen, die beispielsweise hier (zunächst auf symbolischer Ebene) unabhängig von ihrem Geschlecht auch Unternehmungsführung studieren könnten. Wieso kann die Studentin der Bachelorstudiengänge Indienstudien nicht den Masterstudiengang Unternehmensführung repräsentieren? Welche Botschaft würde eine solche Bildsprache vermitteln?

Um ein weiteres prägnantes Beispiel der rassistischen Bildsprache an der Universität aufzuzeigen, weise ich auf die Abbildung der Broschüre des Internationalen Schreibzentrums (ISZ) hin. Mit diesem Bild wurde Anfang März 2016 in vergrößerter Version in der Zentralbibliothek für die lange Nacht des Schreibens geworben (vgl. Abb. 5). 
Auf dem Bild sind zwei junge Frauen zu sehen, die an einem Tisch sitzen. Dabei nimmt eine von ihnen eine wissende und lehrende Haltung ein: Es liegen zwar Blatt und Stift vor ihr, sie schreibt bzw. notiert jedoch nichts; sie hält ihre Faust unter dem Kinn und beobachtet dabei lächelnd die lernende/unwissende andere Frau, die sich gefügig/folgsam Notizen macht. Die erste ist eine weiße Frau, die andere Schwarz. Und auch hier stelle ich mir die Frage, warum es nicht möglich zu sein scheint, dass die Schwarze Frau die Wissende, Lehrende ist? Welche Realitäten (re)produzieren solche Bilder und Darstellungen? Welche Visionen verunmöglicht sie? Der Appell von bell hooks eröffnet in dieser Hinsicht neue Perspektiven:

„Es geht darum, die Bilder umzuwandeln, Alternativen zu schaffen. Wir fragen uns selbst, welche Art Bilder zersetzen, schlagen kritische Alternativen vor und wandeln unsere [hier kolonial-rassistische; Anm. K. P.] Weltanschauung um. [...] Eine wesentliche Voraussetzung für die Umwandlung ist, einem Bild, das den Rahmen sprengt, der Vision der rebellischen Entrechteten, Raum zu geben. Und selbst dann wird uns
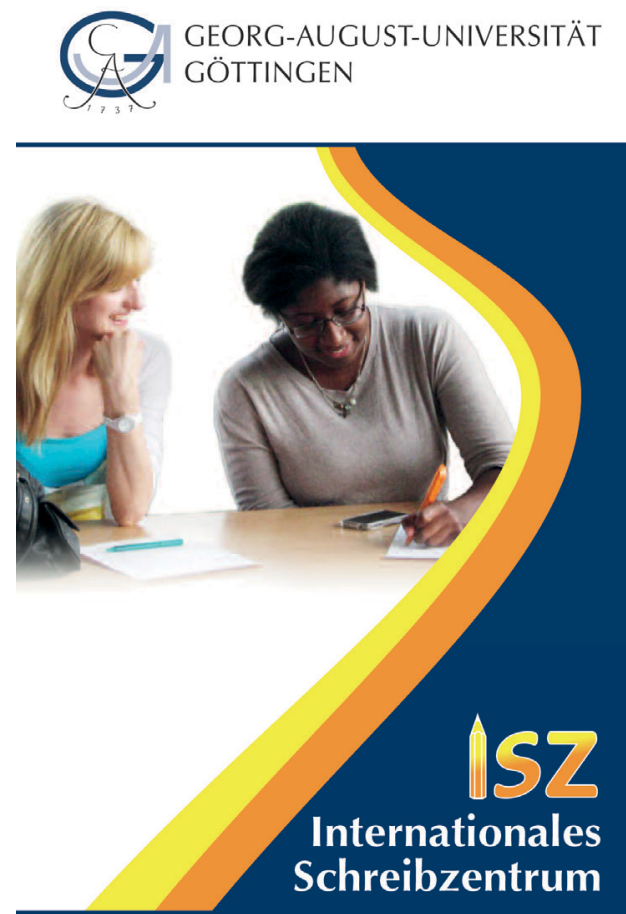

Wissenschaftliches Schreiben in der Fremd-, Zweit- oder Erstsprache Deutsch Mehrsprachiges Wissenschaftliches Schreiben Multilingual Academic Writing

Seminar für Deulsche Philologie

Abteilung Interkulturelle Germanistik

Abb. 5: Flyer des Internationalen Schreibzentrums das kaum weiterbringen, wenn wir nur die Bilder umwandeln, ohne einen Paradigmenwechsel vorzunehmen und die Perspektiven und Sichtweisen zu verändern" (hooks 1994: 13). 


\subsection{Umgang der Hochschule mit Rassismus(erfahrungen): Akademische Verschiebung}

Im Umgang und in der Auseinandersetzung mit Rassismus zeigen sich im akademischen Raum als ein Teil der deutschen Gesellschaft „mehrschichtige Distanzierungen“ (Messerschmidt 2010: 41). Astrid Messerschmidt erläutert in ihrem Artikel Distanzierungsmuster. Vier Praktiken im Umgang mit Rassismus, dass über diese „mehrschichtige[n] Distanzierungen“ (ebd.) seitens der dominanten Mehrheitsgesellschaft Rassismus skandalisiert, verlagert, verschoben und kulturalisiert wird. In der Konsequenz sorgen „alle vier Muster dafür, ein unbeschädigtes Bild von sich selbst zu etablieren. Rassismusdiagnosen wirken darauf bezogen unangebracht und unpassend“ (ebd.: 41f.). Auf diese Weise wird Rassismus in der Öffentlichkeit delegitimiert und somit dethematisiert. Messerschmidt arbeitet heraus, dass der Rassismusbegriff insbesondere in Deutschland historisch belastet ist, weshalb er aktiv und konsequent umgangen wird und stattdessen „Ersatzdiskussionen“ geführt werden (vgl. ebd.: 47). Bezieht man sowohl die o. g. Bestrebung nach einem „unbeschädigten" Selbstbild sowie die Vermeidung des historisch belasteten Begriffs des Rassismus auf universitäre Zusammenhänge, so wird die Fortführung dieses Bestrebens im akademischen Raum erkennbar.

Beispielsweise zeigt sich dies im Leitbild der Georg-August-Universität: „Wissenschaftlicher Pragmatismus und Realitätssinn, dazu ein waches Bewusstsein für die gesellschaftliche Verantwortung der Wissenschaft prägen die Geschichte der Georg-August-Universität bis in die Gegenwart.“ Und weiter heißt es: „Dem Geist der Aufklärung verbunden“ möchte die Georg-August-Universität „zur Verwirklichung der Gleichberechtigung und zur Überwindung aller dem entgegenstehenden geschlechtsbedingten, ethnischen, kulturellen, sozialen und religiösen Benachteiligungen beitragen. " 15 Dieses auf „[d]em Geist der Aufklärung“ basierende Selbstbild, gestützt durch die Eckpfeiler des Pragmatismus, Realitätssinns, der Verantwortung und Gleichberechtigung, beschreibt eine Erhabenheit, Überlegenheit und rationale Distanz der Universität. Ein Selbstentwurf, der in seiner Wirkung wie eine Immunisierung gegen Rassismus sein kann, dessen Benennung und Thematisierung mit Emotionalität, Subjektivität und persönlicher Betroffenheit gleichgesetzt und abgewertet werden kann.

Darüber hinaus zeigt die (unkritische) Identifizierung mit der europäischen Aufklärung die fehlende Auseinandersetzung mit Rassismus, dessen Geschichte sowie der möglichen Verstrickung von Wissenschaft und Akademie in seiner Entwicklung. Die Soziologin Karin Scherschel arbeitet heraus, wie sich der Rassismus im Zuge der europäischen Aufklärung im 18. Jahrhundert „als ein umfassendes Denksystem und als eine Ideologie vergleichbar mit dem Konservatismus, Liberalismus oder Sozialismus“ (Scherschel 2006: 52) entwickelt. Dabei bezieht sich „[d]ie Vergleichbarkeit [...] auf die Weltbilder erzeugende Macht des Rassismus" (Messerschmidt 2010: 52).

15 Unter: http://www.uni-goettingen.de/de/leitbild/43883.html (03.09.2015). 
Die Nichtbenennung und aktive Vermeidung des Begriffs Rassismus lässt sich an der aktuellen Aktion der Hochschulrektorenkonferenz mit dem Titel „Weltoffene Hochschulen - gegen Fremdenfeindlichkeit" gut veranschaulichen. Unter anderem sind Gründe und Ziele der Aktion,

„Willkommenskultur, Weltoffenheit und Toleranz leben und ständig weiterentwickeln zu können. Dabei beteiligen wir uns auch an der gesellschaftlichen Herausforderung, den Flüchtlingszugang zu bewältigen und unterstützen die Menschen, die vor den Folgen von Krieg, Unterdrückung, Gewalt, Armut und Hunger nach Deutschland geflohen sind. Wir sehen darin vor allem eine Chance, in Universität, Stadt und Gesellschaft zu mehr Offenheit, Transparenz und Diversität beizutragen. ${ }^{\text {"16 }}$

Im gesamten Text zur Aktion und zu deren Beteiligung wird kein Bezug zum (aktuell sehr offen gelebten) Rassismus der deutschen Gesellschaft hergestellt. Stattdessen liegt der Fokus auf der Idee von Diversity und Vielfalt sowie auf deren Nutzen und Chancen für die „weltoffene“ und „international ausgerichtete“ Hochschule.

Anstelle einer aktiven, institutionalisierten Auseinandersetzung mit strukturellem Rassismus werden im universitären Kontext, wie Messerschmidt es nennt, Ersatzdiskussionen um Diskriminierung und Rassismus geführt. Im Rahmen der Hochschule kann das Konzept des Diversity-Managements als eine Ersatzdiskussion gesehen werden. Diversity-Management etabliert sich seit einigen Jahren immer weiter als politische Antwort und „Lösung" im Umgang mit Vielfalt.

Dabei äußern kritische Analysen Bedenken gegen Diversity-Konzepte, denn "diversity is predominantly used as a euphemism for racial and ethnic difference" (Lentin/Titley 2011: 180). Merkmale wie z. B. (vermeintliche) Herkunft, Hautfarbe, Geschlecht, sexuelle Orientierung und körperliche Fähigkeiten, die häufig als Grundlage für Diskriminierung dienen, können seitens Hochschulen positiv ausgelegt werden und der Selbstdarstellung der Universität als „weltoffen“ dienen. So kann der Verweis darauf, dass die Institution bestrebt sei, Diversity zu verankern, weitere Auseinandersetzungen mit der (Re)Produktion von Diskriminierung und Rassismus (in den eigenen Strukturen) über die Begründung relativiert und verhindert werden, dass ja bereits etwas "getan“" werde (vgl. ebd.: 111). Sara Ahmed zeigt beispielsweise in ihrer kritischen Analyse der Funktionsweisen und der Wirkmacht von Diversity-Management auf, wie es das Sprechen über (institutionellen) Rassismus (be)hindert, weil „[r] acism is heard as an accusation that threatens the organization's reputation as led by diversity. Racism is heard as potentially injurious to the organization. In other words, institutional racism becomes an institutional injury" (Ahmed 2012: 146). Auf diese Weise wird Diversity-Management zum Teil des Problems, indem es dazu beitragen kann, Rassismus in Institutionen zu verschleiern und die Debatte darum zu verschieben (vgl. ebd. 143).

16 Unter: https://www.uni-goettingen.de/de/526551.html (29.02.2016). 
Ferner weisen kritische Untersuchungen von Diversity-Politiken auf die (Re)Produktion machtvoller Ausschlüsse und Kategorisierungen hin (vgl. Mecheril 2014: 4f.; Lentin/Titley 2011: 6f.). Wer profitiert auf welche Weise und warum von Diversity? Wer kann der Diversity-Vorstellung gerecht werden und wer ist mit welcher Konsequenz von dieser Identitätsposition ausgeschlossen? So stellt Mecheril fest:

„[D]er Zugang zum Bildungsmarkt ist durch komplexe Verhältnisse der Ungleichheit (z. B. Sprache, Qualifikationszertifikate, soziale Netzwerke, physiognomisches Kapital) strukturiert, ,Diversity'-Angebote tendieren dazu, diese Struktur zu bekräftigen" (Mecheril 2014: 4).

Er schlussfolgert, dass Diversity ohne kritische Reflexion eine „raffinierte Fortsetzung von Machtverhältnissen mit auf den ersten Blick, irgendwie achtbar" wirkenden Mitteln“ sein kann (ebd.: 5).

Somit funktionieren Diversity-Politiken entlang der Marktlogik über Einteilung in „verwertbarer" und „unnützer“ Differenz. Der Ersteren wird (unter bestimmten Voraussetzungen und Einschränkungen) das Angebot gemacht, sich im System einzugliedern und inkludiert zu werden. Im „biopolitischen Kapitalismus“ (Altenried 2011: 159) wird der biologistische bzw. kulturalistische Rassismus durch eine Leistungsideologie erweitert. Demnach „erhalten [Migrant_innen] vermeintlich die Möglichkeit, sich durch individuelle Anstrengungen und 'Leistungserbringung' zu inkludieren bzw. durch ,Leistungsverweigerung" weiter zu exkludieren“" (Friedrich 2011: 26). Rassismus funktioniert in neoliberalen Logiken demnach nicht (mehr) nur über Ausschlüsse, sondern auch über die Ebenen des Einbezugs und der Inklusion:

„Damit eröffnet sich zugleich eine neue Dimension der Rassismusanalyse. Es gilt, die rassistischen Praktiken nicht nur über binäre Differenzen und Prozesse der Exklusion zu bestimmen, sondern primär über neuartige Prozesse einer limitierten Inklusion [...]“ (Tsianos/Pieper 2011: 118).

Welche (subjektivierenden) Effekte diese bedingte Inklusion auf rassifizierte Studierende und ihrem Umgang mit Rassismus(erfahrungen) hat, soll im Folgen näher beleuchtet werden.

\subsection{Effekte des Umgangs auf rassifizierte Studierende}

„Inclusion can be read as a technology of governance“

(Ahmed 2012: 163)

Mit dem passenden Titel On Being Included untersucht Sara Ahmed, wie diversity practitioners selbst in das Konzept des Diversity-Managements eingebunden werden. Die Inklusion in das System der Institutionen lässt sie zu einem Teil des Systems werden, innerhalb dessen sie seine Logiken und (ungeschriebenen) Regeln 
(mit) (re)produzieren (vgl. Ahmed 2012: 142). Als eine dieser Logiken und Regeln hält Ahmed die Nichtbenennung von Rassismus fest (vgl. ebd.: 146).

Ähnliches lässt sich im vorliegenden Interviewmaterial finden. Die Gesprächsteilnehmenden negieren an vielen Stellen Rassismus bzw. Rassismuserfahrungen trotz der vielfach geschilderten rassistischen Situationen, die sie erspüren und benennen (können). Jedoch erklären und rechtfertigen sie diese Erfahrungen teilweise mit anderen Ursachen. Being included erscheint mir in diesem Fall u. a. auch als ein passender Ansatz zur Analyse und Reflexion des vorliegenden Paradoxons. Die Gesprächsteilnehmenden sprechen vor allem in und aus ihrer Rolle als Studierende, also als „Inkludierte“ im Hochschulsystem. ${ }^{17}$ In der Nichtbenennung von Rassismus folgen sie in dieser Hinsicht der oben beschriebenen Linie der Hochschule. Allerdings haben weitere Faktoren - hier konkret die Nichtthematisierung - ebenfalls einen zentralen Einfluss auf den Umgang mit Rassismus(erfahrungen).

In der Gruppe A, in der von Anbeginn transparent ist, dass (auch) Diskriminierungserfahrungen für die vorliegende Forschung von Bedeutung sind, ist der erste Impuls die Verneinung solcher Erfahrungen. Aslan eröffnet das inhaltliche Gespräch folgendermaßen:

„Ja, also dann lege ich mal los. Also eigentlich habe ich an der Uni keine schlechten Erfahrungen gemacht, oder allgemein auch sonst nicht. Aber nur letztens ist was gewesen, was mich gestört hat. Und zwar als ich meinen neuen Hiwivertrag unterschrieben habe, haben sie halt nochmal Sachen verlangt, und da war auch unter anderem ((holt kurz Luft)), welcher Religion gehörst du an. Das hatten wir vorher nicht beim Hiwijob und das musste man eintragen und das war auch - also das musste man eintragen. Genau, also man konnte das nicht weglassen. Das finde ich blöd, also man fühlt sich halt beobachtet. Okay, das sind die Arbeitgeber - ich mag das einfach allgemein nicht, dass - oder vielleicht mögen es die meisten Menschen nicht, dass man halt ((holt kurz Luft)) viel mehr Informationen über einen Menschen hat, die man - die Informationen die man nicht eigentlich nicht unbedingt braucht. [...] Und (2) ja, vielleicht hängt das mit den Sachen zusammen, die jetzt in den letzten paar Jahren passieren und vielleicht bezieht man sich - also will man sehen, welche Muslime gibt es hier an der Uni und so. Also das war jetzt nur eine Vermutung, also dass Religion doch eine Rolle spielt (3) naja. Also, das hat mich halt gestört eigentlich, aber vorher hab ich nichts anderes erlebt an der Uni.“

Die spontane Ablehnung, an der Universität diskriminiert zu werden, ist vor dem Hintergrund zu betrachten, dass eine Betroffenheit von Diskriminierung bzw. Rassismus oft mit Ohnmacht, Passivität und „Opfer-Sein“ in Verbindung steht bzw. stehen kann und dies nicht dem Selbstbild der Betroffenen entspricht. Eine weitere Ebene analysiert Grada Kilomba in der Verneinung von Rassismus:

17 Dieser Aspekt wird im 6. Kapitel Der Status Studierende_r eingehend analysiert. 
„Negation thus protects the subject from the anxiety certain information causes once it is admitted to the conscious. As we are taught to speak with the language of the oppressor, in negation the Black subject speaks with the words of the white other: ,There is no racism' [...]" (Kilomba 2013: 153).

Im selben Satz aber fällt Aslan jedoch eine Situation ein, die ihn „eigentlich gestört“ hatte: Dass er seine Religionszugehörigkeit für eine wissenschaftliche Hilfskraftstelle verpflichtend angeben musste, findet er „blöd“, weil die Universität als Arbeitgeberin auf diese Weise „mehr Informationen über einen Menschen hat, die man [...] eigentlich nicht unbedingt braucht". Aslan deutet diese Informationsangabe mit dem Wunsch bzw. der Absicht seitens der Universität zu erfahren, „welche Muslime" an der Uni seien. Für ihn scheint diese Abfrage somit vorrangig mit einem Bedürfnis der Universität nach Kontrolle und Sicherheit in Verbindung zu stehen. Er bemüht sich um Verständnis für dieses Vorgehen und erklärt sich den vermeintlichen Wunsch nach Kontrolle mit „den Sachen [...] die jetzt in den letzten paar Jahren passieren“. Die rassistische Grundlage solch einer Annahme, die möglichen Konsequenzen und sein Gefühl „beobachtet“ zu werden stellt er dabei in den Hintergrund.

Ob es sich bei der erwähnten verpflichtenden Abfrage nach der religiösen Zugehörigkeit um institutionellen Rassismus handelt, wie Aslan vermutet, oder beispielsweise um eine Datenerhebung über allgemein religiöse Vielfalt in der Belegschaft des Instituts, kann an dieser Stelle nicht nachvollzogen werden. Fest steht jedoch, dass solch eine Abfrage für muslimisch_markierte Studierende stets die Befürchtung mit sich bringt, (wieder) kategorisiert und pauschalisiert zu werden, bei gleichzeitigem Bemühen, diese Eindrücke für sich unabhängig von Rassismus und Diskriminierung erklären zu müssen.

Rassismuserfahrungen (an der Universität) werden in beiden Gruppengesprächen nicht mit Rassismus als Ursache erklärt, sondern meistens mit anderen Begründungen. Deutlich wird dies auch am Beitrag von Hafez, der anschließend an Aslan spricht:

"Ja genau, ich war auch oft in Vorlesungen, wo ich so bisschen komische Blikke gemerkt habe ((lacht kurz auf)), gespürt habe. Aber ich weiß gar nicht, wie man so etwas interpretiert. Ob das - es kann auch aus purer, reiner Neugier gewesen sein. Ich würde jetzt nicht sagen, dass das rassistisch war ((lacht kurz auf)) oder so, aber ich merkte schon, dass so ich als - zum Beispiel es gab Seminare, wo ich der einzige Schwarzkopf war, der da saß, und da dachte ich mir, okay das ist jetzt ein bisschen ${ }^{\circ}$ außergewöhnlich ((lacht kurz auf)) vielleicht für die anderen, die halt vielleicht nicht so viele Freunde haben, die so aussehen wie ich. Das war auch so eine Erfahrung. Ich könnte das jetzt nicht mit Rassismus in Verbindung bringen oder mit Diskriminierung gegen mich persönlich, sondern einfach so, dass diese Menschen halt in einer Gesellschaft aufgewachsen sind, in der sie sehr wenig mit so Menschen wie uns zu tun haben." 
Während die anderen Teilnehmenden des Seminars das Privileg haben, als „normal“ zu gelten, da sie nicht auffallen und einfach dazugehören können, macht Hafez die Erfahrung, von „komischen Blicken“ beobachtet zu werden. Selbst wenn diese Blikke „objektiv“ nicht zu erklären sind, kennen rassismus_erfahrene Menschen deren Aufladung und Bedeutung: Die eigene Zugehörigkeit und Anwesenheit ist subtil, unausgesprochen und machtvoll infrage gestellt: „Gazes place me as ,Other " when people stare at me. Every time I am thus placed as,Other', I am experiencing racism, for I am not ,Other.' I am self“ (Kilomba 2013: 43).

Blicke können jedoch kaum sprechbar gemacht, ohne als „hysterisch“ oder „überempfindlich“ degradiert zu werden. Hinzu kommt die Schwierigkeit, keine Räume zu haben, in denen sich eine Sprache für diese Blicke entwickeln kann, die rassifizierte Menschen tagtäglich und fast überall spüren und denen sie ausgesetzt sind. Rassismuserfahrungen sind zudem widersprüchlich und komplex. Die Schwierigkeit, Rassismus zu verstehen ist auch an die daraus resultierende Konsequenz gebunden, diesen benennen zu müssen. Insbesondere für Inkludierte des akademischen Raums kann sich das Sprechen bzw. die Thematisierung von Rassismus als ein Problem erweisen:

„The stakes are indeed very high: to talk about racism is to occupy a space saturated with tension. History is saturation. It is because of how racism saturates everyday and institutional spaces that people of color often make strategic decisions not to use the language of racism. If you already pose a problem, or appear ,out of place' in the institutions if whiteness, there can be good reasons not to exercise what is heard as a threatening or aggressive vocabulary. [...] If racism tends to recede from social consciousness, then it appears as if the one who ,bring it up' are bringing it into existence" (Ahmed 2011: 162).

Folglich wird die Universität von den Gesprächsteilnehmenden als ein Ort frei von Diskriminierung und Rassismus entworfen. Im Gegenzug ermöglicht die Zugehörigkeit zur gesellschaftlich anerkannten und einflussreichen Institution der Hochschule für rassifizierte Studierende (auch) Momente der Ermächtigungen. So identifiziert sich beispielsweise nicht nur Lale mit ihrem jeweiligen Fach bzw. ihrer Fakultät:

„Im Juridicum zum Beispiel, da habe ich auch nicht das Gefühl, dass es aufgeteilt ist in Leute mit Migrationshintergrund und Deutsch und so. So nicht, aber eher halt, Status der Eltern, Geld ((lacht)). Da ist es, glaube ich, eher danach eingeteilt. Und von den Professoren her hatte ich das glaube ich auch nicht. Also, wir haben ja jetzt auch - bei uns ist eher Vorlesungstechnisch immer viel. Also wir haben ja große Vorlesungen, bei uns läuft das so ab, dass wir da zum Teil mit zwei-, dreihundert Leuten in der Vorlesung sitzen, also diesen persönlichen Kontakt zum Professor hast du einfach nicht. Aber wenn man den mal hat, dann - der ist nie negativ ausgefallen bei mir. Da muss ich mich echt sehr glücklich schätzen." 
Im Sprechen von „wir“ und „bei uns“ drückt Lale ihre (subjektive) Zugehörigkeit zur machtvollen Institution aus, hier zur juristischen Fakultät. Die Studierenden befinden sich somit in einer Position, in der sie sich entlang neoliberaler Logiken einer Konkurrenz- und Leistungsgesellschaft durchaus zur „Bildungselite" (Metin) Deutschlands zählen können. Dies erfordert jedoch auch die Einhaltung bestimmter ungeschriebener Regeln, wie beispielsweise oben aufgezeigt die Dethematisierung von erlebter Diskriminierung und Rassismus. Als rassifizierte_r Studierende_r besteht demnach ein besonderer Druck, institutionell durchzugehen: „We could describe this ,going along with' as a form of institutional passing: [...] Passing here would not necessarily mean passing as white [...] but passing as the ,right kind" of minority, the one who aims not to cause unhappiness or trouble" (Ahmed 2012: 157).

\subsection{Zwischenfazit}

Wie ich auf meiner Analyse basierend zeigen konnte, existieren an der Universität weder institutionalisierte Räume noch Sprechweisen, innerhalb derer sich ein Wissen und Bewusstsein über oder eine generelle Auseinandersetzung mit Rassismus entwickeln könnte. An diesem Punkt agiert die Hochschule als Institution einer Gesellschaft, in der die Marginalisierung und Relativierung von Rassismuserfahrungen und Nichtbenennung von Rassismus zur Normalität gehört.

Gleichzeitig ist die Existenz von (institutionellem) Rassismus und rassistischen Verhältnissen an der Universität normalisiert gegeben. Rassifizierte Studierende sind von dieser universitären Verhandlungsweise von Rassismus wesentlich betroffen. Wenn Rassismus institutionell tabuisiert und dethematisiert wird, obwohl er im universitären Alltag präsent ist, verschließt er Möglichkeitsräume von rassismus_betroffenen Studierenden, Rassismus begreifen und benennen zu können. Ein Effekt daraus ist, dass rassifizierte Studierende selbst Rassismus leugnen und nicht benennen, um sich u. a. der Institution und seinen Normen anzupassen. Wie sich diese Anpassung insgesamt auf die studentischen Verhandlungsweisen von Rassismus(erfahrungen) im Weiteren auswirkt, wird im nächsten Kapitel näher beleuchtet. 


\section{Studentische Verhandlungsweisen von Rassismus(erfahrungen)}

In diesem Kapitel liegt der Fokus auf Verhandlungsweisen von Rassismus seitens migrantisierter Studierender. Zentrale Fragen hierbei sind: Wie begegnen sie Rassismus bzw. rassistischen Situationen? Wie sehen ihre Handlungsstrategien aus? Wie verarbeiten sie rassistische Erlebnisse? Welche Effekte hat Rassismus auf ihre Selbstwahrnehmung - insbesondere als Studierende - und wie kommunizieren sie diese?

Im Folgenden wird ersichtlich, dass für Studierende bestimmte (De)Thematisierungsweisen (5.1) von Rassismus eine wichtige Verhandlung von Rassismus darstellen. Zum anderen wird Rassismus zentral im Prozess der Differenzierung und in der Auseinandersetzung mit der Position als Anderes (5.2) verhandelt. Schließlich spielen Interdependenzen von verschiedenen Machtverhältnissen (5.3), im Folgenden Klassismus ${ }^{18}$ sowie Sexismus, eine wichtige Rolle, da diese den Studierenden in der Verhandlung von Rassismus zur Verfügung stehen. Es zeigt sich insgesamt, dass der Status als Studierende_r grundlegend für diese Verhandlungsweisen ist.

18 Zur Definition von Klassismus beziehe ich mich in meiner Analyse auf: Weinbach 2006: 89ff.; Winker/Degele 2009: 42ff.; Kemper/Weinbach 2009. 


\section{1 (De)Thematisierungsweisen}

In den Gruppengesprächen werden unterschiedliche Thematisierungsweisen, d. h. wie über Rassismus gesprochen bzw. nicht gesprochen wird, als eine Verhandlungsweise von Rassismus bzw. von rassistischen Situationen deutlich. ${ }^{19}$ Im Folgenden wird darauf eingegangen, wie die Studierenden rassistische Erlebnisse und Situationen thematisieren, bei gleichzeitiger Dethematisierung von Rassismus als Begriff und Konzept.

\subsubsection{Individualisieren/Personalisieren}

Das Individualisieren bzw. Personalisieren von rassistischen Vorfällen zeigt sich in den Gruppengesprächen als eine zentrale Thematisierungsweise, die es erlaubt rassistische Situationen sprechbar zu machen. Rassismuserfahrungen werden hierbei - entgegen ihrer Alltäglichkeit und strukturellen Gegebenheit - auf die Handlung einer einzelnen Person projiziert und reduziert. Dieser Weg ermöglicht den Studierenden, von rassistischen Erfahrungen zu berichten und sich dabei trotzdem als handlungsfähig wahrnehmen und präsentieren zu können. Dies soll im Folgenden an einer Sequenz aus der Diskussion von Gruppe B bezüglich Suzans Schulzeit verdeutlicht werden:

Suzan: „Mir ist nur einmal eine Situation passiert, in der meine Englischleich hab im Unterricht gekippelt und meine Englischlehrerin, das war neunte zehnte Klasse, hat irgendwann zu mir gesagt, also als ich dann mal wieder am Kippeln war, meinte sie: ,Du kannst da Kippeln, wo du hergekommen bist‘.

|_Lale: „Hohoo!“

Suzan: „Und die Reaktion war, dass mein bester Freund aufgestanden ist, ein großer, blonder, blauäugiger junger Mann, aufgestanden ist und gesagt hat: So gut, dann gehen wir jetzt mal dahin, wo du hergekommen bist, und ist mit mir raus und hinter uns her noch fünf andere.

|_Lale: „Geil.“

Suzan: „Und dann sind wir zu mir nach Hause gegangen. Da haben wir eine Freistunde gemacht, weil ich nämlich gegenüber von der Schule gewohnt habe. Und wir sind dann halt dahin gegangen, wo ich hergekommen bin. Und die Dame hat auch dann ne-“

|_Lale: „Verfahren bekommen ...“

19 Es sei darauf hingewiesen, dass die folgenden dargestellten Thematisierungsweisen stark ineinander übergehen und ineinandergreifen. Zudem lassen sich innerhalb einer Thematisierungsweise noch weitere finden. Die vorliegende Kategorisierung/Zusammenstellung soll als eine Möglichkeit betrachtet werden und erhebt nicht den Anspruch der Vollständigkeit. 
Suzan: „Nicht ein Verfahren, ja irgendwie da eine Konferenz [...]. Und die war einfach gestört. Also jetzt mal abgesehen davon, dass das daneben war, durfte sie dann später auch nur noch Oberstufenschüler unterrichten, weil sie einfach eine gestörte Frau war. Also deswegen würde ich von der nicht auf andere schließen. Und einfach diese Loyalitätsbekundung meiner Freunde in dem Moment, das hat für mich eigentlich das Ganze zum Positiven gewendet, weil ich gedacht hab, oki alles klar, also ihr wisst, wo ich herkomme, und zwar von gegenüber, da die Straße runter. Und ja, das ist das, was ich aus der Schule noch weiß.“

Eingangs verdeutlicht Suzan, dass ihre folgende Schilderung als eine Ausnahmesituation („nur einmal eine Situation passiert“) verstanden werden soll. Ihre damalige Englischlehrerin stellt mit ihrer rassistischen Äußerung Suzans Zugehörigkeit (zur deutschen Gesellschaft) vor ihrer Klassengemeinschaft infrage, indem sie Suzan und ihr „störendes“ Verhalten auf ein Außerhalb, ein Ausland, „da wo [sie] hergekommen“ sei, verweist. Diese Verweisung, die mit entsprechenden Zuschreibungen, Bildern und Erwartungen verbunden ist, fasst die Psychologin Santina Battaglia unter den Akt der natio-ethno-kulturellen Belangung:

„Die Belangungen sind mit dieser Platzierung und ihren Implikationen ,geladen‘. Diese Ladung der sprachlichen Handlungen erzeugt eine Asymmetrie zwischen den Gesprächspartnern. Sie bewirkt eine charakteristische Einschränkung der Selbst-Definitionsmacht des Angesprochenen“" (Battaglia 2007: 186).

Battaglia beschreibt „[n]atio-ethno-kulturelle Belangungen als Rassismuserfahrungen“ (ebd.: 188) und fasst den „Herkunftsdialog und ähnliche Dialogtypen [als ein] Element des Diskurses über Rassismus“ (ebd.: 189). In der oben geschilderten Situation wird Suzan nicht im Rahmen eines „Frage-Antwort-Spiels“ bzw. eines „Herkunftsdialog[s]“ für ihre „prekäre Zugehörigkeit ${ }^{20}$ belangt“ (ebd.: 186), vielmehr ist der Verweis direkt und damit unter Umständen ein noch gewalt-/machtvollerer Akt der natio-ethno-kulturellen Belangung.

Suzan geht in ihrer Schilderung jedoch nicht darauf ein, welche Auswirkungen diese Situation für sie hatte bzw. wie sie sich gefühlt hat, sondern sie legt den Fokus eindeutig auf den Widerstand, den sie gemeinsam mit Freund_innen geleistet hat, die sich zu ihr bekannt und sich mit ihr solidarisiert haben. Suzan hebt in ihrer Darstellung die stärkenden Aspekte dieser Situation hervor, die „das Ganze [für sie] zum Positiven gewendet" haben. Die rassistische Äußerung scheint sie für sich mit der Erklärung abgeschlossen zu haben, dass „diese Frau einfach gestört“ war und

20 In Anlehnung an Paul Mecheril (2003) beschreibt „prekäre Zugehörigkeit“ in Abgrenzung zur „fraglosen Zugehörigkeit“, die Fremdzuschreibung, die dem Selbstverständnis nicht entspricht. Beispielsweise ist Suzans Zugehörigkeit prekär, weil ihr „von außen“ ein sogenannter Migrationshintergrund zugeschrieben wird, wobei sie in ihrem Selbstverständnis als Deutsche diesen für ihre Lebensrealität vollkommen ablehnt (vgl. Kapitel 4.1). 
Suzan deswegen „von der nicht auf andere schließen“würde. Die Reduzierung rassistischer Situationen auf das (Fehl)Verhalten einzelner Individuen hat, wie hier deutlich wird, (auch) eine Selbstschutzfunktion. ${ }^{21}$ Die Verhandlung von Rassismus fällt leichter, wenn das diskriminierende, ausgrenzende Verhalten einer einzelnen Person zugeschrieben wird. So kann es besser eingeordnet und damit auch (zunächst) abgeschlossen werden. Es ist von enormer Wichtigkeit, dass Personen, die im Alltag mit Rassismus konfrontiert werden könnten - wobei selbst die Möglichkeit der rassistischen Konfrontation einen Zustand der Anspannung und des Stresses bedeuten kann - diese Erlebnisse „abschließen“ können, um im Alltag weiter machen zu können.

Nach der oben geschilderten Sequenz wird das Thema zunächst gewechselt und die Teilnehmenden unterhalten sich über andere Lebensbereiche. Von Rassismus ist nicht die Rede. Im Verlauf der Unterhaltung führt Lale das Gespräch jedoch zurück auf Erfahrungen in der Schule, an die sie sich Bezug nehmend auf Suzans Erzählung erinnert:

Lale: „Aber was ich mir gerade gedacht habe, ich glaube- du hast ja jetzt gesagt was in der Schule da bei dir passiert ist. Ich glaube, ich hab das auch nie so wahrgenommen, also (3) dass ich gesagt hätte, okay, das war gerade ziemlich fies, was sie- Das hab ich so gar nicht wahrgenommen. Es ist einmal was passiert bei mir, das war aber auch so eine, die hat dann auch irgendwann aufgehört mit dem Lehrersein, weil die war auch magersüchtig und krank und so ((lachen)) Französisch ..."

|_ Suzan: „((lachend)) ( ) diese Gestörten irgendwie ...“

Lale: „Ja echt. Ich hatte Französisch bei ihr, und das war genau dann, als irgendetwas passiert war wieder mal in der Welt. Ich weiß gar nicht, ob das jetzt- ich war in der Oberstufe, ich bin mir nicht sicher, aber irgendwas Schlimmes war passiert. Halt so ein Attentat oder so. Gerade hatte die Stunde angefangen, ich hatte so eine große Flasche und die ist runtergefallen und es war dann voll laut. Und dann, die sie so, a:::h, c'est une acte-, was hat sie gesagt, c'est une acte islamiste ((unterdrücktes Lachen)) Ist das ein islamistischer Akt? Und ich war so (2) ich konnte nichts sagen. Ey, das war das erste Mal, wo ich so, bähm ((klatscht in die Hände)) ins Gesicht sowas gesagt- und

21 Suzan grenzt sich von Anbeginn des Gruppengesprächs auffällig stark von „den Ausländern“ ab. So betont sie an verschiedenen Stellen, sie habe „immer deutsche Freunde gehabt" und kenne „keine Ausländer“. Sie lehnt den „Migrationshintergrund“ sowohl als Bezeichnung als auch als Konzept, das ihre Lebensrealität beschreiben soll, ab (vgl. Kapitel 7.1). Demzufolge erfüllt die Individualisierung des Rassismus zusätzlich die Funktion, einen (möglichen) Bruch mit dem eigenen Zugehörigkeitsverständnis zum „Deutsch-Sein“ zu vermeiden. In diesem Kontext ist die Beschreibung ihres einschreitenden besten Freundes als „großer, blonder, blauäugiger junger Mann“ zum einen als Bestätigung für ihre Abgrenzung von den „Ausländern“ zu verstehen, zum anderen als zusätzliche Aufwertung des solidarischen Akts. 
dann hat sie darüber gelacht. Ne, das fand sie witzig [...]. Ich habe in dem Moment nichts gesagt, aber ich war richtig (2) perplex. [...] Aber ich glaube, ich habe einiges auch nicht wahrgenommen, weil ich habe das halt so als Witz in dem Moment so- ich erinnere mich auch an nichts (2).“

Angeregt durch die Erzählung Suzans erinnert sich Lale auch an eine „einmalige“ Situation („Es ist einmal was passiert bei mir“), die ihr in der Schule widerfahren ist. Dabei erklärt sie, dass sie aber glaubt, viele diskriminierende Vorfälle „auch nie so wahrgenommen“ zu haben. Damit weist sie darauf hin, dass diskriminierende Situationen durchaus vorgefallen sein können, sie diese jedoch nicht als rassistisch diskriminierend interpretiert habe. Erst dadurch, dass Suzan mit ihrer Erzählung die spezifische Situation als diskriminierende Erfahrung markiert - ohne es so zu benennen -, reflektiert Lale ihre eigenen Erfahrungen im Hinblick auf Diskriminierung neu und stellt dabei fest, dass sie möglicherweise vieles auch einfach „nie so wahrgenommen “ habe. Dies impliziert eine Möglichkeit des Verdrängens bzw. der Nichtauseinandersetzung mit rassistischen Erfahrungen als eine Umgangsweise, um den Alltag, der stets das Risiko der rassistischen Konfrontation beherbergt, meistern zu können.

Lale folgt in ihrer Darstellung den Vorlagen Suzans, indem sie vor der Schilderung ihrer Erfahrung, die diskriminierend handelnde Person im Voraus als „magersüchtig und krank“ einordnet. Suzan sieht sich in ihrer These der individuellen „Gestörten" bestätigt. Die Disqualifizierung der Lehrerin als ernstzunehmende Person stärkt zum einen die Strategie, Rassismus zu individualisieren, da nicht irgendeine Person sich rassistisch verhalten hat, sondern eine, die gesellschaftlich ohnehin nicht zur Norm gehört. Zum anderen kann auf diese Weise die rassistische Erfahrung abgeschwächt werden. Somit zeigt sich, dass Betroffene Rassismus auf einzelne Individuen reduzieren, um sich einerseits zu schützen und andererseits (im Alltag) handlungsfähig zu bleiben, um (zumindest im Gefühl) die „Kontrolle“ über die Situationen zu haben.

Gleichzeitig wird Rassismus, der sich strukturell durch alle Ebenen der Gesellschaft durchzieht, durch das Personalisieren relativiert, sodass er auf diese Weise weder in seiner Struktur noch Wirkmacht erkenn- und greifbar wird.

\subsubsection{Verschiebung}

Eine weitere (De)Thematisierungsweise von Rassismus zeigt sich in der Verschiebung von Rassismus auf die Erfahrungen „anderer“. In der folgenden beispielhaften Sequenz überschneiden sich teilweise die Stimmen der drei Teilnehmerinnen vor Aufregung, weil sie die geschilderten Situationen zu kennen scheinen und dazu selbst etwas sagen möchten. Im selben Atemzug betonen sie aber mehrmals, dass sie das jedoch nicht persönlich erfahren, sondern lediglich von anderen gehört hätten: 
Suzan: „Ja auch die Verwaltung hier in Göttingen ist- die Univerwaltung ist auch völlig in Ordnung, also sogar auch die Stadtbehörden in Göttingen sind völlig in Ordnung, wenn man das vergleicht mit Hannover."

Lale: „Aber da hört man doch immer ganz viel, okay gut-,

Suzan: „Nein wirklich, die sind total nett und freundlich und reden mit dir in normaler Lautstärke und Geschwindigkeit ..."

Lale: „((lachend)) Die reden nicht laut, wenn die denken-,

Suzan: „Laut und la:::ngsa::m, ((lachen)) Weißt du, du verstehst nicht ((lachen))“

Rabia: „Ist schon mal ein Fortschritt.“

|_Suzan: „Ja ja, mir persönlich ist das nicht passiert, aber ich kenn das von Leuten-,

Rabia: „Traurig, dass so etwas ein Fortschritt ((lachen)) ist.“

Suzan: „Ja echt, sie reden mit dir als würdest du sie verstehen, ja su:per, danke, ja ..."

Lale: „Ja, das lieb ich auch, dass man lauter spricht (2)“

Suzan: „Ja und so de::utlich (2) ja, kann ich auch aus persönlicher Erfahrung nicht bestätigen aber-”,

|_Lale: „Ich kann auch nur alltäglichere Sachen erzählen, ich als jetzt[...] von mir gar nicht so viel, aber ich bekomm halt viel mit, weil ich hab einige Freundinnen, die einen Kopftuch auch tragen zum Beispiel (2) Ey, die werden gefragt, ob die damit duschen, ob die damit schlafen ((lachen)) ohne Witz."

I_Rabia: „Duschen?“

Lale: „Ohne Witz, die wurde gefragt, ob die damit duscht.“

Auf diese Weise lässt sich Rassismus thematisieren, ohne sich als darin eingebunden zu betrachten, um möglicherweise die damit einhergehenden Verletzungen und Herabsetzungen nicht zu nah an sich heranzulassen. Ähnliches lässt sich auch in der anderen Gesprächsgruppe finden. Hier berichten zwei Teilnehmende (teilweise sehr ausführlich und detailliert) von ihrer Arbeit mit Geflüchteten und deren Erfahrungen in Deutschland und mit den deutschen Behörden. Dies eröffnet einen Rahmen, innerhalb dessen ungehemmt über Rassismus(erfahrungen) gesprochen werden kann, da es um die Erfahrungen der Anderen geht, mit denen sich die Sprechenden aber durchaus solidarisch zeigen. 
In den Ausführungen über die Erfahrungen der Anderen werden implizit und explizit auch gleichzeitig Begründungen und Erklärungsansätze für die eigene Ausnahme von Diskriminierung angeboten:

Samet: „Wenn mich jetzt, sag ich mal, einer diskriminiert, bin ich ja jetzt schon so weit in Deutschland- oder mein Wortschatz ist ja so weit ausgebildet, dass ich kontern kann im schlimmsten Fall. Und dementsprechend glaube ich, dass wir das deshalb in der Uni nicht so wirklich wahrnehmen. Aber ich glaube schon, dass Menschen, die, sag ich mal, seit kürzerem hier sind, schon diskriminiert werden, in bestimmten Bereichen. Und das ist auch in öffentlichen Ämtern der Fall, das hat man ja jetzt auch schon in verschiedenen Medien gesehen, dass Menschen einfach diskriminiert werden."

Neben der Erklärung, dass die Beherrschung der deutschen Sprache ein Grund dafür sei, weniger diskriminiert zu werden - was aus meiner Perspektive durchaus zutreffend ist -, führten auch Kenntnisse und Orientierung in den Behörden dazu, dass sie persönlich keine Diskriminierungserfahrungen machen würden. In der ersten Gruppe führt Lale an, dass sie selbst kein Kopftuch trägt und erklärt damit implizit, dass sie deshalb auch nicht von eigenen Erfahrungen berichten könne.

Auf diese Weise wird Rassismus als die Erfahrung der Anderen verhandelt, und der eigene Bezug im rassistischen System kann ausgespart bleiben.

\subsubsection{Alternative Erklärungsmuster/-ansätze}

Nachdem alle Teilnehmenden vielfältig und zahlreich von rassistischen Situationen berichtet hatten, entwickelte sich folglich ein Erklärungsbedürfnis, sowohl für sich als auch für den äußeren Rahmen, weshalb diese Ereignisse ihrer Einschätzung nach stattfänden. Da aber die Interviewpartner_innen Rassismus als Konzept und Analysewerkzeug nicht in Betracht zogen bzw. dieses für sie nicht vorhanden zu sein schien, zogen sie alternative Erklärungsansätze für ihre Erfahrungen und Beobachtungen heran. Auf der Suche nach Erklärungen für die erfahrenen rassistischen Situationen bzw. das Gefühl der Ausgrenzung - denn „,[o]ft ist die Wahrnehmung von Rassismus kaum mehr als ein Gefühl“" (Terkessidis 2004: 118) - besprachen die Teilnehmenden viele unterschiedliche Ansätze. Beispielsweise galt das Alter in beiden Interviewgruppen als eine zentrale Alternative bzw. als ein Erklärungsersatz für Rassismus, d. h. rassistische Vorfälle wurden nicht mit Rassismus erklärt, sondern in einen Zusammenhang mit dem Alter der rassistisch handelnden Person gebracht. Dieser These nach hätten ältere „Deutsche“ mehr „Vorurteile“ als jüngere, da sich Letztere im Rahmen von Sportvereinen oder auch des Schulalltags in ständigem und selbstverständlichem Austausch mit „den Ausländern“ befänden. Dies impliziert auch die Kontakthypothese als Erklärungsansatz, d. h. je mehr Kontakt bzw. Austausch zwischen den einen und den anderen bestehe, desto weniger "solcher" Vorfälle kämen vor. 
Daneben wurden einige weitere Erklärungsversuche angebracht, wie beispielsweise in der folgenden Erzählung von Samet, der von einem Gespräch mit einem (,deutschen“) Freund berichtete:

„Er [der Freund] so: ,Ich hab da mal eine Frage an dich. Ich habe viele ausländische Freunde bzw. Freunde mit Migrationshintergrund, und viele davon sind sogar hier in Deutschland geboren eigentlich. Also, die waren maximal ein-, zweimal in ihrem eigenen Land oder Ursprungsland. Aber wenn ich die immer so frage, ob sie sich deutsch oder halt spanisch, türkisch oder so fühlen, sagen sie immer- also hat bis jetzt nie jemand gesagt, dass er sich deutsch fühlt. Woran liegt das?' Ich so: ,Soll ich dir das so eiskalt mal wirklich sagen?' Ich so: ,Ihr Deutschen seid einfach ein kaltes Volk. Ich weiß nicht, ob es am Wetter liegt, ((lacht)) ihr seid einfach kaltblütig."“

Zunächst wird Samet hier als Stellvertreter der angesprochenen Gruppe der „ausländischen Freunde“ bzw. „mit Migrationshintergrund“ adressiert und erhält damit „einen natio-ethno-kulturellen Repräsentationsauftrag, der im weiteren Gesprächsverlauf einzulösen ist“" (Battaglia 2007: 184). In diesem Repräsentationsauftrag wird Samet nach den Gründen gefragt, die dazu führten, dass sich viele Personen der o. g. Gruppe nicht „deutsch“ fühlten, obwohl sie „ihr eigenes Land oder Ursprungsland“ lediglich aus kurzen Aufenthalten kennen würden, aber ,eigentlich“ in Deutschland geboren seien. $\mathrm{Da}$ „Repräsentationsaufträge und Belangungen [...] Selbst-Positionierungen der Angesprochenen“ (ebd.) fordern, geht Samet als (fraglos) Zugehöriger zur o. g. Gruppe der „Aufforderungen zur repräsentativen Stellungnahme“ (ebd.) nach und erklärt den Grund für das fehlende Zugehörigkeitsgefühl zur deutschen Nation in der Kälte der „Deutschen“. Im Spaß bringt er diese subjektiv empfundene Kälte mit dem Wetter in Zusammenhang. Tatsächlich kommt in Samets Aussage ein Gefühl zum Ausdruck, das jedoch ohne eine Auseinandersetzung mit Rassismus nur schwer zu begreifen bzw. zu erklären ist. Eine tiefergreifende Argumentation kann an dieser Stelle nicht stattfinden, weil ihm das analytische Handwerkszeug zu fehlen scheint, um das erfahrene Wissen um Rassismus einordnen und sprechbar machen zu können. Stattdessen wird das Gefühl der rassistischen Ausgrenzung nicht greif- und erklärbar, sodass Samet hier die fehlende Argumentationslinie ironisch überbrückt:

„Dieser Mangel an Sprache ist Teil der Disqualifikation des, Wissens über Rassismus. Dass die Migranten keine gemeinsame Sprache besitzen, um ein Problem anzusprechen, verringert für die hegemoniale Gruppe die Wahrscheinlichkeit von Konflikten erheblich. Viele Personen nichtdeutscher Herkunft kennen den Moment, in dem ihnen die Worte in einer Diskussion förmlich im Halse stecken bleiben. [...] Und plötzlich gehen einem die Argumente aus. Es fehlt einem schlicht und ergreifend die Sicherheit, die der Gleichklang mit einem Konsens bringt. Plötzlich könnte man mit jedem Wort in einen tiefen Strudel der Orientierungslosigkeit stürzen." (Terkessidis 2004: 204) 
Mark Terkessidis stellt fest, dass gesellschaftlich zwar ein verbreitetes rassistisches Wissen existent und wirksam ist, jedoch steht diesem Wissen paradoxer- oder vielleicht logischerweise ein „disqualifiziertes Wissen der Leute über Rassismus“ gegenüber. Das Wissen über Rassismus kategorisiert Terkessidis dementsprechend als eine „unterworfene Wissensart [...], um ein Wissen also, dass [sic!] sehr oft unter dem Druck der Disqualifikation steht" (Terkessidis 2004: 121).

Hafez’ Erklärungsansatz sieht neben dem Handeln einzelner Personen auch die Politik und wirtschaftliche Interessen in der Verantwortung für rassistisch segregierte Zustände in der deutschen Gesellschaft. Eine Kritik, die er jedoch nicht konsequent (für sich selbst) anwendet:

„Und da ist es auch egal, ob du dann irgendwann gut deutsch sprichst oder integriert bist. Als Ausländer bleibst du halt dann immer Ausländer. Wie gesagt, von Person zu Person ist es unterschiedlich, aber es gibt halt einfach diesen Kult in Deutschland, Segetuisierungkult [sic], dass Menschen einfach sehr schnell untereinander sich spalten und dann kritisiert man die ganzen ((lacht kurz auf)) Parallelgesellschaften, obwohl das ja irgendwie, keine Ahnung, ich finde, die Ansätze werden ja von Politik und Wirtschaft auch öfters animiert, dass es einfach so dazu führt, dass Menschen sich einfach untereinander viel besser und wohler fühlen. Es kann auch eine mentalitätsbedingte Sache sein, ich weiß es nicht. Ich bin halt so ein Prototyp für Ausländer, so klein, dunkel und mit Bart und das kann auch einfach optisch ein Grund sein, warum wir lieber mit so Menschen abhängen, die eher so aussehen wie wir, als zum Beispiel Deutsche, der zum Beispiel zwei Meter groß und einfach blond ((kurzes Lachen)) und anders tickt so. Das kann auch vielleicht mit unter anderem ein Grund dafür sein.“

Hafez drückt seine Unzufriedenheit über den Status Ausländer-Sein aus, der sich unabhängig von den eigenen Bestrebungen und Umsetzungsgrad der „Integration“ nicht zu verändern scheint. Weiter stellt er fest, in Deutschland gebe es eine Art „Kult“, der zur gesellschaftlichen „Spaltung“ führe, und sieht die Verantwortung auch bei Politik und Wirtschaft. Die Konsequenz daraus seien „Parallelgesellschaften“ und „dass Menschen sich einfach untereinander ${ }^{22}$ viel besser und wohler fühlen“. Allerdings schlagen seine Argumentationslinie bzw. sein Erklärungsansatz gegen Ende seiner Aussage in Unsicherheit und Unklarheit um („Ich weiß es nicht“). In dieser Unsicherheit überlegt er dann weiter, ob die Gründe für diese gesellschaftlichen Zustände nicht auch durch äußerliche Ähnlichkeiten der Menschen oder „mentalitätsbedingt“ sein könnten. Trotz des Einbezugs unterschiedlicher Ebenen (individuell und politisch), auf denen sich rassistische Effekte zeigen und auf denen Hafez diese wahrnimmt und benennt, ist es ihm ohne ein analytisches Wissen über

22 Die Vorstellung von „Menschen untereinander“ basiert auf konstruierte Dichotomien von „den Deutschen“ und „den Ausländern“ als feste, homogene Gruppen (vgl. dazu Kapitel 2.2 Bezeichnungspraxis). 
Rassismus nicht möglich, seine Beobachtungen der sozialen Ungleichheit zu konkretisieren.

In beiden vorangegangen Beispielen fehlt den Teilnehmenden ein theoretischanalytisches Wissen über Rassismus und damit auch die Sprache, Rassismus zu begreifen und zu benennen.

Allerdings möchte ich in diesem Zusammenhang auch betonen, dass viele der alternativen Erklärungsansätzen im Verlauf des Gesprächs innerhalb der Gruppe Widerspruch erfahren haben, sie dadurch auch widerlegt und zum Teil wieder verworfen wurden. Die Dynamik und Flexibilität dieses Prozesses haben u. a. verdeutlicht, dass alternative Erklärungsansätze für Rassismus selten vollständig greifen (können) und im Grunde genommen unzureichend sind.

\subsubsection{Verleugnung und (Nicht)Wissen}

Insgesamt wird in den o. g. Beispielen deutlich, dass die unterschiedlichen Thematisierungsweisen von rassistischen Erfahrungen, Vorfällen und Zuständen von den Gesprächsteilnehmenden ausschließlich im Rahmen von Dethematisierung und Relativierung bis hin zur Verneinung von Rassismus als Begriff und Konzept stattfanden. Die Verhandlung von Rassismus erfolgt hier im Nichtsprechen und Nichtbenennen von Rassismus, die sich durch das gesamte Material der beiden Gruppeninterviews ziehen. Dass dies kein singuläres Ergebnis ist, zeigen verschiedene Forschungen, u. a. auch die Untersuchung von Terkessidis, in der er zu ähnlichen Ergebnissen kommt und fragt: „Woher kommt diese Verleugnung?“ (Terkessidis 2004: 117). In seiner Schlussfolgerung formuliert er folgende Antwort:

„Es gibt in Deutschland keine Kohärenz und Kontinuität im Nachdenken über den Rassismus; es findet weitgehend unsystematisch und anlassbezogen statt. [...] Zudem existiert [unter den Migranten; Anm. K. P.] keine gemeinsame Sprache, um Rassismus zu thematisieren. Die Ursachen dafür sind vielfältig. Aber die wichtigste ist zweifellos die Verweigerung der Zugehörigkeit“ (ebd.: 203).

Terkessidis erklärt, dass die Verweigerung der Zugehörigkeit eine Art Verdrossenheit bei den „Migranten der zweiten Generation“ (ebd.) auslöst. Ihnen würde mit der fehlenden Zugehörigkeit auch das Selbstbewusstsein fehlen, über Belange zu sprechen, die ihnen wichtig seien. Sie würden sich folglich nicht mit den Themen auseinandersetzen, die ihr Leben in Deutschland betreffen, weil sie sich nicht zugehörig fühlten (vgl. ebd.). Allerdings erachte ich die alleinige Fokussierung der Zugehörigkeit als Erklärungsansatz für die fehlende gemeinsame Sprache von migrantisierten/ rassifizierten Subjekten über Rassismus als unzureichend, da dies u. a. strukturelle Bedingungen des Status quo ausblendet. So ist unabhängig vom Zugehörigkeitsgefühl rassifizierter Personen das Sprechen von und über Rassismus gesellschaftlich tabuisiert und nicht anerkannt. Außerdem stellt sich mit Blick auf neoliberale Ent- 
wicklungen die Frage, ob eine Zugehörigkeit im Sinne von Inklusion/EingebundenSein das Nicht-Sprechen-Können über Rassismus nicht vielmehr verstärkt. ${ }^{23}$

Aus dem vorliegenden Material haben sich zwar auch Ansätze ergeben, die das Nichtsprechen von Rassismus individuell begründen, allerdings sind dies nicht die einzigen. Beispielsweise hat das Individualisieren von Rassismus gezeigt, dass das Nichtbenennen von Rassismus eine Selbstschutzfunktion erfüllen kann: „Negation thus protects the subject from the anxiety certain information causes once it is admitted to the conscious" (Kilomba 2013: 153). Die Ausblendung von Rassismus kann so die eigene Handlungsfähigkeit sichern. Allerdings stellt diese Verhandlungsweise keine nachhaltig effektive Strategie gegen Rassismus dar. So arbeiten Alana Lentin und Garvey Titley heraus, dass unter neoliberalen Gesichtspunkten Rassismus immer stärker als „private Angelegenheit“ verhandelt wird, sodass auch dies zu einer „Unsprechbarkeit“ von Rassismus führt:

„Under neoliberalism race is essentially privatized, in the sense of being silenced or made invisible. When racism is understood as an irrational attribute or behaviour, it has diminished purchase in a social vision that places rational and autonomous actors centre stage“" (Lentin/Titley 2011: 169).

In dieser Logik gehen diejenigen, die von Rassismus sprechen, das Risiko ein, als irrational und überempfindlich degradiert zu werden. Denn trotz der Alltäglichkeit, der strukturellen Gegebenheit und der Wirkmacht von Rassismus sowie rassistischer Bilder, Praxen und rassistischem Wissen in der deutschen Gesellschaft ist ein (Alltags)Wissen über Rassismus bzw. Rassismen und deren Funktionsweisen weitgehend nicht existent. Wie Terkessidis richtig feststellt, ist dieses Wissen im postnationalsozialistischen Deutschland (vgl. Messerschmidt 2010) ein „disqualifiziertes Wissen":

„Diese Disqualifizierung wirft auch das bereits angesprochene Problem auf, was denn eigentlich von den Befragten unter Rassismus kategorisiert werden kann - in einem Land, dessen öffentlicher Diskurs eine Verwirrung über den Phänomenenbereich einerseits und heftige Abwehrreaktion gegen die Thematisierung andererseits transportiert" (Terkessidis 2004: 117).

Die Frage danach, was die Gesprächsteilnehmenden konkret unter Rassismus fassen, hat mich in der Auswertung des Materials zentral begleitet und kann nicht abschließend beantwortet werden. Allerdings war mein vorherrschender Eindruck, dass die Teilnehmenden unter Rassismus das auffassen, was gesellschaftlich, politisch und medial vorherrschend darüber vermittelt wird. Als Folge der konsequenten Nichtexistenz von institutionellen Räumen, in denen ein qualifiziertes Wissen über Rassismus vermittelt werden könnte (vgl. Kapitel 4.2), ist dies auch nicht weiter verwunderlich.

23 Auf den Zusammenhang des inkludiert_Seins und Rassismus wird im 6. Kapitel Der Status Studierende_rnäher eingegangen. 
Astrid Messerschmidt arbeitet beispielsweise die gesellschaftliche Verlagerung des Rassismus auf den sogenannten rechten Rand als eine von vier Praktiken ${ }^{24}$ im Umgang mit Rassismus heraus. Die zentrale Funktion dieser Praktik besteht darin, die „Mitte der Gesellschaft“ als frei von Rassismus zu konstruieren und ihn lediglich als Problem der gewaltbereiten „Rechtsextremisten“ zu verhandeln (vgl. Messerschmidt 2010). So kann die allgemein rassistische Struktur der Gesellschaft ausgeblendet werden.

Diese hegemoniale Auffassung von Rassismus teilen auch die meisten aus den Gruppengesprächen. Vor dem Hintergrund, dass rassistische körperliche Gewalt nicht unbedingt ein alltägliches Erleben von rassismus_erfahrenen Menschen darstellt, ist es teilweise verständlich, dass der Begriff „Rassismus“ für die „kleinen, banalen Ausgrenzungserlebnisse" (Terkessidis 2004: 10) nicht verwendet wird. Allerdings ,sind [es] diese Erlebnisse, die in ihrer Serialität einen Unterschied markieren und die Menschen erst zu ,Fremden“ oder ,Ausländern ' machen“ und „die in ganz entscheidendem Maße eine ausgrenzende Wirkung entfalten" (ebd.: 114). Aber da ein qualifiziertes Wissen über Rassismus im Generellen fehlt, ist es den

„Minorisierten [erschwert], ein Bewusstsein zu entwickeln und aus den Dynamiken von Schuldgefühlen, Introjektion und Identifikation heraustreten zu können. Das generelle Wissen um Rassismus mit seinen widersprüchlichen Double-Binds und das Wissen um die eigenen Verstrickungen und Traumatisierungen kann als kognitive Ressource Minorisierter in der Bewältigung der alltäglichen rassistischen Normalität bezeichnet werden" (Velho 2010: 132).

Rassismus_Betroffene befinden sich somit in einem paradoxen politischen Gefüge, in dem Rassismus einerseits als Praxis alltäglich und allgegenwärtig ist und andererseits im Sprechen und in der (Wissens)Vermittlung nicht existent ist bzw. sein darf. In der Aneignung eines kritischen Wissens über Rassismus, das ihnen möglicherweise andere (wirksamere) Strategien eröffnen würde, sind sie jedoch völlig auf sich gestellt. Dass eine kritische Auseinandersetzung mit der eigenen Position insbesondere für rassifizierte Subjekte von zentraler Bedeutung ist oder sein kann, stellt auch Grada Kilomba heraus: „It is the understanding and the study of one's own marginality that creates the possibility of emanating as a new subject" (Kilomba 2013: 36).

\subsection{Die Position als Anderes}

Die Konstruktion der Anderen ist eine historisch verankerte Praxis, die in einen Macht/ Wissen-Komplex (vgl. Foucault 1978: 119f.) eingelassen ist. Das Andere wird in einem ungleichen Verhältnis zum Eigenen institutionell und diskursiv hervorgebracht

24 Bei den anderen dreien handelt es sich um Skandalisieren, Verlagerung in den Rechtsextremismus, Kulturalisierung und Verschiebung in die Vergangenheit (vgl. Messerschmidt 2010: 41). 
und festgelegt (vgl. Mecheril 2007: 9). Hierfür bestehen verschiedene Marker, die den/ die Andere/n als Anderes kenntlich machen und „verpflichten“. Dazu gehören ein bestimmtes Aussehen, der Name oder auch ein Akzent, wenn sie der festgesetzten Norm nicht entsprechen. Sobald eine Person als anders festgestellt wurde, kann sie jederzeit dafür „belangt“ werden, wie Battaglia (2007) verdeutlicht. Demnach ist die Differenz keine gegebene Tatsache, sondern ein ständiger „Prozess der Differenzierung“ (Terkessidis 2004: 179), in dem die geanderten Subjekte lernen (müssen), sich zu verhalten. Allerdings gibt es bei „prekär Zugehörigen“ (Mecheril 2003) einen entscheidenden Moment, in dem sie „das erste Mal“ verstehen, dass sie nicht wirklich dazugehören. Diesen Moment, der manchmal aus einer ganz „kleinen, banalen“ Erfahrung bestehen kann, bezeichnet Terkessidis als „Urszene“ (2004: 175). In diesem Moment erfahren rassifizierte Subjekte einen Bruch mit ihrem bis dahin als selbstverständlich wahrgenommenen Umfeld. Ihnen wird ihre Zugehörigkeit „aufgekündigt“ (ebd.), womit diese „erstmals bewusst als prekär erfahren“ (ebd.: 176) wird. Da solche Momente im Alltag vorkommen und in der Folge bewusst wahrgenommen werden, beginnen rassifizierte Subjekte an der sodann gegebenen Differenz zu arbeiten und beteiligen sich mit ihrer Selbstmarkierung am Prozess der Differenzierung. In diesem Komplex entsteht sogar eine Notwendigkeit, die eigene Identität als Anderes „zu verhandeln“ (Battaglia 2007: 87). Terkessidis weist zu Recht darauf hin, dass es kontraproduktiv wäre, Selbstmarkierung bzw. ethnisierung (beispielsweise über Sprache oder „Kultur“) unter dem Aspekt Identität anstelle von strukturell rassistischen Bedingungen zu verstehen. Damit würde man die Mechanismen ausblenden, „welche die betreffenden Personen letztlich dazu gezwungen haben, Selbstdefinitionen im Hinblick auf Kultur und ,Identität' vorzunehmen“" (Terkessidis 2004: 178). Denn sowohl die „Identität“ als Anderes als auch ihr Gegenstück, also das Maß, an dem das Andere gemessen und entworfen wird, nämlich das „deutsch_Sein“werden in erster Linie über strukturelle, institutionelle sowie diskursive Praxen hergestellt (vgl. Mecheril 2007: 9; Terkessidis 2004: 148, 165). Dieser hegemonialen Logik nach bestehen auch bei den Gesprächsteilnehmenden konkrete Vorstellungen vom „deutsch_Sein“ als unveränderlicher Kategorie, die zunächst nichts mit Staatsbürgerschaft und politischer Teilhabe zu tun hat. Stattdessen wird diese Kategorie überwiegend als starrer Gegensatz zum eigenen Status des „Ausländer_in-Seins“ verhandelt.

Für den Großteil der Interviewpartner_innen scheint die „Internalisierung als Anderes" (vgl. Vehlo 2010) einen Ausgangspunkt für die Verhandlung dieser rassistisch zugeschriebenen Position darzustellen. Die „Internalisierung als Anderes“ beschreibt die Akzeptanz und darüber hinaus die weitgehende Verinnerlichung der dominanzgesellschaftlich zugeteilten Rolle bzw. Position als Andere in Abgrenzung zur Norm, d. h. nach der "Urszene" verstehen und akzeptieren rassistisch markierte Personen in einer Einwanderungsgesellschaft, dass sie nicht zur Norm gehören bzw. sie in ihrer zugeschriebenen Position dieser Norm nicht gerecht werden (können). An diesem Punkt beginnen die Verhandlungen um die Position als Anderes, die bei jeder/m der Interviewpartner_in unterschiedlich ausfallen. 


\title{
5.2.1 Die (kritiklose) Akzeptanz der Position als Anderes
}

\author{
„Der ,weiße Blick“ ist stets präsent“
}

(Terkessidis 2004: 192)

Michel Foucault bezeichnet mit dem Begriff der Gouvernementalität die „Rationalisierung" gesellschaftlicher Machtverhältnisse „bei der Ausübung politischer Souveränität" (2004: 14). Mit dieser sind indirekte Techniken des (Selbst)Regierens verknüpft, über die Individuen und Kollektive in ihrem Handeln auf subtile Weise angeleitet werden. Ein zentrales Moment moderner Machttechniken ist es, zu „normalisieren“ und „einzuschließen“, dabei können diese jedoch ebenfalls exkludierend und sogar "todbringend“ wirken (vgl. Muhle 2008). Astrid Velho analysiert hierbei diesen Prozess als Othering:

„Othering arbeitet mit Normen und Normalitäten, häufig ohne offensichtliche Gewalt und Kontrolle auszuüben [...]. Minorisierte Subjekte entstehen, werden produziert und bilden sich selbst. Foucaults Konzept der Gouvernementalität differenziert zwischen Herrschafts- und Selbsttechnologien. Subjektivierungsprozesse finden nicht nur durch Disziplinierung und Unterwerfung, sondern mit Hilfe von Techniken des Selbst statt" (Velho 2010: 119).

Aslan sieht sich als Anderer in Deutschland „integriert“, und auf Grundlage dessen verneint er weitgehend eigene Diskriminierungserfahrungen. In einer Gesprächssituation, in der sich Erzählungen der anderen drei Teilnehmenden über rassistische Erfahrungen in Deutschland verdichten - ohne diese so zu benennen -, reagiert er folgendermaßen:

„Ich kann das nicht so verallgemeinern, dass die Deutschen sich nicht gerne mit Ausländern unterhalten oder so. Obwohl das- das gibt es halt auch, das hab ich auch gesehen. Aber ((holt kurz Luft)) es kommt aber auch öfters wieder vor, dass sich irgendwelche Deutschen mit mir unterhalten, und obwohl ich so einen langen Bart habe. Da können ja viele denken, okay, er ist vielleicht ultrareligiös oder sonst was, weil sie es nicht unterscheiden können, ob man jetzt einen (.) religiösen- aus religiösen Gründen so einen Bart macht oder ob es nur mein Stil ist oder so. [...] Also ich sehe dann auch öfters viele Deutsche, $[\ldots]$ die sprechen mich einfach auf Deutsch an, unterhalten sich mit mir und ich merke dann gar nicht, dass sie mich irgendwie anders behandeln oder so, oder dass sie nicht mit mir reden wollen, weil ich halt wie ein Ausländer aussehe."

In diesem Gruppengespräch taucht das Sich-Unterhalten bzw. Sich-nicht-Unterhalten von „Deutschen“ mit „Ausländern“ an vielen Stellen auf und wird auf einer symbolischen Ebene für Akzeptanz, Offenheit bzw. Verschlossenheit und Ablehnung der „Deutschen“ den „Ausländern“ gegenüber verwendet. Aslan möchte mit seinem Beitrag in Reaktion auf die vorangegangenen negativen Erfahrungen der 
anderen Teilnehmenden mit „den Deutschen“, (auch) positiven Erfahrungen Berücksichtigung schenken, weil er nicht „so verallgemeinern“ könne, dass „Deutsche“ nicht offen gegenüber „Ausländern“ seien. Als Indiz für seine Wahrnehmung dient der Umstand, dass ,sich irgendwelche Deutschen mit [ihm] unterhalten, [... ] obwohl [er] so einen langen Bart" habe. Aslan scheint nicht nur die Position des Anderen akzeptiert zu haben, sondern darüber hinaus auch die damit einhergehenden rassistischen Zuweisungen und Grenzen:

„Wenn man ständig mit jenen Zuschreibungen konfrontiert wird und diese zumeist auch bewertet werden - ob positiv oder negativ --, dann ist es kaum verwunderlich, dass Personen sich teilweise oder ganz mit den ihnen zugeschriebenen Eigenschaften identifizieren“ (Terkessidis 2004: 192).

In Aslans Selbstverständnis als Anderer, innerhalb dessen er nicht erwartet, dass mit ihm unbefangen gesprochen wird, weil er „vielleicht ultra religiös oder sonst was“ sein könnte, findet er es bemerkenswert und stellt es gesondert positiv heraus, dass er trotzdem „einfach auf Deutsch“ angesprochen wird. Aslan bewegt sich innerhalb vorherrschender rassistischer Diskurse und Bilder von muslimisch_markierten Personen, die in dem Maße normalisiert zu sein scheinen, dass er zum einen Verständnis für diesen Rassismus aufbringen kann („weil sie es nicht unterscheiden können“) und er es zum anderen der dominanten Seite positiv anrechnet, dass sie trotzdem „einfach“ auf ihn zugehen.

Dabei bleiben in der von Aslan erwähnten Gesprächssituation einige zentrale Fragen offen: In wieweit kann Aslan in diesen Gesprächen als Subjekt agieren und inwieweit wird er angesprochen, weil er von vornherein objektiviert wurde? Warum wird ausgerechnet er angesprochen und welche Rolle spielt vielleicht gerade sein „langer Bart“ beim Angesprochenwerden? Worauf wird er angesprochen? Welche Themen rahmen solch ein Gespräch bzw. werden darin wichtig gemacht? Denn wie Karin Scherschel in Rückgriff auf Erving Goffman herausarbeitet, ruft

„[d] ie sichtbare Differenz [...] Assoziationen [bei dem/der Angehörigen der Dominanzgesellschaft; Anm. K. P.] über Herkunft, kulturelle Werte und soziale Kompetenzen des Gegenübers hervor. Folgt man Goffman (1975: 64), wird durch den Sehsinn das Stigma anderer am häufigsten evident" (Scherschel 2011: 134).

Aslan weiß um den „weißen Blick“ auf sich und die möglichen Bilder, die sein Aussehen dabei beim Gegenüber hervorrufen. Und in der Erwartung einer negativen Erfahrung oder Begegnung rechnet er der abweichenden, vermeintlich positiven Reaktion auf sich Anerkennung zu. Als Anderer befindet sich Aslan lediglich in der Position zu re-agieren, sein Gegenüber ist derjenige, der agiert, schaut, (an)spricht und die Norm setzt.

Paradoxerweise suggeriert das Ansprechen eine Bereitschaft bzw. ein Interesse des Gegenübers, das Andere in die Norm, die er/sie vertritt, „einzubinden“ bzw. zu 
inkludieren. Gleichzeitig aber wird das Andere gerade in dieser Inklusion erst ausgesondert, da sie eine Exklusion voraussetzt:

„Integration“ als biopolitisches Dispositiv wirkt als Element einer für eine ,Normalisierungsgesellschaft' (Foucault 1977: 139) konstitutiven Spannung zwischen Assimilationsforderungen und Ausgrenzung, zwischen Inklusion und Exklusion“ (Altenried 2011: 157).

Folglich merke Aslan „dann gar nicht, dass sie [ihn] irgendwie anders behandeln oder dass sie nicht mit [ihm] reden wollen, weil [er] halt wie ein Ausländer" aussehe. Aslans verwendete Sprache und (Selbst)Beschreibung zeugen von verinnerlichten herrschenden rassistischen Machtstrukturen, die insofern wirksam sind, als er sich im Sinne von Integrationserwartungen „selbst regiert“ (Foucault). Ulrich Bröckling definiert diese (Selbst)Verständnisse bzw. (Selbst)Verhältnisse im Anschluss an Foucault folgendermaßen:

„Regierung im Sinne Foucaults bezieht sich [...] nicht in erster Linie auf die Unterdrückung von Subjektivität, sondern vor allem auf ihre,(Selbst) Produktion', oder genauer: auf die Erfindung und Förderung von Selbsttechnologien, die an Regierungsziele gekoppelt werden können. Sie operiert nicht ausschließlich und notwendig über explizite oder implizite Verbote von Handlungsoptionen, sondern auch und gerade durch ihre Macht, Subjekte zu einem bestimmten Handeln zu bewegen“" (Bröckling u. a. 2000: 29).

Aslan verhandelt hier Rassismus so, dass er sich innerhalb rassistischer Logiken und Grenzen bewegt und sich darin verortet, indem er sich selbstverständlich und kritiklos als rassifiziert denkt. Die Psychologin Astride Velho schreibt in diesem Zusammenhang treffend:

„Die permanente Sichtbarmachung als Andere/r [...] bewirkt die Internalisierung des Selbst als Anderes [...]. Das minorisierte Selbst strebt nach Assimilation, es identifiziert sich mit rassistischer/hegemonialer Norm, da dies beispielsweise vermittelt durch den Integrationsdiskurs Zugehörigkeit und ein Entkommen aus der ewigen Sichtbarmachung und Internalisierung des Andersseins in Aussicht stellt" (Velho 2010: 130).

Weiter kritisiert Velho die Identifikation mit Assimilationsanforderungen, da diese „den Verzicht auf das Selbst“ erfordere und somit „einer symbolischen Auslöschung gleich[kommt]“ (Velho 2010: 134). Obwohl ich ihre Kritik weitgehend teile, möchte ich an dieser Stelle darüber hinausgehend anmerken, dass zum einen Assimilation nie vollständig und durchgehend gelebt wird, sondern auch eine (Handlungs) Strategie sein kann bzw. ist, um sich in bestimmten Räumen bewegen zu können, von denen ausgegangen wird, sie erlaubten einer/m, sich dem „Zentrum der Macht“ zu nähern. Gleichzeitig existieren auch Räume (des Randes), in denen rassifizierte Subjekte nicht „genötigt“" sind, sich anzupassen, sondern in denen sie einfach sein können: 
„In this sense, the margin is a location that nourishes our capacity to resist oppression, to transform, and to imagine alternative new worlds and new discourses. Speaking of the margin as a place of creativity can, of course, convey the danger of romanticizing oppression. To what extent are we idealizing peripheral positions and by doing so undermining the violence of the centre? However, bell hooks argues that this is not a romantic exercise, but the simple acknowledgement of the margin as a complex location that embodies more than one site. The margin is both a site of oppression and a site of resistance (hooks 1990)“ (Kilomba 2013: 36).

Somit würde ich Assimilation nicht ausschließlich als (Selbst)Aufgabe und (Selbst) Auslöschung bewerten, da sie als Handlungsstrategie auch mit (temporären) Vorteilen und (limitierten) Privilegien einhergehen kann. Dennoch teile ich die Kritik an (unhinterfragter) Assimilation, da diese letztendlich zur Stabilisierung der Herrschaftsverhältnisse beiträgt und dem rassifizierten Subjekt nicht erlaubt, „[...] to exist no longer as the ,Other,' but as the self. One is the self, one is the subject, one is the describer, the author of and the authority on one's own reality" (Kilomba 2013: 154).

\subsubsection{Die kritische Akzeptanz der Position als Anderes}

Auch Hafez' folgende Aussage setzt die Internalisierung als Anderes voraus, d. h. er spricht ebenfalls aus der Akzeptanz und Annahme der Position des Anderen. Dabei formuliert er jedoch im Gegensatz zu Aslan aus dieser Position heraus Forderungen und damit implizit Kritik an gesellschaftlich herrschenden Strukturen, für die er insbesondere aus dieser Position heraus sensibilisiert zu sein scheint:

„Wenn die Deutschen wollen, dass wir uns integrieren, ist es ja- ich versuche mich zu integrieren. Ich habe meinen Anteil dafür getan, ich rede deutsch, ich studiere, ich versuche hier ein normales Leben zu führen. Es ist auch ihre Aufgabe, ein bisschen was abzugeben und auf uns zuzukommen. Aber das ist halt einfach meine Voraussetzung ((lacht)). Wenn ihr meine Freunde sein wollt, müsst ihr mich auch ansprechen, so. Aber oft ist es auch so, wo ich mir denke, ja okay, vielleicht ist es wirklich eine gegenseitige Verantwortung und es reicht nicht eben, dass man nur integriert ist, sondern man muss auch auf diese Leute zugehen und es auch wollen. Und das ist halt so ein, ${ }^{\circ}$ wieder so ein Thema, wo ich auch gerne (eure Meinung) ${ }^{\circ}[\ldots]$. “

Hafez thematisiert hier Integrations(an)forderungen, die ihm aufgrund seiner Position als Anderer gestellt werden. Er scheint diese akzeptiert zu haben und erläutert, dass er in diesem Rahmen seinen „Anteil getan“ habe: Er spreche deutsch, studiere und führe ein „normales“ Leben. In diesem Sinne analysiert Astrid Velho die an Andere gestellte Integrationsforderung wie folgt: „[U] nter dem Slogan ,Fordern und Fördern' [wird] definiert, dass Migrant/inn/en die sind, die sich integrationsbe- 
reit zeigen und ihre Integrationsfähigkeit unter Beweis stellen sollen" (Velho 2010: 119). Hafez ist überzeugt, an ihn gestellte Integrationsforderungen erfüllt zu haben, und sieht sich dementsprechend nun in der Position, den zweiten Teil des Integrationsversprechens einzufordern. Deutlich wird, dass erst die Erfüllung dieser Anforderungen ihm die Legitimität zu geben scheint, Ansprüche von „gegenseitige[r] Verantwortung" im gesellschaftlichen Zusammenleben zu formulieren und die Einseitigkeit des Integrationskonzepts zu kritisieren. Mit dieser Voraussetzung entspricht Hafez einer hegemonial gesetzten Norm, denn: „Nur was als, normal' registriert wird, soll wahrgenommen werden“ (Castro Varela/Dhawan 2007: 35).

Die geforderte Gegenseitigkeit drückt Hafez im (symbolischen) Angesprochenwerden aus („Wenn ihr meine Freunde sein wollt, müsst ihr mich auch ansprechen"). Demnach wünscht er sich ein Zugehen der dominanten Gruppe auf ihn als Antwort/Reaktion auf seine Integrationsbemühungen.

Allerdings schwächt Hafez seine Forderungen wieder ab, indem er (sich) unsicher fragt, ob das bloße „Integriertsein“ ausreiche, oder ob es darüber hinaus nicht auch seine Aufgabe wäre, „auf diese Leute [zu]zugehen und es auch wollen“ zu müssen. Paradox ist an dieser Stelle die Formulierung des Gegensatzes des Wollens und Müssens. Er sieht sich in der Verantwortung, es „auch wollen“ zu müssen. Dies interpretiert er dann als eine „wirklich gegenseitige Verantwortung“. Auch hier ist ein Widerspruch zu erkennen: Die wirkliche Gegenseitigkeit zeige sich nicht darin, dass es jetzt ,ihre Aufgabe [sei], ein bisschen was abzugeben und auf uns zuzukommen“, sondern dass er neben der „Erfüllung" seiner Integrationsforderungen noch zusätzlich (ungewollte) (Beziehungs)Arbeit für die dominante Gruppe leisten müsse. Eine abschließende Antwort hat er jedoch nicht: Er lässt diese Frage (für sich) offen und gibt sie in die Gruppe („eure Meinung“). Hafez' Verunsicherung trotz seiner (anfänglichen) Klarheit weist auf die Komplexität rassistischer Dynamiken und Machtstrukturen hin. Velho erklärt eine solche Verunsicherung mit

„der unbewussten Identifikation mit und Anpassung an hegemoniale Normen [...]. Erfahrungen des Otherings stellen widersprüchliche Dynamiken her: Prozesse der Internalisierung des Selbst als Anderes finden in paradoxer Bewegung zu oder mit assimilativen Identifikationen statt. Dynamiken der Identifikation und Internalisierung können als Strategie des Überlebens und der Beibehaltung von Handlungsfähigkeit verstanden werden. Das minorisierte Selbst ist in seinen Subjektivierungsprozessen Schauplatz internalisierter Andersheit und Assimilationsbestrebungen. Dies verweist auf die subjektivierende Wirkung von Rassismuserfahrungen, die in Ambivalenzen, Paradoxien und Schuldgefühlen eingebettet ist" (Velho 2010: 128). 


\subsubsection{Das Andere als (umkämpfte) Ressource}

Am Beispiel von Lale wird eine weitere Aushandlung der Position des Anderen deutlich. In diesem fortwährenden Prozess reflektiert und benennt Lale bewusst ihre Position als Andere mit türkischem Migrationshintergrund, die sie (auch) als eine Ressource erlebt und sich deshalb positiv und wertschätzend darauf bezieht:
„Aber ich muss schon sagen, ich fühle mich schon- meine Persönlichkeit ist schon geprägt dadurch, dass ich nicht rein deutsch bin. ${ }^{\circ}$ Rein deutsch ${ }^{\circ}$, das hört sich auch komisch an ((lacht)). Also ich bin- die türkische Sprache vor allem, das ist so das, was ich sage, ohne geht es nicht. Ohne geht es einfach nicht, das macht mich aus. Ich kann mich auf Türkisch zum Teil viel, viel besser ausdrücken. Und was bei mir nochmal ein bisschen Ticken überwiegt, ist dann die Religion, also der Islam, der zu mir gehört und wo ich sage, so, ne, da mache ich keine Abstriche und sag, ich bin jetzt irgendwie so sehr in- tegriert, dass ich sagen könnte, ich bin jetzt Deutsche oder so was."

Neben dem „Bekennen“ zu ihrer (Teil)Identifikation mit dem „Türkischen“ erhebt Lale mit ihrem Ausdruck, „nicht rein deutsch“ zu sein, auch den Anspruch, Teil der deutschen Gesellschaft zu sein. Diese Hybridität betont sie an verschiedenen weiteren Stellen im Interview. Dennoch scheint für Lale hinsichtlich der nationalen Zugehörigkeit eine Aushandlungsnotwendigkeit zu bestehen, die sie bereit ist einzugehen. Eine selbstverständliche Zugehörigkeit zu „beidem“ scheint allerdings nicht möglich zu sein, sondern ist zwingend mit „Abstrichen“ verbunden. Die Grenze ihrer Aushandlungsbereitschaft erreicht sie jedoch, wenn es um ihre Religionszugehörigkeit geht:

„Das ist auch immer so ein Thema, also meine Eltern kommen aus der Türkei, sind dort geboren, ich nicht. Damit habe ich kein Problem, dass man da zum Beispiel sagt, dass man da Abstriche macht [...]. Aber so wenn es um den Islam geht, bin ich halt empfindlicher. Das ist so meine empfindliche Stelle, glaube ich. Und da sage ich, ich bin bewusst und dass ich dann auch damit sage, ich bin Muslimin [sic!] und dass ich da auch drauf beharre, sag ich mal.“

Lale empfindet die Notwendigkeit, in diesem von Macht durchdrungenem Feld ihrer „Kompromiss- und Aushandlungsbereitschaft“ Grenzen setzen zu müssen. Wenn es um den Islam ginge, würde sie „keine Abstriche“ zugunsten ihrer „Integration" machen. Die Zugehörigkeit des Islams (und damit auch der Muslime) zu Deutschland ist in den vergangenen Jahren stark umkämpft, mit Höhepunkt in den anhaltenden bundesweiten Aufmärschen von Pegida- und Co. Sebastian Friedrich zeigt anhand der sogenannten Sarrazindebatte, wie sich die "Integrationsdebatte“ zur "Islamdebatte“ entwickelt hat und Integration letztendlich an migrantisierte bzw. muslimisch_markierte Personen ,angehaftet“ wird (vgl. Friedrich 2011: 14f.). 
Dies wirkt sich folglich auf die Wahrnehmung und das Zugehörigkeitsgefühl vieler muslimischer wie auch muslimisch_markierter Subjekte aus, die in Deutschland geboren sind und dort ihren Lebensmittelpunkt haben. In den vorherrschenden rassistischen Diskursen und Debatten werden sie ohne ihren öffentlichen Einbezug als bedrohlich, fremd, unintegrierbar etc. konstruiert, sodass den Subjekten wenig Raum für Aushandlungen (der Zugehörigkeit) gegeben ist.

Paul Mecheril stellt in diesem Zusammenhang fest: „In der (deutschen) migrationsgesellschaftlichen Wirklichkeit ist öffentliche Darstellung, politische und soziale Vertretung für die unterschiedlichen kulturellen Lebensformen nicht in gleicher Weise gegeben“" (Mecheril 2007: 10). Demnach gibt es eine (dominante) Gruppe, „die über die Mittel der politischen, kulturellen und auch wissenschaftlichen Re-Präsentation verfügt" (ebd.), und zwar nicht nur hinsichtlich der eigenen Darstellung, sondern auch in der Darstellung der Anderen (vgl. ebd.). Unter diesen asymmetrischen Machtverhältnissen der Repräsentation starteten im Zuge der Sarrazindebatte

„viele Zeitungen eine Reportagen-Offensive, um gewissermaßen Sarrazins Thesen einen qualitativen Faktencheck gegenüberzustellen. Die in den Reportagen re-produzierten Bilder von Migrant_innen glichen einerseits erwartbaren klischeebeladenen und rassistischen Mustern bei der Zeichnung des Bildes des ,Anderen'. Andererseits ist eine Zuspitzung der Einteilung ,erfolgreicher'versus, unnützer Migrant' anhand der Kategorie ,Integrationsleistung' und ,Verwertbarkeit" festzustellen" (Friedrich 2011: 14).

Dabei sind es überwiegend Angehörige der Dominanzgesellschaft, die die Bilder über die Anderen produzieren und Schwerpunkte in den Reportagen setzen. Wenn beispielsweise „integrierte“ Migrant_innen zu Wort kommen, „[w]eisen [sie] fast durchgängig auf Diskriminierungserfahrungen in Institutionen hin" (Friedrich/ Schultes 2011: 86). Da aber nicht sie es sind, die die Artikel letztendlich schreiben und damit entscheiden, welche Aspekte Wichtigkeit erhalten, wird „Rassismus [...] zum einen als Analysekategorie außer von den Porträtierten selbst nicht mit einbezogen, zum anderen bleiben solche Äußerungen entweder unkommentiert oder werden relativiert" (ebd.: 87).

Und so werden in der vermeintlich wohlwollenden Darstellung einer Gegenthese zu Sarrazin „erfolgreiche Migrant_innen“ vorwiegend in Abkoppelung ihres „Migrantenstatus“ (ebd.: 85) präsentiert, wie Sebastian Friedrich und Hannah Schultes anhand einer Medienanalyse zur Sarrazindebatte aufzeigen. In dieser Logik „zeichnen sich ,integrierte 'Migrant_innen [...] durch perfekte Deutschkenntnisse, eine erfolgreiche Schullaufbahn (mit Abitur), ,normale‘ oder gar keine Religiosität und vor allem durch ihre ,Nützlichkeit" für die Mehrheitsgesellschaft aus" (ebd.: 84). Migrantisierten Subjekten werden darüber wichtige Elemente ihrer Identität zugunsten eines - dominanzgesellschaftliche Erwartungen erfüllenden - Bildes der/ des „perfekten Migrant_in“ abgesprochen. Ob diese Darstellung den Selbstkonzepten der Anderen entspricht, ist von keiner Relevanz. Das Beispiel von Lale zeigt 
hierbei, dass migrantisierte Subjekte große innere Widerstände gegen die dominanzgesellschaftlichen Erwartungen haben, auch wenn sie vordergründig diesen zu entsprechen scheinen. Lale zieht eine klare Linie und hält am religiösen Teil ihrer Identität fest, weil sie diese bedroht zu sehen scheint: „Wie gesagt, mein religiöser Hintergrund ist mir dann wichtiger, dass ich- ja doch, wichtiger, und dass ich dahinterstehe und sage, das gehört zu mir."

\subsubsection{Ablehnung der Position als Anderes}

In den vorangegangenen Ausführungen wurden die Annahme und Akzeptanz der Position als Anderes in verschiedenen Aushandlungsformen und in unterschiedlichem Ausmaß dargestellt. Allen Aushandlungsformen gemeinsam ist die Internalisierung bzw. Annahme dieser Position, die den Ausgangspunkt der Handlungen darstellt. Suzan hingegen wird zwar in der Fremdbestimmung als Andere festgesetzt, in ihrem Selbstverständnis jedoch lehnt sie diese Kategorie für ihre Lebensrealität vollkommen ab. Dies ist möglich, da „[d] as Selbstbild [...] im Prozess der Verinnerlichung nicht nur durch die bloße Übernahme der Zuschreibungen geprägt und womöglich erschüttert [wird], sondern auch in dem Versuch, sich von diesen abzusetzen“" (Velho 2010: 127). Konkret bedeutet dies für Suzan als migrantisch_markierte Person in den meisten Fällen Konfrontationen und kontroverse Diskussionen, da sie jede andere Positionierung erklären und erkämpfen muss:

„Irgendwann fragte er mich dann, wo ich denn herkäme, so im dritten Satz. Und ich sagte dann, ja Hannover [...]. Nein, ursprünglich. ${ }^{\circ}$ Ich sag ja ${ }^{\circ}-$ immer wieder diese Diskussion - ich sag ja, Hannover, und du? Sagt er, na Magdeburg. So, ich sag, ne, ursprünglich. Ja, wie? Ja, Magdeburg. Ich sag, ja gut. Ich dachte du hast ja so ein bisschen braune Haare. Ich dachte vielleicht so, Spanien, Saudi-Arabien so. Und er guckte mich an, seine Gesichtszüge entgleisten völlig ((Lachen)). Ne, so, und das war für ihn völlig schlimm, dass ich aus seiner Haarfarbe auch Rückschlüsse ziehen könnte, weil, er war ja nicht blond und blauäugig, ja also das, was er von mir erwartet hat, ja [...]. Also das war so eine Situation, wo ich gedacht hab, das kann ja wohl nicht wahr sein, ne, dass man da im dritten Satz schon wieder darauf angesprochen wird."

Ihren Widerstandskampf führt Suzan einerseits gegen die Markierung von Außen und damit gegen den machtvollen Ausschluss aus der Dominanzgesellschaft, zu der sie sich zugehörig fühlt. Zum anderen grenzt sie sich in der Konsequenz an vielen Stellen auch von „den Ausländern“ ab, zu denen sie nicht gezählt werden möchte und die sie dementsprechend aus dem Blickwinkel der dominant weißen Gesellschaftsgruppe betrachtet: 
Suzan: „In meiner Schulzeit [hatte ich] gar keine Erfahrungen in der Richtung [gemeint sind rassistische Erfahrungen]. Ich hab aber auch immer deutsche Freunde gehabt. Also, ich kenne keine Ausländer.

Lale: Okay.

Suzan: Beziehungsweise, natürlich kenne ich Ausländer, ne ((lacht)), aber halt- oder Leute, die halt sich auch wirklich bewusst als- wie jetzt zum Beispiel du [zu Lale], die halt sagen, ja ich bin einfach mit Migrationshintergrund, wie auch immer das heißt, wie man das nennt, blablabla, also die ihre eigene Community haben, die ihre Traditionen haben, die ihre- und das aber auch sehr offensiv und offen machen."

Suzan betont, dass sie „gar keine Erfahrungen in der Richtung“ von Rassismus gemacht habe und erklärt es damit, dass sie „aber auch immer deutsche Freunde gehabt“ habe. Damit verknüpft sie Rassismuserfahrungen mit dem Freundeskreis bzw. mit dem sozialen Umgang, sodass Rassismus_Betroffene indirekt selbst verantwortlich gemacht werden. Gleichzeitig glaubt sie entgegen ihrer Erfahrungen, dass der „deutsche“ Freundeskreis sie vor rassistischen Erlebnissen schützen würde. Ihr Abgrenzungsbedürfnis geht so weit, dass sie absolute Aussagen trifft, wie beispielsweise, sie kenne ,gar keine Ausländer“. Nach Mecheril stellt die Positionierung Suzans eine sehr eindeutige Form der prekären Zugehörigkeit dar:

„Wer unter dieser Bedingung beansprucht: ,Ich bin Deutscher" und auf weiteres Nachfragen einräumt, ausländischer Abstammung zu sein, riskiert, als solcher nicht anerkannt zu werden bzw. zu hören: ,Du verleugnest deine Herkunft, warum?‘. Prekär Zugehörige befinden sich demnach in einer Situation herabgesetzter Selbstwirksamkeit“" (Battaglia 2007: 195).

Um u. a. diesem Spannungsverhältnis ein Stück weit zu entkommen, scheint für Suzan eine extreme Abgrenzung von den Anderen notwendig zu sein, da das dominante Verlangen nach Eindeutigkeit und Bestimmung immer wieder eine klare, eindeutige Zugehörigkeit fordert.

Für Suzan haben die Anderen eine „eigene Community“ und Traditionen, die sie „sehr offensiv und offen“ leben. Dies entspreche nicht ihrer Lebensrealität. Daneben ähnelt ihre abgrenzende Argumentationslinie an vielen Stellen den medial vermittelten, rassistischen Diskursen wie beispielsweise denen der jungen, gewaltbereiten „ausländischen“ Männern und verweist damit implizit auf das geschlechtliche Gegenstück der „unterdrückten“ und vom Mann kontrollierten Frau, zu der sie (potenziell) markiert wird, zu denen sie aber unter keinen Umständen gezählt werden möchte:

Suzan: „Ich war in Hannover auf einer Schule mit großem Ausländer- in Anführungszeichen- Anteil, weil, das sind ja auch alles Deutsche, also jetzt auf dem Papier, ne. Und das waren immer so ein bisschen die Krawallbürsten, 
also das waren wirklich die, die dann auch mit Baseballschlägern auf dem Schulhof gestanden haben und gewartet haben, weil irgendwer mit irgendeinem Bruder mit der Schwester von irgendwem irgendwie, was weiß ich ((holt Luft)) Und, das war für mich ganz weit weg. Also das war für mich so, pf, oh Gott ne, nicht die, ne so. Und (3) ich hab da einfach überhaupt gar keinen Bezug dazu gehabt."

Hierbei bedient und reproduziert Suzan rassistische Stereotype, wegen derer sie selbst Ausschlüsse erfährt. Dies scheint für sie jedoch in keinem Widerspruch zu ihren eigenen Erfahrungen zu stehen. Sie homogenisiert, kategorisiert und markiert die „anderen“ Anderen entlang rassistischer Bilder. Sie setzt die „anderen“ Anderen als gewaltbereit, patriarchal und unvernünftig fest. Diese Lebensrealität, die für Suzan „ganz weit weg“" gewesen sei und zu der sie „gar keinen Bezug [...] gehabt“ habe, stellt sie als ungebrochene, starre Normalität und Alltag der Anderen dar. Auf diese Weise entwirft Suzan gleichzeitig ein Bild von sich selbst bzw. ihrer Zugehörigkeitsgruppe. Auch stellt sie die eigentliche Zugehörigkeit der Anderen zur deutschen Gesellschaft infrage („weil, das sind ja auch alles Deutsche, also jetzt auf dem Papier, ne“) und ist damit bei dem Themenbereich, der $\mathrm{u}$. a. ihre eigenen Diskriminierungserlebnisse bestimmt.

Aber da sie sich zu der dominant weißen Gesellschaftsgruppe zugehörig sieht, stehen deren Argumentationslinien für sie (auch) zur Verfügung - selbst, wenn sie ihre eigene Betroffenheit von der rassistischen Struktur nicht gänzlich absagen kann. Die Position als Anderes ist keine „kulturelle“ oder „naturgegebene“ Tatsache, sondern entsteht im Prozess der Differenzierung, die durch aktive Diskriminierung erzeugt wird. Dabei hat „[e]ine bestimmte Gruppe die Ressourcen, die Diskriminierung mit jener Autorität zu versehen, welche die Differenzierung in Gang setzt “ (Terkessidis 2004: 173f.). Hier wird unter Diskriminierung nicht (ausschließlich) intentionaler, direkter Ausschluss oder gar körperliche Gewalt verstanden, sondern eben auch, wie Terkessidis herausarbeitet, kleine, „banale“ Erlebnisse. Die müssen nicht unbedingt „böse“ gemeint sein, aber in ihren Effekten stabilisieren und reproduzieren sie die strukturelle Spaltung zwischen dem Wir und den Anderen.

Die unterschiedlichen Aushandlungen der Position als Anderes, die durch politische Diskurse und strukturell rassistische Zusammenhänge bedingt sind, sind für rassifizierte Subjekte von Brüchen und Widersprüchen durchzogen. Somit ist weder die Akzeptanz noch die Ablehnung der Position als Anderes durchgehend eindeutig, sondern flexibel und situationsbedingt. Die Aushandlung findet zudem in einem starren Verhältnis zur Norm des „deutsch_Seins“ statt. Folglich sind Norm und Abweichung eng miteinander verknüpft, da sie sich gegenseitig bedingen und hervorbringen. Die migrantisierten Studierenden werden als Abweichung einer Norm gesetzt und versuchen darin - auf jeweils sehr unterschiedliche Weise -, einen „guten" Weg für sich auszuhandeln:

„Die Antwortmöglichkeiten sind unendlich: Manche bestehen auf ihrer Individualität, andere passen sich an, etliche bewerten die Differenz neu und erfinden neue kulturelle Praxen, manche wiederum suchen sich eigene Spekularisations- 
objekte. Einige nennen sich selbst ,Kanaken“ und nutzen die Beschimpfung als Angriff. [...] Die permanente Infragestellung durch die Umgebung ist - so seltsam das klingen mag - auch eine produktive Situation: Sie bedeutet, dass man in der Lage sein muss, Paradoxa auszuhalten und zur Gewinnung und Absicherung der eigenen Position zu entfalten" (Terkessidis 2004: 201).

\subsection{Verwendung zugänglicher Machtverhältnisse}

Eine weitere Verhandlung des Rassismus zeigt sich in der Verwendung von anderen Machtverhältnissen, die den Studierenden innerhalb der herrschenden gesellschaftlichen Struktur zur Verfügung stehen. Das heißt, in rassistischen Situationen gehört es mit zum Repertoire der Studierenden, auf ihnen zugängliche Machtverhältnisse - hier vor allem Klassenstatus und Sexismus - zurückzugreifen. Velho betrachtet „eine Vertiefung des Verständnisses über und eine Debatte um die Involviertheit Minorisierter in die Machtverhältnisse [als] Grundlagen, um Handlungsfähigkeit und widerständige Praxen weiterentwickeln und vermehren zu können" (Velho 2010: 114).

Die Darstellung und Aufarbeitung dieser Verhandlung von Rassismus forderte mich als Wissenschaftlerin mit einem Anspruch der bewussten Solidarität mit den Interviewpartner_innen stark heraus. Es erfordert einen Balanceakt zu kritisieren, ohne stigmatisierende Diskurse zu bedienen und zu (re)produzieren. In der Bemühung um eine differenzierte Betrachtung von verschiedenen Machtverhältnissen sowie deren Beziehung und Wirkung zu- und untereinander sollten jedoch diskriminierende Verhaltensweisen von rassifizierten Subjekten nicht relativiert oder gar gerechtfertigt werden. Hier erlaubt eine analytische Herangehensweise die vielschichtigen Bedeutungen im Gesamtkontext zu verstehen und „ermöglicht es vielen von uns, für Opfer und Täter Empathie zu entwickeln“ (hooks 1996: 96).

Innerhalb der rassistischen Ordnung befinden sich Rassismus_Betroffene an einem Rand, abseits der Zugänge zu gesellschaftlichen Ressourcen. Aber Rassismus existiert nicht unabhängig von weiteren Machtstrukturen, sodass der Grad der Verweisung an den Rand in Abhängigkeit zu diesen Verhältnissen steht. Demzufolge können sich Studierende der zweiten oder dritten Generation aufgrund ihrer Privilegien, die mit diesem Status ${ }^{25}$ einhergehen können, näher am Zentrum bewegen als beispielsweise Geflüchtete ohne sicheren Aufenthaltsstatus, gesicherte Einkommens- und Wohnverhältnisse.

Eine gelungene Analyse dieser verstrickten und komplexen Zusammenhänge eröffnet die Arbeit von bell hooks (1996), in der sie aus einer feministischer Perspektive einerseits den rassistischen Rahmen und den damit einhergehenden Druck, den Ausschluss und die die Benachteiligung Schwarzer Männlichkeiten im

25 Auf den Status Studierende_r sowie dessen Auswirkungen wird im nachfolgenden Kapitel (6) eingegangen. 
US-amerikanischen Kontext kritisch beleuchtet. Dabei kritisiert sie als (Schwarze) Feministin (weiße) feministische Debatten und Diskurse, die zum rassistischen Bild „des“ Schwarzen Mannes beitragen. Andererseits gelingt hooks der Balanceakt, im selben Rahmen den Sexismus Schwarzer Männlichkeiten zu kritisieren, ohne ihre solidarische Haltung ihnen gegenüber aufzugeben. Übersetzt auf die vorliegende Arbeit würde es bedeuten, sexistische und klassistische Äußerungen der Studierenden aus machtkritischer Perspektive zu reflektieren und diese im Verhältnis zu herrschenden Machtstrukturen zu betrachten, von denen sie - trotz ihrer Betroffenheit von Rassismus - profitieren (können). Gleichzeitig ist es wichtig, das klassistische/ sexistische Verhalten im Kontext (hier beispielsweise von Rassismus) zu untersuchen, um eine noch differenziertere Herangehensweise und Analyse zu ermöglichen.

Aus diesem Grund werden die beiden folgenden Aussagen der Interviewpartner_innen in ihrer Ausführlichkeit wiedergegeben, um den (rassistischen) Kontext der klassistischen bzw. sexistischen Äußerungen erfassen zu können und diese nicht verzerrt abzubilden, ohne sie jedoch damit zu legitimieren.

\subsubsection{Die Verwendung zugänglicher Machtverhältnisse: Klassismus}

Lale berichtet an verschiedenen Stellen des Gesprächs von ihren Erfahrungen während eines Praktikums bei der Polizei. Dabei hebt sie oft hervor, dass dies das erste Mal gewesen sei, in der sie verstanden habe: „Du hast so ne richtige Arschkarte, dass du einen türkischen Namen hast“, und: „Du hast direkt einen Minuspunkt, wenn du einen ausländischen Namen hast". Sie schildert, dass bei der Polizei meist ein „ausländisches Aussehen“" genüge, um Personen zu verdächtigen und beispielsweise bei einer Verkehrskontrolle den Kofferraum öffnen zu lassen, um ihn zu kontrollieren. Lale führt diese Erfahrungen als Hintergrund für ihre folgende Aussage an:

Lale: „Aber wisst ihr, wie weit ich bin? Und das ist eigentlich auch richtig unfair von mir und voll fies [...]. Aber dann kamen natürlich auch Einsätze, wo es um Deutsche ging-“

Rabia: „Bei der Polizei?““

Lale: „Mhm ((lacht)) Und dann waren bei wir auf einer Party, Party ((verwendet die Geste von Anführungszeichen)). Die waren zum Teil elf oder zwölf Jahre alt und die ((lachend)) hießen Chantal und Jaqueline ((Lachen)). Echt, das ist so unfair von mir, ne. Aber als wir dann da waren, die waren stockbesoffen, eine wurde mit dem Krankenwagen ins Krankenhaus gebracht. [...] Super asoziale Familie, also die Familie war auch so richtig- die Mutter- du hast so gemerkt, ey scheiße, was ist das für eine Familie. Aber in dem Moment denkst du dir so: ,Okay, Gott sei Dank, gibt es auch solche Deutsche (2) Total unfair von mir, aber-"

Suzan: „Ja, ja.“ 
Lale: „Wisst ihr, wie ich das meine, was sich dahinter- also was ich damit sagen möchte, ist halt so: Immer geht es um die Ausländer, hier der Türke, hier der Kurde, hier der dies und das und dann kommt halt irgendwie so etwas und man denkt sich ((atmet aus)): Okay, das gibt es nicht nur bei uns so, es gibt auch asoziale deutsche Familien ((lacht)) Und dann ist es halt so- aber dann denke ich mir, ey wie unfair das gerade von dir ist, und es ist ja eigentlich auch total egal, was für eine Dings dahinter ist. Aber es ist schon eine Art Befriedigung, wenn man so etwas auch dann mal erlebt. Vor allem, wie gesagt, im Praktikum war ich komplett am Verzweifeln und dachte mir so, okay du musst dein Leben in Deutschland abbrechen und du musst irgendwo anders hin, weil das geht hier nicht (2).“

Lale leitet ihre Aussage mit einer Frage („Aber wisst ihr, wie weit ich bin?“) ein, mit der sie darauf verweist, dass sie (durch die o. g. Erfahrungen) ihre Grenzen erreicht sieht und dass diese Tatsache sie letztendlich dazu veranlasst, „richtig unfair und voll fies“ zu denken und sich an dieser Stelle zu äußern. Demnach setzt sie ihre diskriminierende Äußerung selbst in einen direkten Zusammenhang mit dem Rassismus, den sie während ihres Praktikums in der polizeilichen Praxis täglich beobachtet habe. Dann berichtet sie von folgender Situation: Zwei sehr junge Mädchen, „die hießen Chantal und Jaqueline“, seien „stockbesoffen“, und eine hätte aufgrund von Alkoholmissbrauch ins Krankenhaus eingeliefert werden müssen. Die Thematisierung der Namen setzt voraus, dass diese bemerkenswert sind. Mark Schrödter arbeitet in der Analyse von Rassismus heraus: „Namen geben immer auch Auskunft über die sozio-kulturelle Herkunft der Person. Sie sind schon Identifikationsmarker" (Schrödter 2007: 83). Hieran zeigt sich u. a., wie eng die verschiedenen Machtverhältnisse miteinander verbunden sind und in ähnlicher Weise funktionieren. Hier reproduziert Lale jedoch einen hegemonialen Diskurs über „die Unterschicht“, die etwa auch mit diesen Namen assoziiert werden (sollen).

Lale homogenisiert eine gesamte soziale Gruppe unter bestimmten Merkmalen und stellt entlang eines klassistischen Diskurses „logische Zusammenhänge“ her: In dieser Logik steht der unkontrollierte Alkoholkonsum der Minderjährigen in einem Zusammenhang mit den Namen und der „asozialen Familie“ der Jugendlichen, die allesamt der „Unterschicht“ zugewiesen werden und damit abgewertet sind. Der abwertende und diskriminierende Gehalt ihrer Äußerung und Denkweise ist Lale bewusst. Sie markiert diese mehrmals als „unfair und fies“. In diesem Rahmen ist für Lale jedoch zentral, dass „,es auch solche Deutsche“ gibt, und sie versucht ihre Äußerung zu erklären und damit auch zu rechtfertigen: „Immer geht es um die Ausländer, hier der Türke, hier der Kurde, hier der dies und das“, und dann sei es „eine Art Befriedigung, wenn man sowas auch dann mal erlebt“. Sie versucht ihre „unfaire“ Einstellung in ein Gefühl der Unfairness („Immer geht es um die Ausländer“) einzubetten. bell hooks hält in vergleichbarer Weise bezüglich Schwarzer Männer fest:

„Viele schwarze Männer, die sich unter permanenter Anspannung [...] fühlen, begreifen tatsächlich nicht, daß dieser Zustand der ,Machtlosigkeit' ihre 
Fähigkeit, auf dominierende und unterdrückende Weise Macht über schwarze Frauen auszuüben, nicht aufhebt und daß er sexistisches Verhalten weder rechtfertigt noch entschuldigt" (hooks 1996: 113).

Die sogenannte Sarrazindebatte veranschaulicht exemplarisch die enge Verstrickung von Rassismus und Klassismus. Trotz Sarrazins vorherrschend rassistischer Thesen sind klassistische Elemente darin maßgeblich eingebaut. Demnach wurde im Zuge dieser Debatte nicht nur gegen rassifizierte Subjekte und Gruppen gehetzt, sondern grundsätzlich gegen „alle Hartz-IV-Empfänger_innen, Leiharbeiter_innen, etc.“ (Friedrich 2011: 30). Die Anklage rassistischer Strukturen auf Grundlage klassistischer Argumentationslinien dient demnach nicht der Destabilisierung bzw. Infragestellung von Rassismus, so wie es Lales Absicht zu sein scheint. Ganz im Gegenteil führt diese Herangehensweise zur Stabilisierung eines anderen Herrschaftsverhältnisses, wovon „andere“ rassifizierte Subjekte im Sinne der Intersektionalität zusätzlich betroffen sind.

Gegen Ende ihrer Aussage kommt der Widerspruch, in dem sich Lale offensichtlich befindet, klar zum Vorschein: Einerseits ist ihr die Unangemessenheit ihrer Haltung bewusst und auch, dass es „eigentlich auch total egal“ sein müsste, warum die jungen Mädchen so viel Alkohol getrunken haben. Andererseits kann Lale anscheinend das Gefühl der Ungerechtigkeit nicht loslassen, das sie letztendlich dazu veranlasst, „asoziale deutsche Familien“ als eine „Art Befriedigung“ ihres Schmerzes zu erleben. Nicht nur dieser Widerspruch, sondern auch die Feststellung, dass die Existenz jener Familien im Grunde genommen nichts an der rassistischen Praxis der Polizei ändert, leiten Lale zum Gedanken, ihr „Leben in Deutschland ab[zu] brechen“ und „irgendwo anders hin[zugehen], weil das geht hier nicht (2). “ Lale erreicht in diesen Erfahrungen ihre Grenzen, in denen sich (auch) eine Macht- und Perspektivlosigkeit ausdrückt, die der Rassismus hinterlassen kann. Dies zeigt, dass selbst die „Verfügbarkeit“ klassistischer Macht den Schmerz des Rassismus nicht gänzlich mildern kann.

\subsubsection{Die Verwendung zugänglicher Machtverhältnisse: \\ Klassismus + Sexismus}

Am Beispiel einer weiteren, ähnlich argumentierten Aussage möchte ich tiefer auf Funktionsweisen interdependenter Machtverhältnisse eingehen.

Um eine Erklärung für gesellschaftlich herrschende „Vorurteile“ gegen Muslime in Deutschland zu finden, erinnert sich Samet an die folgende Situation und berichtet:

„Wie gesagt, der Islam steht seit Jahren jetzt wieder im Mittelpunkt der Medien, hat man ja viele Negativbeispiele in den Medien gesehen. Oder was ich selber mal erlebt habe, wo ich dann mir nicht zusammenreimen konnte, was das Verhalten einer Frau sein sollte. Ich wollte zur Uni und hab auf den Zug gewartet, weil ich ja pendle, und da war eine Frau mit ihrer Tochter am 
Bahnhof (2), die sind halt Richtung Schienen gegangen und ich hab in die Richtung geguckt. Nicht, weil ich die angeguckt habe, weil der Zug aus der Richtung kam halt. [...] Die Frau hat mich dann komisch angeguckt, hat die Gesichtsseite zu mir verdeckt und ist komplett einmal über den Bahnhof gegangen und hat sich ganz am Ende des Bahnhofs gestellt, wo es nicht mehr weiterging. Wo ich dann mir dachte, was sollte das? Wo ich dann mir dachte, ja nur, weil ich Dings aussehe (2), ja: ausländisch aussehe oder hat sie irgendwas erlebt, was sie negativ beeinflusst hat. Aber was deutlich zu sehen war, dass es keine Frau war, die gebildet war, sag ich mal. Muss ich- man ehrlich sagen, das war so eine Frau so, sie war etwas kräftiger gebaut, hat auch nicht wirklich viel auf Hygiene geachtet, muss man ehrlich sagen. Sie hatte so ein T-Shirt, wo halt halb bauchfrei war, aber das war nicht jetzt beabsichtigt, sondern einfach nur zu kurzen T-Shirt ((unterdrücktes Lachen)). So einen alten Einkaufwagen hinter sich und so. Also ja, eher von der- würde man Menschen nach Klassen teilen, würde man sagen, eher von der unteren Klasse ((kurzes leises Gemurmel)). Wo man auch sagt- oder wo ich mir denken kann, dass sie vieles nicht selber nachrecherchiert oder nachschaut, und eher diese Menschen- durch diese Menschen, kommen diese Vorurteile oder diese Menschen haben besonders diese Vorurteile."

Samet ist sich sicher, dass das Verhalten der Frau auf seine äußere Erscheinung zurückzuführen ist („nur, weil ich [...] ausländisch aussehe“), sodass hier eine Form der "gendered nature of racial stereotypes“ (Ahmed 2011: 160) zum Vorschein tritt, die vor allem auf männliche rassifizierte Subjekte greifen: männlich, muslimisch, Macho und potenziell gefährlich.

Samet versucht zunächst verständnisvoll darauf einzugehen, weshalb die Frau ihr Gesicht auf die beschriebene demonstrative Art verdeckt habe und bettet ihr Verhalten in die eingangs erklärte Auffassung ein, dass der Islam „seit Jahren jetzt wieder im Mittelpunkt der Medien“ steht und man von den „viele[n] Negativbeispiele[n] in den Medien“ beeinflusst sein könne. Weiter versucht er zu erklären, sie habe vielleicht „irgendwas erlebt, was sie negativ beeinflusst hat“. Allerdings scheinen diese eher verträglichen Erklärungsansätze das Gefühl der erfahrenen Herabsetzung nicht zu beruhigen, sodass er auf Machtstrukturen zurückgreift, die ihm als männlichen Studenten zur Verfügung stehen: Am Äußeren der Frau, das Samet entlang sexistischer und klassistischer Normen be- und abwertet, sei „deutlich zu sehen [...], dass es keine Frau war, die gebildet war“, sodass er aufgrund dessen auf ihre Klassenzugehörigkeit schließt („eher von der unteren Klasse“).

Auch Samet (wie Lale) ist bewusst, dass seine Äußerung diskriminierend und „unfair“ ist. Dies zeigt sich bei ihm in der wiederholten Aussage „muss man ehrlich sagen“: Er weiß, dass es nicht in Ordnung ist, auf diese Weise über andere Personen zu sprechen, daher sucht er nach einer Legitimation, es trotzdem auszusprechen, nach dem Motto: „Die Wahrheit muss man ja sagen (dürfen)?!“ 
Mit ihrer Klassenzugehörigkeit zur „eher unteren Klasse“ disqualifiziert Samet die Qualität und Bedeutung ihres rassistischen Verhaltens, d. h. der eigene Klassenstatus zur (zukünftigen) Bildungsschicht wird hier in der Verhandlung um Rassismus dazu eingesetzt, rassistische Vorfälle als minderwertiges Verhalten der „unteren Klasse“ zu disqualifizieren. Auch in der Gruppe scheint diese Verhandlung um Rassismus Zustimmung zu finden, denn das kurze Gemurmel, das nach dieser Aussage in der Gruppe aufkommt, kann als ein „Aha-Gemurmel“ interpretiert werden, als erkläre die vermeintliche Klassenzugehörigkeit der Frau ihr rassistisches Verhalten. Mit ihrer Einordnung als Person der „unteren Klasse“ kommt in der Gruppe eine Art Erleichterung auf. Somit muss nicht mehr von Rassismus gesprochen werden. Die „Erkenntnis“ über ihren Klassenstatus bedarf keiner weiteren Erklärung, weil (nur) „diese Menschen besonders diese Vorurteile“ haben. Diese Verhandlung von Rassismus kommt der weiß-bürgerlich dominanten Gesellschaftsgruppe zugute, indem sie somit implizit „frei von Rassismus“ konstruiert wird. Hier werden die unterschiedlichen Dynamiken der Herrschaftsstabilisierung durch diese Herangehensweise deutlich.

Die Denk- und Handlungsmöglichkeiten, denen sich die Studierenden in dieser Verhandlung von Rassismus bedienen, sind bereits strukturell und institutionell angelegt. Sowohl Sexismus als auch Klassismus gehören neben Rassismus mit zu den strukturgebenden Verhältnissen in dieser Gesellschaft. Die vorliegenden Beispiele zeigen, wie diese Machtverhältnisse zueinanderstehen und gegeneinander verhandelt werden können, je nachdem, welche Machtstrukturen den Subjekten zugänglich sind bzw. gemacht werden. Damit bewegen sich die Studierenden in einem Komplex, der Widerstand erfordert, mit Widersprüchen verbunden ist und eine ständige Aushandlung verlangt. Insbesondere der Status „Studierende_r“ eröffnet den migrantisierten Studierenden Zugänge, die ihnen erlauben, sich immer wieder als Akteur_in der eigenen (von Rassismus durchzogenen) Lebensrealität zu generieren. Sie sind nicht lediglich „Opfer von Rassismus“, sondern Teil der herrschenden Verhältnisse und aktiv darin involviert, sodass der erfahrene Rassismus sie nicht ihrer Verantwortung entledigt. Analog dazu stellt bell hooks fest:

„Erst wenn schwarze Männer der Realität ins Auge sehen können, daß der Sexismus ihnen Macht gibt, trotz der Auswirkungen des Rassismus auf ihr Leben, wird es möglich sein, in einen sinnvollen Dialog über die Geschlechter einzusteigen. Hört man schwarze Männer über ihre gesellschaftliche Realität sprechen, so ist oft von Schikanen die Rede. [...] Das ist vergleichbar mit der Selbstwahrnehmung vieler privilegierter weißer Frauen in der weißen feministischen Bewegung, die so entschlossen waren, ein Bewußtsein dafür zu schaffen, wie sie innerhalb des Patriarchats zu Opfern wurden, daß sie keine komplexere Analyse ihrer Erfahrung akzeptieren konnten; eine solche Analyse hätte ihnen Formen von Macht gezeigt, die sie besitzen, auch wenn und während sie sexistisch ausgebeutet werden, nämlich Klassen- und ,Rassen`privilegien" (hooks 1996: 114f.). 


\subsection{Zwischenfazit}

Alle drei vorgestellten Verhandlungsweisen von Rassismus, die (Nicht)Thematisierungsweisen, die Position als Anderes sowie die Verwendung zugänglicher Machtverhältnisse sind durch eine indirekte Passivität der Studierenden gekennzeichnet. Sie sind nicht direkt passiv, weil sie innerhalb der rassistischen Formationen handeln und Strategien entwickeln, um Rassismus zu verhandeln. Allerdings finden die Verhandlungen primär innerhalb rassistisch vorgegebener Bedingungen, beispielsweise innerhalb des rassistischen Integrationskonzepts statt. Sie setzten nicht den Rahmen ihrer Verhandlung, indem sie z. B. das Konzept der Integration infrage stellen, sondern sie nehmen den Rahmen als bereits gesetzt an. An dieser Stelle erhält der Status „Studierende_r" eine zentrale Bedeutung: Welchen Einfluss hat der Status auf die indirekt passive Verhandlung von Rassismus?

Ist nun das Fazit, dass der Status "Studierende_r" Widerstand schwächt und Anpassung fördert? Nein. Insbesondere das Studium bzw. der Status kann Möglichkeiten des Intervenierens und Zugänge zu Sprecher_innenpositionen eröffnen. Allerdings ist eine kritische Haltung und ein kritisch-reflektiertes Bewusstsein für herrschende Machtverhältnisse eine wichtige Voraussetzung, um sich mit den gegebenen Privilegien in gesellschafts-politische Transformationen einbringen zu können. Um nicht nur die individuelle Verantwortung anzurufen, muss an dieser Stelle zudem vor allem die Rolle und Verantwortung der Universität als Institution hervorgehoben werden. 


\section{Der Status Studierende_r}

Die im vorangegangenen Kapitel analysierten Verhandlungsweisen von Rassismus sind meines Erachtens zentral mit dem Status der Subjekte als Studierende verknüpft. Das gesamte Material ist durch diesen Status geprägt und spielt in allen bereits angebrachten Beispielen eine grundlegende Rolle. Deshalb ist es notwendig, sich im Weiteren genauer mit diesem Faktor zu befassen. Dabei wird zunächst auf ermächtigende bzw. ermöglichende Aspekte des Status „Studierende_r“ für rassifizierte Subjekte eingegangen. Welche Zugänge eröffnet dieser Status und welchen Einfluss hat dies für die Gesprächsteilnehmenden auf ihre Rassismuserfahrungen?

Im Anschluss daran werden neben den Möglichkeiten des Status „Studierende_r“ auch die Grenzen und insbesondere Einschränkungen beleuchtet, die damit für rassifizierte Studierende ebenfalls einhergehen (können).

Abschließend soll in diesem Kapitel die Frage nach der politischen Repräsentationsaufgabe diskutiert werden: Welche Chancen, aber auch Fallstricke beinhaltet die Idee von Studierenden als „legitime“ Vertreter_innen von minorisierten Gruppen? 


\subsection{Der Status Studierende_r und Ermächtigung}

Der Status „Studierende_r" wird mittlerweile in der öffentlichen Wahrnehmung häufig mit Erfolg, Fleiß, Strebsamkeit und Intellekt assoziiert. Er eröffnet potenziell eine beruflich erfolgreiche(re) Perspektive und genießt insgesamt hohe gesellschaftliche Anerkennung. Dies bestätigt sich im Wesentlichen auch für die Teilnehmenden der Gruppengespräche, die sich, wie bereits im Kapitel 4.3 aufgezeigt, zum großen Teil mit ihren jeweiligen Fächern und der Zugehörigkeit zum akademischen Kreis identifizieren. Lale erklärt:

„Im Gesamten ist der Status ,Studentsein` sehr cool. Und die Anerkennung, die man bekommt, die genießt man auch. Ist so. Ah, du studierst, schön. Es ist eine schöne Anerkennung. Mal Lob ist auch angenehm, tut auch mal dem Ego ganz gut ((lacht)) und ja, es ist schön. Ich empfehle es jedem."

Das Studieren an sich garantiert unabhängig von der Fachrichtung oder den (erbrachten) Leitungen bereits eine Form der gesellschaftlichen Anerkennung, die insbesondere für rassifizierte Subjekte einen Zugang zu gesellschaftlichen Ressourcen in Aussicht stellt: Inklusion über Leistungsideologie. Damit eröffnet der Status "Studierende_r" den Subjekten Momente der Ermächtigung - auch oder gerade innerhalb einer rassistisch geprägten Struktur. Hafez, der als Hauptschüler auch die klassistische Seite der rassistischen Ordnung erlebt hat, ist der Auffassung:

„Für die [Deutschen] sind das halt einfach Ausländer und die können einfach schwer damit umgehen, dass ein Schwarzkopf auch studiert und intellektuell einem Deutschen überlegen ist. Die kommen damit nicht so klar."

Hafez beschreibt, dass das vorherrschende Bild von rassifizierten Personen in Deutschland der von „Bildungsverlierer_innen“ ist, d. h., „Ausländer“ könnten dieser Vorstellung zufolge nicht in einer bildungserfolgreicheren Position sein. Er erlebt das Studium deshalb als eine Möglichkeit, aus dieser rassistischen Anordnung auszubrechen und sich über die reduzierenden Bilder zu erheben: Das Studium bestätige seine intellektuelle „Überlegenheit“, sodass er darüber seiner sozial untergeordneten Position als rassifizierter Hauptschüler widersprechen kann. Dies stehe jedoch im Gegensatz zum hegemonialen rassistischen Diskurs über „die Ausländer“, sodass er sich in seiner Rolle als Student zum einen verpflichtet und zum anderen aber auch fähig sieht, strukturelle Veränderungen im Bewusstsein einzelner („Deutsche") herbeizuführen:

„Und deshalb denke ich, dass es einfach für uns als Studenten wichtig ist, weil wir gerade dieses Denken, dieses Strukturdenken bei vielen Deutschen verändern können. Dass wir einfach nicht mit diesen Klischees behaftet sind. [...] Ich finde als Student- wichtig ist halt nur, [...] dass wir verstanden haben, dass dieses Konzept [der Integration; Anm. K. P.] auch fehlerhaft ist, dass diese Erwartungen, die an uns gestellt werden, oft falsch sind und dass wir auch da diesbezüglich- weil wir auch die rechtlichen und gesetzlichen Wege 
kennen, weil wir auch wissen, wie das abläuft. Mein Vater hätte sich niemals beschwert, wenn er Opfer von Diskriminierung geworden wäre. Der hätte sich niemals beschwert. [...] Der hätte sich das irgendwie zurechtgeredet. [...] ((lachend)) Aber ich reagiere da ganz anders oder wie du schon gesagt hast, wir kontern, wir stellen auch die Leute bloß, die so denken, und blamieren sie auch offen und sagen, ja das ist scheiße, wie ihr seid. Und das ist halt einfach eine ganz andere Haltung, eine In-die-Fresse-Haltung, ((lachend)) die einfach auch für die Deutschen vielleicht neu ist (2) Und deshalb, wie gesagt, das muss auch einfach sachlich und (3) souverän und neutral bleiben. Aber [...] es muss sich einfach was verändern, wenn die nächste Generation hier besser leben will als wir."

Hafez betont und ruft implizit dazu auf, das Konzept von Integration und damit einhergehende Erwartungen an sie als Studierende kritisch zu hinterfragen, da diese „oft falsch“ seien. Seine Legitimation zieht er aus der Tatsache, dass er Student ist („für uns als Studenten“). Über den Zugang zum Wissen über die „rechtlichen und gesetzlichen Wege“, die ihnen als Studierende offen stünden, sieht sich Hafez ermächtigt „zu kontern“, „die Leute bloß[zustellen], die so [rassistisch] denken“, „sie auch offen [zu blamieren] “ und ihnen zu sagen, dass es „scheiße [ist], wie ihr seid“. Als Studierende, die „auch wissen, wie das abläuft“, sieht er sich und auch seine Kommilitonen in einer (privilegierten) Position, sich eine Stimme zu verschaffen, gehört zu werden, Forderungen zu stellen und Kritik an gesellschaftliche Verhältnisse auszuüben, um damit eine Veränderung in der Denkweise über „die Ausländer“ zu realisieren. Diese Sequenz eröffnet einen tiefen Einblick in die Handlungs- und Möglichkeitsräume, die rassifizierte Subjekte für sich über ihren Status als Studierende sehen und erkennen.

Interessant ist jedoch, dass Hafez selbst seine Aussage zum Schluss an Voraussetzungen knüpft: Nur „sachlich, souverän und neutral“ könnten die Umstände angegangen werden und benennt damit Normen, Ansprüche und Eigenschaften, die dem Status als Studierende_r unabdingbar sind. So geht die Position nicht nur mit Ermächtigung einher, sondern fordert im Gegenzug auch die Einhaltung bestimmter „ungeschriebener Regeln“, sodass rassifizierte Subjekte einer bestimmten Norm entsprechen müssen, um die Privilegien des Status „Studierende_r“ für sich in Anspruch zu nehmen. Zudem sind die Privilegien und die gesellschaftliche Anerkennung dieses Status innerhalb einer „Konkurrenz- und Leistungsgesellschaft“ (Messerschmidt 2010: 48) auch stets an hohe Belastung und Druck geknüpft. Rabia verdeutlicht dies im Folgenden:

„Von außen hin ist es auf jeden Fall so, [...] dass man dann schon das Gefühl bekommt, dass man jetzt, keine Ahnung, als angehende Akademikerin oder als angehende Ärztin sozusagen ein Image dann später hat. Also das hört man dann, wenn man das in der Familie oder so etwas erzählt. Also das stört mich schon, dann kommt so ein gewisser Druck von außen oder Erwartung an einen." 
Für rassifizierte Studierende kommt neben dem allgemeinen Druck, der tendenziell auf einen Großteil von ihnen lastet, zusätzlich der Faktor hinzu, nicht nur für sich zu stehen bzw. zu studieren, sondern auch stets repräsentativ für die „eigene Gruppe“ zu sein (vgl. hooks 1989: 60). Jedoch kann in diesem Kontext die eigene Repräsentation für die Gruppe auch mit Ermächtigung einhergehen, da der eigenen Position eine Möglichkeit zukommt, rassistische Bilder zu entkräften, wie Samet erklärt:

„Wir sind ein Modell dafür, dass wir bewiesen haben, dass es nicht so ist, was immer die Deutschen denken, ja: Die Ausländer werden eh kein Abschluss machen. Das war ja so eine Zeit lang immer ein Klischee, 70 \% der Ausländer haben nur einen Hauptschulabschluss. Und obwohl sich auch immer mehr zeigt, dass die Leute, die studieren, meistens ja Menschen mit Migrationshintergrund sind, hat man immer noch dieses Vorurteil."

Samet betrachtet seine eigenen Leistungen nicht nur für sich selbst, sondern weiß, dass er in seinem Status Student als ein „Modell“ für die Gruppe der „Ausländer“ betrachtet werden kann. Seine Aussage verdeutlicht die Beweislast, unter der diese Gruppe in der Dominanzgesellschaft steht, sodass sie sich ungeachtet von möglichen Veränderungen stets profilieren muss (vgl. Velho 2010: 121). Innerhalb dieser rassistischen Logik scheint sich eine Notwendigkeit zu entwickeln, gegen bestehende „Vorurteile“ für die Gruppe einzustehen und sie zu verteidigen.

Es wird deutlich, dass der Status "Studierende_r" für rassifizierte Subjekte in komplexe Dynamiken und Prozessen eingebunden ist. Einerseits kann er Zugang zu gesellschaftlichen Ressourcen, Anerkennung sowie Teilhabe an Machtstrukturen eröffnen bzw. begünstigen. Der Status schafft dominante Identifikationsmöglichkeiten. Andererseits stehen ihnen diese Privilegien nicht ohne Bedingungen zu, sondern können nur unter Erfüllung gewisser Voraussetzungen in Anspruch genommen werden. Diese sollen im Weiteren näher beleuchtet werden.

\subsection{Bedingungen der Ermächtigung}

Migrantisierte bzw. rassifizierte Studierende werden im öffentlichen und hegemonialen Diskurs gerne als Vorzeigeexemplar für "Integration“ herangezogen. Im Zuge der Sarrazindebatte kamen ihnen als „bildungserfolgreiche“ Repräsentant_innen eine besondere Aufmerksamkeit zu. Ihre Aufgabe war es, das „gelungene“ Gegenstück zu den rassistischen Thesen darzustellen. Auf diese Weise wurde die gesellschaftlich anerkannte Position von rassifizierten Studierenden bzw. Akademiker_innen instrumentalisiert, um die Defizite der „anderen“ Anderen hervorzuheben. Die Herausstellung der Lebensrealitäten einzelner rassifizierter Personen, die „es geschafft“ haben, ermöglicht es, rassistisch-klassistische Strukturen und Normalitäten der Gesellschaft zu relativieren und stattdessen auf individuelle Verantwortung und Leistungen zu verweisen. Hier- 
bei erweitert sich die biologistische bzw. kulturalistische Legitimation von Rassismus durch Leistungsideologie (vgl. Friedrich 2011: 27).

Im Hinblick auf die o. g. potenzielle Funktionalität bzw. Instrumentalisierung des akademischen Status von rassifizierten Subjekten zeichnen sich dessen Bedingungen und Grenzen ab. Der Möglichkeitsraum für rassifizierte Studierende ist auf das „Integrationsdispositiv“ beschränkt, d. h. das Handeln, Sprechen und Entscheiden ist durch diffuse, aber wirkmächtige Integrations(an)forderungen gerahmt. Einerseits bestehen konkrete Vorstellungen, unter welchen Umständen Integration "gelungen“ sein kann, andererseits sind weder Grenzen noch ein Ende dieser (An)Forderungen an rassifizierte und kulturalisierte Subjekte formuliert. Dies kann bei Adressierten Unsicherheit, Widerstand und/oder Widerwillen auslösen. Metin führt aus:

„Ich finde halt, es kann von der Gesellschaft nicht vorausgesetzt werden, dass man [als Muslim] genauso sein muss wie die anderen [Nichtmuslime]. Und genau das wird halt beim Thema Integration falsch gemacht, finde ich. Weil, wenn einer perfekt deutsch spricht und hier auch zur Uni geht und auch Teil der Gesellschaft ist- selbst, wenn er schon Abitur gemacht hat, gehört er ja zur Bildungselite von Deutschland. Und es gibt auch viele Muslime die- oder Andersgläubige [...], die auch zum Wohl des Landes beitragen. Und deswegen finde ich, wie gesagt, dass das an der Integration falsch gemacht wird. Das Bild von Integration müsste sich in der Gesellschaft ändern.“

Die konkrete Vorstellung von Integration ist für Metin durch die „perfekte“ Beherrschung der deutschen Sprache sowie einen hohen Bildungsabschluss erfüllt, die im Gesamten einen verwertbaren Nutzen für das „Wohl des Landes“ haben sollten. Seine Denkweise spiegelt einen hegemonialen (Integrations)Diskurs wider (vgl. Friedrich/Schultes 2011: 84), von dem er glaubt, ihn im Rahmen seiner Position als Student auch gerecht zu werden. Gleichzeitig sieht er jedoch auch, dass dies nicht zu genügen scheint, sondern vielmehr eine Assimilation gefordert ist („dass man genauso sein muss wie die anderen“), und kritisiert diesbezüglich „das Bild von Integration“. Demnach übt Metin keine Kritik am rassistischen Konzept von Integration, sondern an der Verwehrung seiner vollwertigen Anerkennung und Zugehörigkeit zur „Bildungselite“.

Die Politolog_innen Maria do Mar Castro Varela und Nikita Dhawan beschreiben Integrationsdiskurse als „gewalttätige Diskurse. Sie stabilisieren die üblichen Bilderwelten und klinken sich so in einen Herrschaftsdiskurs ein, der bestimmt, wer dazugehört, wer nicht und wer eventuell dazu gehören darf, wenn er/sie sich Mühe gibt“ (Castro Varela/Dhawan 2007: 31). Studierende werden in diesem Herrschaftsverhältnis zu denen gezählt, die aufgrund ihrer Bemühungen potenziell „dazugehören“ dürfen. Auf die Frage, was der Status „Studierende_r“ für sie bedeute und was für sie damit zusammenhänge, wird in beiden Gruppengesprächen ein überwiegend einheitlich harmonisches Bild von Studierenden und der studentischen Lebensphase entworfen. Sehr zugespitzt und klar formuliert es Aslan an folgender Stelle: 
„Und wir haben schon ganz am Anfang gesagt, Studenten sind toleranter und deswegen gibt es weniger Diskriminierung oder die Menschen sind offener. (2) Das entsteht einfach auch durch den ganzen Kontakt, weil man halt einfach viel miteinander zu tun hat. Alle wollen studieren, alle setzen sich in die Vorlesung und dann tauschen sie sich aus und gehen zusammen mensen und so weiter und lernen sich kennen. Das trägt auch dazu bei [dass es keine Diskriminierung unter Studierenden gibt; Anm. K. P.].“

Die harmonische Imagination von Studierenden, der Phase des Studiums sowie der Hochschule als diskriminierungsfreiem Raum vereinfacht das inkludiert_Sein bzw. die Zugehörigkeit zum akademischen Raum. Gleichzeitig setzen diese auch die Grenzen der Wahrnehmungs- und Handlungsmöglichkeiten fest. Hinsichtlich der Verhandlung(sweisen) von Rassismus bedeutet dies beispielsweise die (Fortsetzung der) Dethematisierung von Rassismus, da das Sprechen von Rassismus nicht nur als Bedrohung für die o. g. imaginierte Harmonie im akademischen Raum gelten kann, sondern auch für das eigene inkludiert_Sein darin.

Rassifizierte Studierende befinden sich somit oft vor der Herausforderung, einen Spagat in drei Richtungen machen zu müssen: zwischen den Bemühungen um Integrations(an)forderungen, die eine Voraussetzung für die Inklusion im akademischen System darstellen, einer simultanen Kritik an den gesonderten (An)Forderungen sowie der Aushandlung von rassistischen Erfahrungen im Rahmen jener (An) Forderungen.

Gleichzeitig lässt eben dieser offenbar gelingende Balanceakt rassifizierte Studierende als Politikum interessant erscheinen. Sie erfüllen normative Voraussetzungen eines „gut integrierten“ Subjekts, sodass die Frage nach der Aufgabe einer politischen Repräsentation auf struktureller sowie individueller Ebene zentral wird. Im Folgenden sollen Chancen und Fallstricke einer solchen Repräsentationsaufgabe diskutiert werden.

\subsection{Die Frage nach der politischen Repräsentation}

Das Feld der politischen Repräsentation bildet bestehende Machtverhältnisse einer Gesellschaft ab (vgl. Mecheril 2007: 11). Wer fühlt sich repräsentiert, wenn er/sie Nachrichten liest oder das Fernsehprogramm durchgeht? Wer findet sich in welchen Rollen und Positionen wiedergegeben und vertreten? Wer sieht ihre/seine Themen berücksichtigt? Wer spricht in politischen Talksendungen? Über wen wird gesprochen? Wer kann sich selbst darstellen, wer wird dargestellt?

Im Generellen ist das aktuelle Feld der Repräsentation in Deutschland überwiegend homogen und hegemonial bestimmt, worin Alternativ- und/oder Minderheitspositionen in jeglicher Hinsicht selten vertreten sind, da „[i]hnen nicht der (kulturelle) Status zu[kommt], legitime Vertreter Deutschlands zu sein“ (ebd.). 
Jedoch wird der Einbezug jener Positionen im Zuge sozialpolitischer Auseinandersetzungen immer wieder notwendig. Dabei wird in der Regel eine feine „Auslese“ der Minderheitspositionen vorgenommen: „Nicht jedem und jeder wird es gleichermaßen zugestanden, bestimmte Lebensformen zu repräsentieren. Es gibt anerkannte und weniger oder gar nicht anerkannte Lebensformen" (ebd.: 10). Folglich geht ",[d]ie Anerkennung als Subjekt der Repräsentation unweigerlich voraus" (Castro Varela/Dhawan 2007: 32).

In den Gruppengesprächen verwiesen die Teilnehmenden, wie hier Hafez, an verschiedenen Stellen auf die Eignung ihrer sozialen Position für die politische Repräsentation „ihrer Gruppe“:

„Viele Ausländer wissen, die werden in Deutschland niemals irgendwas werden, und das ist so ein Teufelskreis, der sich dreht. Daran können wir glaube ich- daran müssen wir etwas ändern, weil wir eben diese Generation sind, die diese Verantwortung haben. Wir sind ja genau an dieser Brücke es zu verändern ((leichtes Schmunzeln zu hören)). Ja, [...] ich denke es muss schon größere politische Verbände von Ausländern und Muslimen geben, die da irgendwas politisch und wirtschaftlich bewegen. Und nicht die ganze Zeit irgendwelche islamischen Gemeinden, wie- was weiß ich, was diese ganzen Gemeinden sind, die überall eingeladen werden: bei Maischberger und Maybrit Illner ((lacht)), die uns vertreten und einen totalen Scheiß reden und uns gar nicht repräsentieren. Ich finde, wir Studenten müssen da versuchen irgendwas zu- das klingt jetzt sehr revolutionär ((Lachen)), aber ganz ehrlich, wenn du da- das ist unsere Aufgabe einfach. Studierende Menschen, studierende Ausländer, dass die da zusammenhalten und versuchen etwas zu verändern."

Hafez sieht sich, seine Gesprächspartner und möglicherweise darüber hinaus weitere Personen, die seine soziale Stellung teilen, in einer verpflichtenden Verantwortung, den „Teufelskreis“, in dem sich viele rassifizierte Subjekte befinden, zu unterbrechen und die gesellschaftlichen Verhältnisse mithilfe „größere[r] politische[r] Verbände von Ausländern und Muslimen" zu verändern. Er bemängelt - zu Recht - die derzeitigen Repräsentationsverhältnisse in Deutschland und fühlt sich „gar nicht repräsentier[t]". Sebastian Friedrich und Hanna Schultes arbeiten in diesem Zusammenhang heraus:

„Die gegenwärtigen Repräsentationsformen von Migrant_innen sind geprägt durch ein Gebilde aus herrschendem Integrationsparadigma, der Negierung und Unsichtbarkeit rassistischer Strukturen und Regierung im Sinne einer leistungsorientierten Selbstdisziplinierung bei gleichzeitiger Kontrolle durch Instanzen der Mehrheitsgesellschaft“" (Friedrich/Schultes 2011: 93).

Hafez ist der Auffassung, dass sie als „studierende Menschen, studierende Ausländer" dies verändern müssten. Aus verschiedenen Gründen liegt es nahe, Studierende in der Repräsentationsfunktion einzusetzen. Zum einen haben sie innerhalb der rassifizierten Gruppe aufgrund ihrer gesellschaftlich anerkannten Position am ehesten 
eine Chance, zu Wort zu kommen und (unter bestimmten Bedingungen) gehört zu werden. In diesem (potenziell) emanzipativen Akt des „Für-sich-selbst-Sprechens“ bestünde zum Beispiel die Möglichkeit auf soziale Missstände, die (nicht nur) ihre Lebensrealität betrifft, aufmerksam zu machen. Zum anderen hätten sie die Gelegenheit, das vorherrschende rassistische Bild entlang sarrazinischer Thesen über kulturalisierte und rassifizierte Subjekte zu entkräften.

Das Problem der (Selbst)Repräsentation ist jedoch gerade an der Idee einer „authentischen Stimme“ geknüpft, denn „[w]er spricht wann und wo mit welcher Legitimation und mit welchem Effekt über wen?" (Mecheril 2007: 23). Die Idee, Studierende als „legitime Vertretung " mit der Aufgabe der "richtigen Darstellung“ (ebd.) in die Welt hinauszuschicken, läuft Gefahr, den rassistisch-klassistischen Diskurs von „guten, integrierten und verwertbaren“ sowie „schlechten, integrierunfähigen und unnützen" Anderen zu reproduzieren:

„Das Zulassen einiger Wenigen [...] ermöglicht dabei den weiteren konstanten Ausschluss der Mehrheit der Minorisierten. Repräsentation ist immer auch Interpretation. Aus diesem Grund ist es wichtig, den Fokus darauf zu richten, wer die Aufgabe des Interpretierens übernommen hat. [...] Das Zentrum, so Spivak, erlaubt einigen auserwählten RepräsentantInnen am Spiel der Macht teilzuhaben, damit eine effektivere Ausgrenzung der Anderen möglich wird" (Castro Varela/Dhawan 2007: 41f.).

Außerdem ist auch zu bedenken, dass „das Sprechen der Einen durch das Schweigen der Anderen erst ermöglicht wird" (ebd.: 44).

Es kann festgehalten werden, dass es die endgültig richtige Repräsentationsform nicht gibt und nicht geben kann, da selbst alternative Repräsentationsformen machtproduktiv sein können. Die politische Frage der Repräsentation ist komplex und gar eine "Unmöglichkeit" (Castro Varela/Dhawan 2007: 31), deshalb muss die „Daueraufgabe einer Kritik der Repräsentationsverhältnisse“ (Mecheril 2007: 23) als Bedingung (voraus)gesetzt sein. Die Vermeidung bzw. Ausweichung von Repräsentation kann keine Konsequenz darstellen, da der Anspruch einer Herrschaftskritik ohne minorisierte Stimmen nicht aufgehen kann. Die Autor_innen Castro Varela und Dhawan schlagen als Ausweg den „strategischen Essentialismus“ nach Spivak vor:

„Dieser ermöglicht es über und für eine minorisierte Gruppe zu sprechen, diese zu repräsentieren, obschon die Fallen dieser Repräsentation offenkundig sind. [...] Eine der größten Herausforderungen liegt deshalb in der effektvollen Problematisierung der Kategorien selbst, die unhinterfragt als Instrumente der Kritik fungieren" (Castro Varela/Dhawan 2007: 32).

Demnach kann rassifizierten Studierenden sogar eine gewisse Verantwortung aufgrund ihrer (beschränkt) privilegierten Position zukommen, sozial benachteiligte(re) n Gruppen durch Repräsentation Gehör zu verschaffen. Dies setzt jedoch ein kritisches Bewusstsein sowie eine kritische Haltung bestehenden Machtverhältnissen 
gegenüber voraus. Dementsprechend ist auch eine kritische (Selbst)Reflexion der eigenen Verstrickung in jenen Verhältnissen unabdingbar, um sich nicht am „Spiel der Macht" zu beteiligen, sondern dieses anzuklagen und neue Forderungen für eine andere Zukunft zu stellen.

\subsection{Zwischenfazit}

Die soziale Position als Studierende_r beeinflusst zentral Rassismuserfahrungen sowie deren Verhandlung. Durch (partiellen) Zugang zu Ressourcen und Teilhabe an (anderen) Machtstrukturen bietet der Status dominante Identifikationsmöglichkeiten, die das (Ver)Handlungsfeld im Umgang mit Rassismus erweitern können. Jedoch steht der Zugang zu Machtstrukturen und den damit einhergehenden Privilegien für rassifizierte Studierende nicht bedingungslos zur Verfügung. Die Position als Studierende_r formuliert also nicht nur Möglichkeiten, sondern gleichzeitig auch Grenzen des Handlungsraums für rassifizierte Studierende. Die Grenzen sind durch rassistische Integrationsparadigmen gerahmt. Dabei stellt es für viele der Gesprächsteilnehmenden keine Schwierigkeit dar, sich innerhalb dieser Grenzen zu bewegen und damit den Integrations(an)forderungen zu entsprechen bzw. ihnen gerecht zu werden. Die Grenzen werden dennoch benannt und auch kritisiert.

Die Aushandlung eigener Möglichkeitsräume innerhalb rassistisch gesetzter Grenzen lässt Studierende für die Frage der politischen Repräsentation interessant erscheinen: Sind bzw. sollten Studierende „legitime“ Vertreter_innen für minorisierte Gruppen sein? Hierbei zeigte sich, dass ein kritischer Umgang mit Repräsentationsverhältnissen eine Herausforderung darstellt, die jedoch als Daueraufgabe einer kritischen Auseinandersetzung mit Machtverhältnissen möglich und notwendig ist. Unter diesen Voraussetzungen kann die Aufgabe von Repräsentation auch eine Verantwortung von (minorisierten) Studierenden sein, aus ihrer (partiell) privilegierten Position heraus rassistische Bilder zu entkräften und Kritik an bestehende gesellschaftliche Zustände zu formulieren. 



\section{Fazit und Ausblick}

Die Analysen des Materials zeigen insgesamt auf, wie komplex, facettenreich und dynamisch sowohl die Erscheinungsformen, die Erfahrungen als auch die Auswirkungen von Rassismus sein können. Dies kann u. a. ein Grund dafür sein, weshalb unterschiedliche Auffassungen und Vorstellungen von dem, was Rassismus ist, in der deutschen Öffentlichkeit kursieren. Ein fehlendes Grundverständnis davon, was Rassismus ist bzw. dass Rassismus nicht nur ein historisch abgeschlossenes Ereignis darstellt, sondern Normalität und strukturelles Machtverhältnis ist, führen dazu, dass eine öffentliche Sprechbarmachung bzw. kritische Thematisierung weitgehend nicht existent sind.

Die strukturell fehlenden Möglichkeiten, Rassismus zu begreifen und zu benennen, prägen in einem besonderen Ausmaß die Lebensrealitäten derjenigen, die im Alltag davon betroffen sind. Die Gruppengespräche bezeugen nicht nur die Schwierigkeiten, Rassismus in der deutschen Gesellschaft, sondern auch sich selbst zu benennen. Für sie bestehen in der deutschen Sprache keine geeigneten Begriffe, mit denen sie sich identifizieren und positiv benennen könnten. Eine gesellschaftspolitische Auseinandersetzung mit einer geeigneten Bezeichnungspraxis steht derzeit noch aus. Die Auswirkungen rassistischer Verhältnisse und Normalitäten zeigen sich darin in deutlicher Form.

Diese gesellschaftlichen Normalitäten des Nichtumgangs mit Rassismus sowie mit den Lebensrealitäten derer, die davon betroffen sind, setzen sich im univer- 
sitären Kontext fort. Hier konnte nachgezeichnet werden, dass (subtilere Formen des) Rassismus trotz seiner Verstrickung an der Hochschule nicht thematisiert oder benannt werden. Diese Formen des Rassismus erlauben Rassismus_Betroffenen ein Gefühl der (begrenzten) Zugehörigkeit, das in der Konsequenz das Ignorieren von rassistischen Erlebnissen erfordert und damit eine (Re)Produktion und Stabilisierung von rassistischen Verhältnissen bedeutet. Anstelle einer aktiven Kritik und Auseinandersetzung mit Rassismus bestehen akademische Wege, wie beispielsweise im Rahmen des Diversity-Managements, Rassismus zu verschieben und unsichtbar zu machen.

Rassifizierte Studierende verhandeln dementsprechend Rassismus sowie ihre Erfahrungen damit entlang dieser gesellschaftlich-strukturellen und institutionellen Linie. So sind beispielsweise in den studentischen Verhandlungsweisen verschiedene, paradoxe (De)Thematisierungsweisen vorherrschend: Einerseits erleben und berichten sie von Rassismus(erfahrungen), andererseits verneinen und relativieren sie Rassismus als Begriff und Erklärung dafür.

Aus den Gruppengesprächen wird ersichtlich, dass die unterschiedlichen Verhandlungsweisen von Rassismus (die (De)Thematisierungsweisen, die Verhandlung der Position als Anderes sowie die Verwendung ihnen zugänglicher Machtverhältnisse) primär im Rahmen rassistischer Bedingungen und Verhältnisse stattfinden. So stellen die Studierenden beispielsweise das Konzept von Integration nicht als rassistische Praxis in Frage, sondern sind im Gegenteil zunächst um Erfüllung dieser Erwartungen im Rahmen ihrer Position als Andere bemüht. Lediglich unter Nichteinhaltung von Integrationsversprechungen wird die fehlende Gleichbehandlung kritisiert.

Der Status als Studierende_r spielt in den studentischen Verhandlungsweisen von Rassismus eine zentrale Rolle. Einerseits eröffnet er über eine (limitierte) Inklusion in den akademischen Raum u. a. weitere Verhandlungsmöglichkeiten von Rassismus, hier beispielsweise den Rückgriff auf ihnen zugängliche Machtverhältnisse wie Klassismus. Andererseits kann dieser Status auch Grenzen in der (kritischen) Verhandlung von Rassismus setzen, indem das Sprechen davon beispielsweise institutionell tabuisiert ist und sie aufgrund ihres inkludiert_Seins dieser Linie (un) bewusst folgen. Ihre rassifizierte Position in der Gesellschaft verwehrt ihnen letztendlich eine vollwertige Inklusion, sodass sie innerhalb einer rassistisch organisierten Gesellschaft schließlich Exkludierte bleiben.

Um diese Verhältnisse und die eigene Verstrickung darin als rassifiziertes Subjekt begreifen zu können, erfordert es eine aktive kritische Auseinandersetzung mit Rassismus, seinen Funktionsweisen und Interdependenzen mit weiteren Machtverhältnissen. Grada Kilomba argumentiert mit bell hooks, dass die Auseinandersetzung mit Machtverhältnissen die Voraussetzung dafür ist, sich selbst (neu) zu entwerfen:

„This process of inventing oneself anew, argues bell hooks, emerges as one comes to understand how: structures of domination work in one's own life, as one develops critical thinking and critical consciousness, as one invents new 
alternative habits of being [...]' (hooks: 1990: 15). It is the understanding and the study of one's own marginality that creates the possibility of emanating as a new subject" (Kilomba 2013: 36).

Entlang der eigenen Ansprüche der Universität Göttingen, das „analytische Denkvermögen [der Studierenden] zu fördern sowie ihnen Freiraum für Kreativität zu geben" ${ }^{26}$, ist es ihre verpflichtende Aufgabe und Verantwortung die Tabuisierung und Dethematisierung um Rassismus zu brechen. Die Hochschule bildet für (rassifizierte) Studierende einen zentralen Rahmen, innerhalb dessen sie sich (neu) und rassismuskritisch entwickeln können, sodass sich hier mit besonderer Dringlichkeit der Bedarf nach einem strukturellen Umbau der Institution Universität abzeichnet.

Zunächst bedarf es beispielsweise einer klaren Stellungnahme zum aktuell sehr offen gelebten Rassismus in der deutschen Gesellschaft. Statt von „ethnische[r], kulturelle[r] und religiöse[r] Benachteiligung“ und „Fremdenfeindlichkeit“ zu sprechen, wäre ein erster Schritt, das Problem beim Namen zu nennen und konkret von Rassismus zu sprechen. Im Weiteren müssen u. a. institutionalisierte Räume geschaffen werden, in denen eine kritische Wissensproduktion um Rassismus erfolgen kann, beispielsweise, indem Rassismusforschung im Rahmen eines Studiengangs institutionalisiert wird. Eine kritische Auseinandersetzung mit Rassismus müsste zudem interdisziplinär in Lehre und Forschung Eingang finden. Grundlagen- bzw. Einführungsmodule zur Geschichte, Kontinuitäten und Gegenwart von Rassismus müssten entsprechend in allen Fächern angeboten werden. Insbesondere Fächer wie die Islamwissenschaften (ursprünglich: Orientalistik ${ }^{27}$ ), Turkologie, Indologie oder Iranistik ebenso wie die Ethnologie, die allesamt auf kolonialistische Ursprünge zurückblicken, sind zu einer aktiveren Auseinandersetzung um den immanenten Rassismus innerhalb der Disziplinen aufgefordert.

Darüber hinaus wären Anwerbung und Einstellung Schwarzer und migrantischer Forscher_innen und Professor_innen erforderlich, um deren Perspektiven sowie Mitwirkung an der Wissensproduktion zu stärken. Dies würde rassifizierten Studierenden zumindest die Möglichkeit eröffnen, nicht durchgehend durch den weißen Blick an der Universität betrachtet und geandert zu werden. Zudem würde auch die Wissensproduktion nicht mehr überwiegend aus einer weißen, hegemonialen Perspektive und Erfahrungswelt betrieben, sie würde vielmehr ebenso marginalisierte Positionen zulassen, die sodann Selbstverständnisse und Sichtweisen der Institution Hochschule sowie der Dominanzgesellschaft infrage stellen könnten.

Angesichts neoliberaler Tendenzen und Entwicklungen der Hochschulen zu einer weiteren „Haltestelle“ der (bloßen) Produktion von (elitärer) Arbeitskraft, ist

26 Unter: http://www.uni-goettingen.de/de/505393.html (03.09.2015).

27 Bezüglich der kolonialen Vergangenheit dieser Disziplin konstatieren Castro Varela und Dhawan: „Das, Wissen' über den Orient diente dabei insbesondere der Legitimierung von Gewalt und Herrschaft. Einerseits wurde der Orient durch Europa erst geschaffen, anderseits wurde dieses akademisch informierten, Wissens' zur kolonialen Herrschaftsstabilisierung genutzt. Wissen und Macht greifen hier ineinander" (Castro Varela/Dhawan 2007: 36). 
mit ihr ein zentraler Ort der Entstehung und Vermittlung von Kritik im foucaultschen Sinne „als die Kunst, nicht dermaßen regiert zu werden“ (Foucault 1992: 12, zit. in Leiprecht u. a. 2009: 9) bedroht und muss wieder stärker in ihrer Aufgabe und als ein Ort der kritischen Wissensvermittlung angerufen werden. Die Universität muss reflektierter und kritischer mit bestehenden und strukturgebenden Machtverhältnissen agieren, sodass sie mehr zum Ort des kritischen Lernens und Denkens werden kann. 


\section{Literatur}

Ahmed, Sara (2012): On Being Included: Racism and Diversity in Institutional Life. Durham/London.

Akka, Abou Soufiane (2008): „Wir sind alle Schwarzköpfe“. Selbstethnisierung als Strategie der Selbstbehauptung. In: Reader zum Fachgespräch „Rassismus bildet“. Bildungsperspektiven unter Bedingungen rassistischer Normalität. Bonn, S. 197-202, URL: http://www.ida-nrw.de/cms/upload/PDF_ tagungsberichte/Reader_2009.pdf.

Altenried, Moritz (2011): Rassismus und biopolitischer Kapitalismus. Sarrazin und das Dispositiv der Integration. In: Friedrich, Sebastian (Hg.): Rassismus in der Leistungsgesellschaft: Analysen und kritische Perspektiven zu den rassistischen Normalisierungsprozessen der Sarrazindebatte. Münster, S. $147-161$.

Attia, Iman (2013): Privilegien sichern, nationale Identität revitalisieren. Gesellschafts- und handlungstheoretische Dimensionen der Theorie des antimuslimischen Rassismus im Unterschied zu Modellen von Islamophobie und Islamfeindlichkeit. In: Journal für Psychologie 21/1, URL: http://www. journal-fuer-psychologie.de/index.php/jfp/article/view/258 (zugegriffen am 6.4.2016).

Battaglia, Santina (2007): Die Repräsentation des Anderen im Alltagsgespräch: Akte der natio-ethno-kulturellen Belangung in Kontexten prekärer Zugehörigkeiten. In: Broden, Anne/Mecheril, Paul (Hg.): Re-Präsentationen: Dynamiken der Migrationsgesellschaft. Düsseldorf, S. 181-202.

Bohnsack, Ralf (2000): Rekonstruktive Sozialforschung: Einführung in Methodologie und Praxis qualitativer Forschung, 1. Auflage. Opladen.

Bohnsack, Ralf (2007): Gruppendiskussion. In: Flick, Uwe/von Kardoff, Ernst/ Steinke, Ines (Hg.): Qualitative Forschung. Ein Handbuch. Reinbek bei Hamburg.

Bohnsack, Ralf/Marotzki, Winfried/Meuser, Michael (2011): Hauptbegriffe qualitativer Sozialforschung, 3. durchges. Aufl. Opladen u. a..

Bröckling, Ulrich/Krasmann, Susanne/Lemke, Thomas (2000):

Gouvernementalität der Gegenwart: Studien zur Ökonomisierung des Sozialen, 7. Aufl. Frankfurt am Main. 
Broden, Anne/Mecheril, Paul (Hg.) (2007): Re-Präsentationen: Dynamiken der Migrationsgesellschaft. Düsseldorf.

Broden, Anne/Mecheril, Paul (2007): Migrationsgesellschaftliche

Re-Präsentationen. Eine Einführung. In: Broden, Anne/Mecheril, Paul (Hg.):

Re-Präsentationen: Dynamiken der Migrationsgesellschaft. Düsseldorf,

S. 7-28.

Broden, Anne/Mecheril, Paul (2010): Rassismus bildet: Bildungswissenschaftliche

Beiträge zu Normalisierung und Subjektivierung in der Migrationsgesellschaft, 1. Aufl. Bielefeld.

Castro Varela, Maria do Mar/Dhawan, Nikita (2007): Migration und die

Politik der Repräsentation. In: Broden, Anne/Mecheril, Paul (Hg.):

Re-Präsentationen: Dynamiken der Migrationsgesellschaft. Düsseldorf,

S. 29-46.

Foucault, Michel (1977): Der Wille zum Wissen. Sexualität und Wahrheit I.

Frankfurt am Main.

Foucault, Michel (1978): Dispositive der Macht. Über Sexualität, Wissen und Wahrheit. Berlin.

Foucault, Michel (1992): Was ist Kritik? Berlin.

Foucault, Michel (2004): Two Lectures: Lecture One: January 7, 1976. Michel Foucault. In: Carroll, William K. (Hg.): Critical Strategies for Social Research. Toronto.

Foroutan, Naika (2010): Neue Deutsche, Postmigranten und

Bindungs-Identitäten. Wer gehört zum neuen Deutschland? In: APuZ 46-

47. URL: http://www.bpb.de/publikationen/ZRECU3,0,Neue_Deutsche_

Postmigranten_und_BindungsIdentit\%E4ten_Wer_geh\%F6rt_zum_neuen_

Deutschland.html (zugegriffen am 03.03.2016).

Friedrich, Sebastian (2011): „Rassismus in der Leistungsgesellschaft: Analysen und kritische Perspektiven zu den rassistischen Normalisierungsprozessen der Sarrazindebatte“. 1. Aufl., Münster.

Friedrich, Sebastian/Schultes, Hannah (2011): Von „Musterbeispielen“ und „Integrationsverweigerern“. Repräsentationen von Migrant_innen in der Sarrazindebatte. In: Friedrich, Sebastian (Hg.): Rassismus in der Leistungsgesellschaft. Analysen und kritische Perspektiven zu den rassistischen Normalisierungsprozessen der „Sarrazindebatte“. Münster, S. 77-95.

Friedrich, Sebastian/Schultes, Hannah (2013): Mediale Verbindungen antimuslimische Effekte. Zur gegenwärtigen Verschränkungen des Islamdiskurses. In: Journal für Psychologie, H.1, Bd. 21, S. 1-28. URL: http:// www.journal-fuer-psychologie.de/index.php/jfp/article/view/262 (zugegriffen am 27.02.2016).

Fuchs, Brigitte, u. a. (1996): Rassismen \& Feminismen: Differenzen, Machtverhältnisse und Solidarität zwischen Frauen. Wien. 
Goel, Urmila (2007): (Frei)Räume der 2. Generation Wege und Formen von Repräsentation. In: Broden, Anne/Mecheril, Paul (Hg.): Re-Präsentationen: Dynamiken der Migrationsgesellschaft. Düsseldorf, S. 203-227.

Goffmann, Erving (1967): Stigma. Über Techniken der Bewältigung beschädigter Identitäten. Frankfurt am Main.

Golly, Nadine (2006): Postkoloniale Schwarze deutsche Erfahrungswelten im akademischen Kontext. In: Bechhaus-Gerst, Marianne (Hg.): Koloniale Und Postkoloniale Konstruktionen von Afrika Und Menschen Afrikanischer Herkunft in Der Deutschen Alltagskultur. Afrika Und Europa: Koloniale und Postkoloniale Begegnungen. Frankfurt am Main, S. 395-399.

Gomolla, Mechthild und Frank-Olaf Radtke (2009): Institutionelle Diskriminierung: die Herstellung ethnischer Differenz in der Schule, 3. Aufl. Wiesbaden.

Hall, Stuart (1999): From Scarman to Stephen Lawrence. In: History Workshop Journal 1999/48, S. 187-197, URL: http://hwj.oxfordjournals.org/ content/1999/48/187 (zugegriffen am 6.4.2016).

Hirth, Claudia/Ziegler, Michael (2006): „Das Gruppendiskussionsverfahren“. URL: https:/www.ph-freiburg.de/quasus/einstiegstexte/ erhebungsinstrumente/gruppendiskussionsverfahren.html (zugegriffen am 26.02.2016).

hooks, bell (1990): Yearning. Race, Gender and Cultural Politics. Boston.

hooks, bell (1994): Black Looks: Popkultur - Medien - Rassismus. Übers. von Karin Meissenburg. Berlin.

hooks, bell (1996): Sehnsucht und Widerstand: Kultur, Ethnie, Geschlecht. Übers. von Helga Pfetsch und Marion Sattler Charnitzky. Berlin.

IDA NRW (Hg.) (2008): Reader zum Fachgespräch ,Rassismus bildet‘ . Bildungsperspektiven unter Bedingungen rassistischer Normalität. URL: http://www.ida-nrw.de/cms/upload/PDF_tagungsberichte/Reader_2009.pdf.

k. A. (2013): Georg-August-Universität Göttingen - Leitbild. URL: http://www. uni-goettingen.de/de/leitbild/43883.html (zugegriffen am 6.5.2016).

Kilomba, Grada (2013): Plantation Memories: Episodes of Everyday Racism. 2. Aufl., Münster.

Konuk, Kader (1996): Unterschiede verbünden. Von der Instrumentalisierung von Differenzen, Rassismen \& Feminismen: Differenzen, Machtverhältnisse und Solidarität zwischen Frauen. In: Fuchs, Brigitte u. a. (Hg.): Rassismen \& Feminismen: Differenzen, Machtverhältnisse und Solidarität zwischen Frauen. Wien, S. 233-240.

Kuria, Emily Ngubia (2015): Eingeschrieben.: Zeichen setzen gegen Rassismus an deutschen Hochschulen. Übers. von Saboura Naqshband, 1. Aufl., Berlin. 
Lauré al Samarai, Nicola (2011): „Schwarze Deutsche““, In: Arndt, Susanne und Ofuatey-Alazard (Hg.). (K)Erben des Kolonialismus im Wissensarchiv deutsche Sprache. Ein kritisches Nachschlagewerk. Münster, S. 611-613.

Lemke, Thomas/Krasman, Susanne/Bröckling, Ulrich (Hg.) (2000):

Gouvernementalität, Neoliberalismus und Selbsttechnologien. Frankfurt am Main, S. 7-40.

Lentin, Alana/Titley, Gavan (2011): The Crisis of Multiculturalism: Racism in a Neoliberal Age“. London/New York.

Marinic, Jagoda (2013): Give me a German Word for White Supremacy. In: Neue Deutsche Medienmacher: Dokumentation des Workshops „Neue Begriffe für die Einwanderungsgesellschaft" am 29. Und 30. April 2013 in Nürnberg. Nürnberg, S. 6-13. URL: http://www.neuemedienmacher.de/ wp-content/uploads/2014/01/Tagungsdokumentation-NDM-Begriffe-2013. pdf (zugegriffen am 26.03.2016).

Mecheril, Paul (2014): Diversity. Die Macht des Einbezugs. URL: https:// heimatkunde.boell.de/2007/01/18/diversity-die-macht-des-einbezugs (zugegriffen am 21.12.2015).

Mecheril, Paul/Melter, Claus (2009): Rassismustheorie und forschung in Deutschland. Kontur eines wissenschaftlichen Feldes. In: Melter, Claus/ Mecheril, Paul (Hg.): Rassismustheorie und -forschung, Rassismuskritik; Bd. 1, Schwalbach/Ts., S. 13-25.

Mecheril, Paul/Melter, Claus (2009): Rassismuskritik: Rassismustheorie und forschung. Schwalbach/Ts..

Messerschmidt, Astrid (2010): Distanzierungsmuster. Vier Praktiken im Umgang mit Rassismus. In: Broden, Anne/Mecheril, Paul (Hg.): Rassismus bildet: Bildungswissenschaftliche Beiträge zu Normalisierung und Subjektivierung in der Migrationsgesellschaft. Bielefeld, S. 41-57.

Muhle, Maria (2008): Eine Genealogie der Biopolitik. Bielefeld.

o.V. (2008): „Amtliche Mitteilungen der Georg-August-Universität Göttingen vom 28.03.2008/Nr. 8.“, URL: Rahmenplan Gleichstellung der GeorgAugust-Universität Göttingen. https://www.google.com/url?sa=t\&rct=j\& $\mathrm{q}=\&$ esrc $=s \&$ source $=$ web\&cd $=1 \& \mathrm{cad}=\mathrm{rja} \&$ uact $=8 \& \mathrm{ved}=2 \mathrm{ahUKEwib0vj}$ s94vhAhUKyKYKHe-0BpQQFjAAegQICRAB\&url=https\%3A\%2F\% 2Fwww.uni-goettingen.de\%2Fde $\% 2$ Fdocument $\% 2$ Fdownload $\% 2$ Ff 40 979ef5d88257f67c0056dee0ef15d.pdf\%2FRahmenplan\%2520Gleichst ellung.pdf\&usg=AOvVaw1sbALcUDRcRR-6iSP-C6eC (zugegriffen am 16.03.2019).

Rommelspacher, Birgit (2009): Was ist eigentlich Rassismus?, In: Mecheril, Paul/ Melter, Claus (Hg.): Rassismustheorie und -forschung, Rassismuskritik. Bd. 1, Schwalbach/Ts., S. 25-39. 
Rosenthal, Gabriele (2005): Interpretative Sozialforschung. In der Reihe: Grundlagentexte Soziologie. Hrsg. von Klaus Hurrelmann. Weinheim und München.

Scharathow, Wiebke/Leiprecht, Rudolf (2009): Rassismuskritik: Band 2: Rassismuskritische Bildungsarbeit, 2. Auflage. Schwalbach/Ts..

Scharathow, Wiebke, u. a. (2009): Rassismuskritik. In: Mecheril, Paul/Melter, Claus (Hg.): Rassismustheorie und -forschung. Rassismuskritik Bd. 1, Schwalbach/Ts., S. 10-13.

Scherschel, Karin (2011): Rassismus als flexible symbolische Ressource: Eine Studie über rassistische Argumentationsfiguren. In: Mecheril, Paul/Melter, Claus (Hg.): Rassismustheorie und -forschung, Rassismuskritik; Bd. 1, Schwalbach/Ts., S. 123-139.

Scherschel, Karin (2006): Aufgeklärtes Denken und Abwertung ethnisch Anderer - historische und aktuelle Aspekte. S. 49-71. In: Zeitschrift für Genozidforschung, Heft 7,1.

Schrödter, Mark (2007): Die Objektivität des Rassismus. Anerkennungsverhältnisse und prekäre Identitätszumutungen. In: Broden, Anne/Mecheril, Paul (Hg.): Re-Präsentationen: Dynamiken der Migrationsgesellschaft. Düsseldorf, S. 69-94.

Shooman, Yasemin (2011): Keine Frage des Glaubens. Zur Rassifizierung von „Kultur" und „Religion“ im antimuslimischen Rassismus. In: Friedrich, Sebastian (Hg.). Rassismus in der Leistungsgesellschaft. Analysen und kritische Perspektiven zu den rassistischen Normalisierungsprozessen der „Sarrazindebatte“. Münster, S. 59-76.

Spivak, Gayatri Chakravorty (1988): Can the Subaltern Speak?“, In: Nelson, Gary/Grossberg, Lawrence (Hg.): Marxism and the Interpretation of Culture, Urbana/Chicago, S. 271-313.

Terkessidis, Mark (2004): Die Banalität des Rassismus: Migranten zweiter Generation entwickeln eine neue Perspektive, 1. Aufl. Bielefeld.

Tsianos, Vassilis/Pieper, Marianne (2011): Postliberale Assemblagen. Rassismus in Zeiten der Gleichheit. In: Friedrich, Sebastian (Hg.): Rassismus in der Leistungsgesellschaft: Analysen und kritische Perspektiven zu den rassistischen Normalisierungsprozessen der Sarrazindebatte. Münster, S. 114-133.

Velho, Astride (2010): (Un-)Tiefen der Macht. Subjektivierung unter den Bedingungen von Rassismuserfahrungen in der Migrationsgesellschaft. In: Broden, Anne/Mecheril, Paul (Hg.): Rassismus bildet: Bildungswissenschaftliche Beiträge zu Normalisierung und Subjektivierung in der Migrationsgesellschaft. Bielefeld, S. S.113-137.

Witzel, Frank/Riechel, Andreas (o. J.): Georg-August-Universität Göttingen Hochschulentwicklung. URL: http://www.uni-goettingen.de/de/505393.html (zugegriffen am 6.5.2016). 


\begin{abstract}
$A^{\prime}$ Is historisch gewachsenes Machtverhältnis unterscheidet sich Rassismus in Form komplexer Konfigurationen je nach sozial-politischem sowie lokalhistorischem Kontext. Die vorliegende Untersuchung nimmt studentische Verhandlungsweisen von Rassismus in den Blick und arbeitet heraus, welchen Einfluss dabei die Institution Hochschule hat. Das Adaptionspotenzial aktueller Rassismen eröffnet Betroffenen paradoxe (Verhandlungs-)Räume, sodass sie im akademischen Raum zwar (limitiert) Inkludierte sein können, aber gleichzeitig immer wieder die Erfahrung als Exkludierte machen (müssen). Die Analysen zeigen, dass im gesellschaftlichen als auch institutionellen Umgang mit Rassismus (-erfahrungen) eine Tabuisierung bzw. Dethematisierung vorherrscht. Dieser Umstand wirkt sich grundlegend auf die studentischen Verhandlungsmöglichkeiten von Rassismus aus.
\end{abstract}

ISBN: 978-3-86395-367-6

elSSN: 2512-7055

\title{
Universitätsverlag Göttingen
}

